\title{
From macro to micro
}

Citation for published version (APA):

Qi, S. (2017). From macro to micro: the functioning of financial intermediaries. [Doctoral Thesis, Maastricht University]. Datawyse / Universitaire Pers Maastricht. https://doi.org/10.26481/dis.20170621sq

Document status and date:

Published: 01/01/2017

DOI:

10.26481/dis.20170621sq

Document Version:

Publisher's PDF, also known as Version of record

\section{Please check the document version of this publication:}

- A submitted manuscript is the version of the article upon submission and before peer-review. There can be important differences between the submitted version and the official published version of record.

People interested in the research are advised to contact the author for the final version of the publication, or visit the DOI to the publisher's website.

- The final author version and the galley proof are versions of the publication after peer review.

- The final published version features the final layout of the paper including the volume, issue and page numbers.

Link to publication

\footnotetext{
General rights rights.

- You may freely distribute the URL identifying the publication in the public portal. please follow below link for the End User Agreement:

www.umlib.nl/taverne-license

Take down policy

If you believe that this document breaches copyright please contact us at:

repository@maastrichtuniversity.nl

providing details and we will investigate your claim.
}

Copyright and moral rights for the publications made accessible in the public portal are retained by the authors and/or other copyright owners and it is a condition of accessing publications that users recognise and abide by the legal requirements associated with these

- Users may download and print one copy of any publication from the public portal for the purpose of private study or research.

- You may not further distribute the material or use it for any profit-making activity or commercial gain

If the publication is distributed under the terms of Article $25 \mathrm{fa}$ of the Dutch Copyright Act, indicated by the "Taverne" license above, 


\title{
From Macro to Micro:
}

\section{The Functioning of Financial Intermediaries}

\author{
Shusen Qi \\ School of Business and Economics, Maastricht University
}

A thesis submitted for the degree of

Doctor of Philosophy at Maastricht University

June 21, 2017 
(C) 2017 Shusen Qi

All rights reserved. No part of this publication may be reproduced, stored in a retrieval system, or transmitted, in any form, or by any means, electronic, mechanical, photocopying, recording or otherwise, without the prior permission in writing from the author.

ISBN 9789461597106

Printed by Datawyse / Universitaire Pers Maastricht

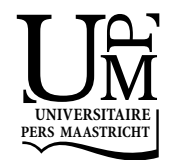




\section{From Macro to Micro:}

The Functioning of Financial Intermediaries

\section{DISSERTATION}

to obtain the degree of Doctor at Maastricht University, on the authority of Prof. dr. Rianne M. Letschert, Rector Magnificus, in accordance with the decision of the Board of Deans, to be defended in public on Wednesday, June 21, 2017, at 12:00 p.m.

by

\section{Shusen Qi}


Supervisor:

Prof. dr. Stefanie Kleimeier

Co-supervisors:

Dr. Stefan Straetmans

Prof. dr. Steven Ongena (University of Zurich)

Evaluation committee:

Prof. dr. Jaap Bos (Chairman)

Prof. dr. Hans Degryse (KU Leuven)

Prof. dr. Tom van Veen

Dr. Chen Zhou (Erasmus School of Economics) 


\section{Acknowledgements}

Looking back the past three years, I am so happy that I have chosen Maastricht University to do my PhD (of course, also thanks Maastricht University to choose me). Doing a PhD is not only a job, but is more likely to be a life style. Being a PhD means a mixture of work and life, means regularly working on a research project late at night, but also means the flexibility of occasionally rewarding myself with a sleep-in during work days. I enjoyed it a lot, and this is also one of the reasons that drive me into the academia after completing my PhD. Everyone around me has been involved, willingly or unwillingly, during this process and without them, I doubt if I can still finish this dissertation. Therefore, everyone deserves to be thanked. Due to space limit, even if you cannot find your name below, you are on my thank list.

When thinking about my $\mathrm{PhD}$, three names deserve special attention and those belong to of course Prof. dr. Steven Ongena, Prof. dr. Stefanie Kleimeier and Dr. Stefan Straetmans. Steven, we got to know each other in the spring of 2012 and since then, you have always been helping and supporting me. You are an excellent supervisor and are always there whenever I need a hand. I admire your work and the insights you have in your projects. If I remember right, we have met each other in Ji'nan, Tilburg, Boston, Lenzerheide, Beijing, Maastricht and Chicago. Let's keep adding more places on the list.

Stefanie and Stefan, I am so lucky to have you as my supervisors. I still remember we got to know that we are the right match when we first met in 2014. Almost immediately after our talk, I have decided to pursue my PhD in Maastricht. During my PhD, we get to know each other better and I realize that without your nice advice, I would never be able to reach the finish of my PhD in such a manner. You always believe in me and give me absolute support.

I am also extremely thankful for my co-authors Dr. Ralph De Haas, Prof. dr. Fengming Qin and Prof. dr. Harald Sander. Thank you for giving me the opportunity to collaborate with you. Your ambition to pursue excellence and strive for perfection really impresses me and allows me to bring the quality of my work to the next level. I enjoy working with you so much and am looking forward to more collaboration in the future. Ralph, special thanks for getting me in London and we should also try to add more places where we meet (currently we have Tilburg, Maastricht, London and Cape Town).

Of course, this dissertation would not be in the current form without the comments from the evaluation committee. Thanks Prof. dr. Jaap Bos, Prof. dr. Tom van Veen, Dr. Chen Zhou, and Prof. dr. Hans Degryse for your invaluable insight and expertise.

This dissertation is also built on the support of the Finance Department. You are the ones that attract me to come to work every day and thanks for being around. It is difficult for me to name everyone, but special thanks to Carina, Francien, Els and Cecile. Thank you all for arranging basically everything I need in my work, including the fresh fruits every week. Jaap, thanks for doing such an excellent work in leading our department. Iman and Mike, thank 
you for arranging the PhD Colloquiums where I got many nice comments for my papers. Thank you to Thomas and Paulo for coordinating the extremely helpful seminars in our department. Harry, it was nice to teach a course under your guidance. Dennis, I am still missing the days when sharing an office with you. My sincere thanks go to my officemates Alexander and Hang. Thanks for sharing your wisdom and fun with me. In the interest of time and space, I would like to thank all the other faculty members and all my fellow PhD colleagues.

From deep in the heart, I would like to thank my family. Without their support, I would not be strong enough to reach the finishing of my PhD. Doing a PhD is like an adventure, I have ups and downs. It is the family that shares the joy with me when I succeed and encourages me when I get trapped. I would then thank my wife, Yu Yan, for your endless love and inspiration. Thanks for accompanying me and being the brightest part of my life. Having met you and got married with you during my PhD is the thing that level up my whole life. Mom and Dad, thank you so much for bringing me up and leading me to find my beloved career. Your selfless love is the most invaluable treasury of my life. 


\section{Contents}

Acknowledgements $\quad$ i

1 Introduction 1

1.1 Deposit Insurance and Cross-border Deposit 2

1.2 Information Sharing and Bank Branching 2

1.3 Firm Bribery and Credit Access 3

2 Deposit Insurance and Cross-border Deposit 5

2.1 Introduction $\quad 5$

$\begin{array}{ll}2.2 \text { A Gravity Model of Cross-Border Deposits } & 7\end{array}$

$\begin{array}{ll}2.3 \text { Data } & 11\end{array}$

$\begin{array}{ll}2.4 \text { Results } & 19\end{array}$

2.4.1 Safe Haven and Regulatory Arbitrage in Cross-Border Depositing 19

2.4.2 Cross-Border Banking and Home Country Banking Crisis 22

2.4.3 The Role of Emergency Actions during Global Financial Crisis 24

$\begin{array}{lr}2.5 \text { Conclusions } & 28\end{array}$

$\begin{array}{ll}\text { Appendix } & 30\end{array}$

3 Information Sharing and Bank Branching $\quad 42$

3.1 Introduction $\quad 42$

3.2 Theoretical Model $\quad 45$

$\begin{array}{ll}3.3 \text { Data } & 52\end{array}$

3.3.1 Branch Data $\quad 52$

3.3.2 Data on Information Sharing 54

$\begin{array}{ll}3.4 \text { Methodology } & 56\end{array}$

3.5 Empirical Results $\quad 57$

3.5.1 Baseline Results 57 
3.5.3 Heterogeneous Impacts by Effectiveness of the Information-Sharing Regime 61

3.5.4 Robustness and Placebo Tests

3.6 Conclusions

Appendix

4 Firm Bribery and Credit Access

4.1 Introduction

4.2 The Impact of Bribery

4.3 Data and Variables

4.4 Methodology

4.5 Results

4.5.1 Baseline Estimates

4.5.2 Instrumental Variable Estimates

4.5.3 Robustness Checks

4.5.4 Demand versus Supply

4.5.5 Economic Impact

4.6 Conclusions

Appendix

5 Concluding Remarks

6 Valorization

References

Curriculum Vitae 


\section{Chapter 1}

\section{Introduction}

A healthy and growing economy is built on a financial system that moves funds from people who save to people who have productive investment opportunities. The financial system is complex in structure. But if we take a closer look at the financial structure throughout the world, we can find an important common fact. That is, indirect finance, which is channeled by financial intermediaries, is many times more important than direct finance, where companies raise funds directly in the financial markets (Beck, Demirgüç-Kunt, \& Maksimovic, 2008). As a matter of fact, the primary source of external funds for corporations all over the world comprises loans made by financial intermediaries (Beck, Demirgüç-Kunt, \& Levine, 2010).

Without capital market imperfections, there would be no need for financial intermediaries and savers and borrowers would be able to easily reproduce all their functions. In the presence of these market imperfections, financial intermediaries help to reduce transaction costs and information asymmetries (Leland \& Pyle, 1977; Campbel \& Kracaw, 1980). Over the years, the growing complexity of the financial system required financial intermediaries to come up with alterative business models to meet the customers' diverse needs. However, these new and innovative products and services would bring greater uncertainty and risk into financial markets. At the same time, financial intermediaries remain the most important source of external finance (Allen \& Santomero, 2001). Therefore, it has become even more important to examine how the financial intermediaries function, and what are the implications of their functioning for the policy makers.

As a first step, this dissertation focuses on the functioning of financial intermediaries, from both macro and micro perspectives. My aim is to identify the factors that determine the access to financial services through various aspects, including macro factors in cross-border banking and bank branching, as well as micro drivers of access to credit. Specifically, I combine three research projects in my dissertation. I start with a globalized framework that investigates deposit insurance as determinants for cross-border deposit allocations in the first project. This research investigates the impact of deposit insurance schemes on bilateral cross-border deposits, whether deposit insurance schemes act primarily as a "Safe Haven" or enabling "Regulatory Arbitrage". The second project follows up with a country level analysis on the contributing factors of bank branching, and ultimately, of access to bank services. We analyze theoretically and empirically how information sharing among banks influences the geographical clustering of their branches. Moving from macro to micro, this dissertation is concluded by a firm level analysis in the third project on the factors that constrains firms' credit access. We examine the impact of bribery on firms' credit access and 
present a microeconomic channel through bank lending whereby corruption impedes firm growth. In the reminder of Chapter 1 , we will provide a brief overview of each project, including backgrounds, motivations and main findings.

\subsection{Deposit Insurance and Cross-border Deposit}

Over the past decades, cross-border deposit increases rapidly both in the interbank market and in the retail market. Global deregulation, regional integration initiatives and elimination of capital controls in many emerging markets enabled banks to rapidly expand cross-border financial services and take foreign deposit. From the customers' point of view, the foreign deposit insurance schemes provide the cross-border depositors with an opportunity for regulatory arbitrage and access to a safe haven, especially during financial crises. However, large-scale re-allocations of cross-border deposits could also contribute to an intensification of financial crises in a globalized financial market.

The existence of deposit insurance may have contradictory impacts on the banking market. On the one hand, deposit insurance can make a banking market more attractive, as the depositor's funds are guaranteed. As such, deposit insurance would contribute to a more stable banking system by preventing bank runs (Diamond \& Dybvig, 1983). On the other hand, deposit insurance can also induce excessive risk taking by banks (Demirgüç-Kunt \& Detragiache, 1997, 2002; Rossi, 1999) and may provide banks with hidden subsidies instead of reducing systematic risk (Calomiris \& Jaremski, 2016).

In Chapter 2, we examine the impact of deposit insurance schemes on bilateral cross-border retail deposits. The results indicate that the way deposit insurance schemes are designed also influences the allocation of cross-border deposits (next to the mere existence of deposit insurance). Moreover, the regulatory differences between the bank and depositor countries also matter and enable "Regulatory Arbitrage". In times of crises, the safe haven motive persists while regulatory arbitrage can only be observed with respect to a few specific DI design features. During the 2008/09 global financial crisis, many countries took emergency actions to maintain the effectiveness of the deposit insurance. These emergency actions led to substantial relocations of cross-border deposits. Therefore, these results suggest that un-coordinated policy actions across countries matter in times of crises and harmonization of deposit insurance schemes could contribute to the stabilization of the financial markets.

\subsection{Information Sharing and Bank Branching}

Over the past decades, banks across the world have adjusted their branch networks in response to changes in regulation, competition, and technology. More importantly, these dynamics do not play out in a geographically uniform way. Bank branches increasingly cluster together as banks close branches in sparsely populated areas while opening new ones in economically stronger population centers. For example, of the 600 branches that 
British banks closed between April 2015 and April 2016, over 90 percent were in areas with a below-median household income. In contrast, about two-thirds of all branch openings took place in wealthier urban neighborhoods (MacAskill \& White, 2016). A similar trend can be observed in the United States, where branch clustering is mirrored by an increase in "banking deserts", i.e. localities entirely devoid of bank branches (Morgan, Pinkovsky, \& Yang, 2016).

Despite this observed increase in geographic branch clustering, hardly any theoretical and empirical research exists on what drives the physical location of bank branches. The starting point of the analysis in Chapter 3 is the assumption that spatial branch clustering intensifies price competition and lowers loan rates because loans from different banks are (imperfect) substitutes. In order to understand why bank branches cluster to start with, we analyze both theoretically and empirically how information sharing among banks influences geographical clustering of their branches. To that aim, we first construct a spatial oligopoly model with price competition that explains why bank branches cluster and how the introduction of information sharing impacts this clustering. Using time-varying information on bank branches in a cross-country setting, we then show that information sharing has two main effects. First, banks increasingly spread their branch networks by opening branches in localities that are new to them. Second, they do so in localities that are already relatively well served by other banks. This clustering makes local banking markets both more competitive and more similar. Taken together, the results indicate that branch clustering is a function of the public availability of trustworthy borrower information. Information sharing can not only directly improve access to credit by reducing information asymmetry, but also lead to denser bank branch networks and expand credit indirectly.

\subsection{Firm Bribery and Credit Access}

Corruption is found to significantly impede economic growth (Mauro, 1995) and investment (Rajan \& Zingales, 1998; Wei, 2000) on the macro level, while also decrease firms' growth opportunity (Fisman \& Svensson, 2007) and competitiveness (Gaviria, 2002) on the micro level, through various channels including investment, trading, political stability and human capital (Pellegrini \& Gerlagh, 2004; Mo, 2010). This chapter presents a bank lending channel for corruption to affect firm growth by tightening firms' access to bank credit. This channel is important because bank credit is a major source of external finance and a driving force for economic growth (Levine, Loayza, \& Beck, 2000), and a well-functioning banking system can enhance the performance and productivity of the whole economy (Levine \& Zervos, 1998; Beck \& Levine, 2004).

Yet, despite the fact that this phenomenon is non-negligible in banking markets, only one other study have investigated firm-level impact of corruption on bank credit (Fungáčová, Kochanova, \& Weill, 2015). In Chapter 4, we partly fill this gap by investigating the firm-level impact of bribery on credit access in a cross-country setting. To address endogeneity issue, we utilize both an instrumental variable approach and various robustness checks. 
We find that credit access is tighter for firms that are more involved in bribery. Theoretically, these findings may be explained by the law and finance theory that bureaucratic corruption induces greater uncertainty on the enforcement actions and claims of the banks, therefore discouraging banks from lending to these bribing firms. More importantly, this detrimental impact is mainly driven by supply-side rather than demand-side factors. In other words, the impact is predominantly driven by banks being less willing to lend to the bribing firms. More specifically, this impact is less pronounced in localities with more foreign banks or if the competition among banks is either very low or very high. In the end, this research finds that bribery significantly impedes growth, partially through the tightening of firms' credit access. 


\section{Chapter 2}

\section{Deposit Insurance and Cross-Border Deposit ${ }^{1}$}

\subsection{Introduction}

Until the 2008/09 financial crisis, cross-border depositing increased rapidly not only in the interbank market, but also in the retail market. After a short period of retrenchment during the crisis, cross-border depositing started growing again and by September 2014 rose to US\$26 trillion, of which US\$8 trillion constitute cross-border liabilities to non-banks. ${ }^{2}$ Global deregulation, regional integration initiatives such as the introduction of the euro, and the elimination of capital controls in many developing countries enabled banks to expand crossborder financial services rapidly. For customers, foreign deposit markets offer not only return opportunities and product diversity but foreign deposit insurance (DI) schemes also provide cross-border depositors with an opportunity for regulatory arbitrage and access to a safe haven, especially during financial crises. This paper provides an in-depth investigation of the relationship between cross-border retail depositing and national DI schemes in tranquil and crisis times. By evaluating the impact of the emergency actions taken during the 2008/09 global financial crisis, we also provide a unique analysis of the impact of crisis policies on cross-border banking.

The existence of a DI can make a banking market more attractive to cross-border depositors in two ways: First, depositor's funds are guaranteed by the DI agency. Second, a DI scheme may contribute to a more stable banking system by preventing bank runs as argued by Diamond \& Dybvig (1983). However, this effect is disputed as moral hazard can induce banks to engage in riskier activities thereby increasing the likelihood of a banking crisis (Demirgüç-Kunt \& Detragiache, 1997, 2002; Rossi, 1999). The empirical literature does not yet offer any unambiguous evidence on the relevance of DI for cross-border depositing. For example, Lane \& Sarisoy (2000) examine the relationship between an explicit DI and several measures of private capital inflows to developing countries but find no significant link. However, their measures of capital inflows are mainly composed of funds that are not insured. ${ }^{3}$ Huizinga \& Nicodème (2006) focus more closely on international liabilities including deposits. ${ }^{4}$ While they find that non-bank external liabilities increase after introduction of an explicit DI, they do not find any role for specific DI features. Similar to Lane \& Sarisoy (2000), their results are at least in part driven by the inclusion of uninsured

\footnotetext{
${ }^{1}$ This chapter is co-authored with Stefanie Kleimeier (Maastricht University; Open Universiteit; University of Stellenbosch Business School) and Harald Sander (Technische Hochschule Köln; Maastricht School of Management).

${ }^{2}$ As reported by the Bank for International Settlements' Locational Banking Statistics.

${ }^{3}$ Lane \& Sarisoy (2000) focus on developing countries in 1990s and analyze gross private capital flows, net private capital flows, international syndicated loans, and international bond issues.

${ }^{4}$ Huizinga \& Nicodème (2006) focus on developed countries from 1983 to 1999 and analyze the impact of the existence of an explicit DI scheme on external liabilities. Their data differentiate interbank and non-bank liabilities and originate from the BIS's International Banking Statistics. Note however that (1) interbank liabilities are generally not insured and (2) non-bank liabilities include insured deposits but also a certain amount of uninsured funds.
} 
liabilities. Furthermore, due to the aggregate level of their data at the bank country level, they are only able to investigate whether a DI system makes a given country more attractive to all foreign depositors in general.

By contrast, our paper employs a uniquely suitable data set of bilateral cross-border retail deposits provided confidentially by the Bank for International Settlements (BIS). Our data are based on the BIS's Locational Banking Statistics and cover cross-border deposits between 131 depositor countries and 22 bank countries for the period from 1998 to 2011 . We are - to the best of our knowledge - the first to use such a detailed dataset and are therefore able to contribute to the understanding of the role of DI schemes for cross-border depositing in numerous ways. First, our study extends the literature by analyzing retail deposits, e.g. deposits of households and non-financial corporations that are actually covered by DI schemes. As such, we can investigate the direct insurance effects and do not need to make any interference about the implications of DI systems on financial systems. Second, we investigate not only the attractiveness of the bank countries' DI, but also the importance of DI differences between the depositor's home country and the bank country. Analyzing the role of bank countries' regulations builds on the existing literature and inquires whether DI provides a "Safe Haven". The analysis of DI differences across countries adds to the literature and is informative about "Regulatory Arbitrage". Third, we investigate not only the effect of an explicit DI but also consider its specific features. As argued by Eisenbeis \& Kaufman (2015) the effectiveness of a DI depends crucially on its design and implementation. Despite deposit market internationalization, significant heterogeneity still exists across national DI schemes ${ }^{5}$ potentially increasing the relative attractiveness of a deposit market. As our analyses will cover regulatory differences across countries we can provide in-depth insights into which features of a DI scheme can induce regulatory arbitrage. ${ }^{6}$ Fourth, we provide an analysis of the potentially changing importance of safe havens and regulatory arbitrage during stable versus crisis times using the Laeven \& Valencia $(2008,2010,2012)$ financial crisis database. Here we build on Kleimeier, Sander, \& Heuchemer (2013) who find that during systemic banking crises, depositors discipline their home banking system by re-locating deposits to foreign safe havens. ${ }^{7}$ Fifth and finally, we investigate the impact and efficiency of emergency actions taken by many countries in response to the severity of the 2008/09 crisis, which included explicit and often enhanced government guarantees over and above the regular DI coverage. We find that both, the quest for safe haven and regulatory arbitrage are important drivers of cross-border depositing in stable times. Conversely, in times of financial crisis, the safe haven motive

\footnotetext{
${ }^{5}$ See Dale, Bruni, \& De Boissieu (2000), Eisenbeis \& Kaufman (2006, 2008).

${ }^{6}$ We thereby contribute indirectly to the literature on DI design including optimal DI schemes and implications on the banking systems and financial markets. See Anginer, Demirgüç-Kunt, \& Zhu (2014); DeLong \& Saunders (2011); Demirgüç-Kunt \& Detragiache (2002); Demirgüç-Kunt, Kane, \& Laeven (2008, 2014); Demirgüç-Kunt, Karacaovali, \& Laeven (2005); Demirgüç-Kunt \& Sobaci (2001); Engineer, Schure, \& Gillis (2013); Garcia (1999); Hardy \& Nieto (2011); Hoelscher, Taylor, \& Klueh (2006); loannidou \& Penas (2010); Laeven \& Beck (2006); Lambert, Noth, \& Schüwer, (2015).

${ }^{7}$ Kleimeier, Sander, \& Heuchemer (2013) build on the literature on the disciplining role of (domestic) depositors pioneered by Berger (1991). Later contributions e.g. report evidence for a "flight to quality (safety) by depositors" during the Asian crisis of 1997/08 (Ding, Domac, \& Ferri, 1998). Rochet (2004) reports empirical evidence for direct market discipline in crisis periods when depositors are able to "vote with their feet". Park \& Peristiani (1998) and Martínez Pería \& Schmukler (2001) find similar effects during the banking crises in USA in the 1980 s and Argentina, Chile, Mexico in the 1980 s and 1990s, respectively.
} 
persists while regulatory arbitrage can only be observed with respect to a few specific DI design features. This safe haven motive is particularly important during the financial crisis of 2008/09. We also provide evidence that the emergency actions taken in bank countries, in particular the introduction of government guarantees, are major drivers of global retail deposit relocations towards safe havens.

The plan of the paper is as follow. In section 2 we develop our gravity model for analyzing the impact of DI on cross-border deposits by formulating five hypotheses and the corresponding specifications of the gravity model. Section 3 details the various extensive databases we are using. Section 4 reports the results. Section 5 concludes.

\subsection{A Gravity Model of Cross-Border Deposits}

We apply a gravity model framework to empirically analyze the impact of DI on bilateral cross-border deposits. Based on Tinbergen (1962) and Pöyhönen (1963), the gravity model has been proven successful in explaining international trade and, in its basic form, explains bilateral trade with the trading partners' economic masses and geographical distance (Baltagi, Egger, \& Pfaffermayr, 2003; Helpman \& Krugman, 1985; Krugman, 1980). Later studies extend this basic model to capture additional bilateral characteristics more precisely, including joint trade agreements, common currency membership, or cultural distance (Baxter \& Kouparitsas, 2006). In line with Portes \& Rey (2005), who argue that gravity models could at least work as well in explaining asset trades as good trades, gravity modelling has more recently extended to the realm of international finance as well (Aviat \& Coeurdacier, 2007; Buch, 2005; Buch \& Lipponer, 2007; Coeurdacier \& Martin, 2009; Heuchemer, Kleimeier, \& Sander, 2009; Kleimeier, Sander, \& Heuchemer, 2013; Lane \& Milesi-Ferretti, 2008; Martin \& Rey, 2004; Okawa \& Van Wincoop, 2012; Portes \& Rey, 2005; Sander, Kleimeier, \& Heuchemer, 2013, 2016). The bilateral character of the dependent variable makes the gravity approach the model of choice to analyze both, the safe haven behavior and, in particular, regulatory arbitrage behavior.

We start with the investigation of safe haven behavior and employ the following gravity model that tests the relationship between DI schemes in the bank countries and crossborder deposits:

$$
\operatorname{Dep}_{i j t}=\alpha_{i j}+\alpha_{i}+\alpha_{j}+\alpha_{t}+\beta_{1} D I_{i t}+\beta_{2} \operatorname{size}_{i j t}+\delta X_{i j t}+\varepsilon_{i j t}
$$

where $D e p_{i j t}$ are the exchange rate adjusted stocks of cross-border deposits from depositors in country $\mathrm{j}$ to banks in country $\mathrm{i}$ in year $\mathrm{t}$. Size ijt $_{t}$ refers to the economic masses of bank country $i$ and depositor country $j$ in year $t$, which equals to the sum of logarithmic GDP of the two countries. $X_{i j t}$ represents other control variables commonly used in gravity models, including proxies for de facto and de jure openness (e.g. bilateral trade, financial openness, and a globalization index) augmented by banking market characteristics (e.g. banking market size, bank competition, and foreign banks), currency unions and free trade agreements. Following Baldwin \& Taglioni (2006) and in accordance with Bekaert, Harvey, Lundblad, \& Siegel (2013) we use a full set of country pair, bank country, depositor country, and year fixed effects given by $\alpha_{i j}, \alpha_{i}, \alpha_{j}$ and $\alpha_{t}$, respectively. Thus, instead of adding controls for transactional frictions such as geographical and culture distance, legal origin, 
and common language, we employ country pair fixed effects to control for all these timeinvariant variables that may affect cross-border deposits. ${ }^{8}$ Country pair fixed effects can control for bilateral trade resistance which is the size of the barriers to trade between countries i and j. In addition, we follow Anderson \& Van Wincoop (2003) and include bank and depositor country fixed effects to control for multilateral trade resistance, which refers to the barriers which each country $i$ and $j$ faces in their trade with all their trading partners (including domestic and internal trade). Finally, we employ year fixed effects to control for common time-varying factors. $D I_{i t}$ is our variable of interest and captures the different features of the bank country's DI scheme. In its simplest form, it represents a dummy variable equal to 1 when an explicit DI exists in the bank country $i$ in year t but we also explicitly measure various design features of the DI scheme in the bank countries.

We postulate that depositors are attracted to a given bank country when its DI provides depositors with a safe haven. As banks transform deposits into risky loans and other risky assets, depositors are exposed to the bank's credit risk. However, depositors prefer to reduce or even eliminate their exposure to bank risk and thus value the protection provided by DI. However, only a well-designed DI scheme can provide depositors with effective risk reduction and avoid moral hazard problems (Diamond, 1986; Diamond \& Dybvig, 1983; Merton \& Thakor, 2015). As such, specific features of the DI scheme such as coverage limit or intensity, repayment history, moral hazard mitigation, or power of the DI agency should matter to depositors. These considerations lead to our first hypothesis:

\section{H1: Safe Haven Hypothesis}

Compared to bank countries without an explicit DI, the existence of an explicit DI makes a bank country more attractive for cross-border depositors. In addition, the attractiveness of a bank country for cross-border depositors increases with the strength of its DI scheme relative to the strength of other bank countries' DI schemes.

As countries also have their own freedom to design their DI schemes, this provides room for international regulatory competition and thus for regulatory arbitrage by depositors. Specifically, the differences in DI schemes between bank and depositor countries may matter in a relative way, with the DI system in the depositor country serving as a benchmark. Thus, besides the absolute quality of a DI system in the bank country, depositors may also care about the relative quality of a DI system in the bank country, taking into account other variables such as physical and cultural proximity or the existence of joint trade agreements or a joint currency. This leads to our second hypothesis.

\section{H2: Regulatory Arbitrage Hypothesis}

\footnotetext{
${ }^{8}$ Our focus does not lie on the general determinants of international deposits. Regarding specific determinants of cross-border deposits, Grilli (1989) finds that non-bank deposits are driven by interest taxes and bank secrecy, while interbank deposits are determined by dividend taxes and economic size. Alworth \& Andresen (1992) use a gravity model to explain cross-border deposits with reserve ratios. Huizinga \& Nicodème (2004) find a weak linkage between bilateral bank liabilities held by non-banks and income taxes. Sander, Kleimeier, \& Heuchemer (2016) find that cultural differences act as barriers to cross-border depositing in the Eurozone.
} 
The existence of an explicit DI makes a bank country attractive for cross-border depositors from countries that lack an explicit DI. In addition, the attractiveness of a bank country for cross-border depositors increases with the strength of bank country's DI scheme relative to the strength of depositor country's DI scheme.

In order to test the Regulatory Arbitrage Hypothesis, we adjust model (1) to allow for the differences in DI schemes across bank and depositor countries, as shown by $D I_{i j t}$ below.

$$
\operatorname{Dep}_{i j t}=\alpha_{i j}+\alpha_{i}+\alpha_{j}+\alpha_{t}+\beta_{1} D I_{i j t}+\beta_{2} \text { size }_{i j t}+\delta X_{i j t}+\varepsilon_{i j t}
$$

But do the effects postulated in the Safe Haven and Regulatory Arbitrage Hypotheses hold when the depositor experiences a banking crisis at home ${ }^{9}$, and if so, which effects are more pronounced? For instance, depositors from countries that are undergoing a systemic banking crisis may search for a better $\mathrm{DI}$ abroad either in the relative sense of regulatory arbitrage or in the absolute sense of a safe haven. However, it may also be possible that depositors totally lose faith in the banking sector and its DI and as a result the relationships between DI and cross-border depositing diminishes or even disappears. Thus we formulate two hypotheses with respect to financial crisis in depositor countries:

\section{H3: Safe Haven in Crisis Hypothesis}

The importance attributed by cross-border depositors to the existence and strength of the bank country's DI increases when depositors experience a banking crisis at home.

\section{H4: Regulatory Arbitrage in Crisis Hypothesis}

The importance attributed by cross-border depositors to the existence and strength of the bank country's DI relative to the depositor country's DI increases when depositors experience a banking crisis at home.

To test these hypotheses, we estimate the following two regressions, with model (3) focusing on the bank country features and thus testing the Crisis Hypothesis in the context of our save haven argument and model (4) focusing on the differences across countries and thus testing the Crisis Hypotheses in the context of regulatory arbitrage:

$$
\begin{aligned}
\operatorname{Dep}_{i j t}= & \alpha_{i j}+\alpha_{i}+\alpha_{j}+\alpha_{t}+ \\
& \beta_{1} D_{i t} * \text { stable }_{j t}+\beta_{2} \text { DI }_{i t} * \text { crisis }_{j t}+\beta_{3} \text { size }_{i j t}+\delta X_{i j t}+\varepsilon_{i j t} \\
\operatorname{Dep}_{i j t}= & \alpha_{i j}+\alpha_{i}+\alpha_{j}+\alpha_{t}+
\end{aligned}
$$

\footnotetext{
${ }^{9}$ We would also like to investigate what happens when a bank country experiences a crisis. As described in the next section, our sample period covers 1998 to 2011 and covers 22 bank countries and 131 depositor countries. However, we observe systemic banking crises only in depositor countries with a single exception: The 2008/09 crisis also affected bank countries. Due to its unique features, i.e. the fact the countries adjusted their DI schemes in response to the crisis, we will study the 2008/09 crisis separately in the context of our Emergency Actions Hypothesis.
} 


$$
\beta_{1} D I_{i j t} * \text { stable }_{j t}+\beta_{2} D I_{i j t} * \text { crisis }_{j t}+\beta_{3} \text { size }_{i j t}+\delta X_{i j t}+\varepsilon_{i j t}
$$

where stable $_{j t}$ is a dummy variable equal to 1 when there is no systemic banking crisis in depositor country $\mathrm{j}$ in year $\mathrm{t}$. Similarly, crisis $_{j t}$ is a dummy variable equal to 1 when there is a systemic banking crisis in depositor country $\mathrm{j}$ in year $\mathrm{t}$. An insignificant $\beta_{2}$ implies that DI does not matter for cross-border depositors during a crisis. Similarly, if $\beta_{2}$ is significantly smaller than $\beta_{1}$ or has the opposite sign, a banking crisis destroys the faith in DI systems and thus diminishes or even eliminates the relationships. However, a $\beta_{2}$ that is significantly larger in absolute values and has the same sign as $\beta_{1}$ suggests that depositors trust foreign DI schemes during crises, which supports either the Safe Haven in Crisis Hypothesis or Regulatory Arbitrage in Crisis Hypothesis or both.

The two crisis hypotheses as outlined above are applicable to the majority of historic banking crises as these are country specific. The 2008/09 banking crisis which started in the US is however different as it spilled over into numerous countries and became an almost global crisis. In response to the severity of the crisis, many countries revised their DI schemes. According to International Association of Deposit Insurers (IADI), at least 49 countries enhanced depositor protection, including 20 countries with maximum coverage increases (e.g. full guarantees), 22 countries with permanent coverage increases and seven countries with temporary coverage increases. These actions were initiated in Europe but quickly spread to nearly every continent, e.g. most revisions took effect between September 2008 and March 2009. These emergency actions to enhance DI systems provide us with a great opportunity to more specifically examine how the changing design features of DI impact cross-border deposits. Before the 2008/09 crisis, the main goal of DI agencies was protecting small depositors, as they did not have the ability to understand and monitor the risks taken by financial institutions. However, after the crisis, maintaining and strengthening the stability of the financial system has been set as the primary goal delegating the protection of small depositors to secondary importance (Bernet \& Walter, 2009). Thus our fifth and final hypothesis postulates the following:

\section{H5: Emergency Actions Hypothesis}

The emergency actions taken by the bank country regarding its explicit DI ensure that the bank country remains an attractive safe haven for cross-border depositors.

To empirically test this hypothesis, we will employ a difference in difference analysis within our gravity model setting:

$$
\begin{aligned}
& \text { Dep }_{i j t}=\alpha_{i j}+\alpha_{i}+\alpha_{j}+\alpha_{t}+ \\
& \quad \beta_{1}(\text { emergency action } * 2008 / 09 \text { crisis period })_{i t}+\beta_{2} \text { size }_{i j t}+\delta X_{i j t}+\varepsilon_{i j t}
\end{aligned}
$$

where emergency action is a dummy variable equal to 1 if a bank country adopted various emergency actions to enhance its DI, and 0 otherwise. These emergency actions include an explicit DI Introduction or the provision of an official government guarantee, limited government guarantee or unlimited government guarantee. 2008/09 crisis period is a dummy variable equal to 1 for the period from 2008 to 2011 when emergency actions are 
taken. Our model already includes bank country fixed effects and year fixed effects, thus the separate effects of these two variables are already included. $\beta_{1}$ represents the treatment effect, which measures the impact of these emergency actions on cross-border deposits.

\subsection{Data}

Our paper is -to the best of our knowledge- unique in that it utilizes all major recent databases on global DI in a systematic manner and investigate their effects on cross-border retail depositing using a custom made, confidential, and bilateral country-level data set provided by BIS. Using bilateral data allows us to examine cross-border depositing for all pairs of bank and depositor countries. Furthermore, we only consider non-bank deposits, which are mainly held by individuals and businesses as DI schemes tend to only cover nonbank deposits but exclude interbank deposits from coverage. The BIS Locational Banking Statistics are perfectly suited to analyze such cross-border banking activities as they are compiled using principles that are consistent with the balance of payments and thus the principle of residence. However, the publicly available data can only be disaggregated either by bank country or by depositor country, instead of being disaggregated bilaterally by both at the same time. Therefore, our paper uses a customized and confidential data set made available by BIS, which exactly provides this bilateral disaggregation. Although the BIS Consolidated Banking Statistics publicly provide bilateral data, these data only report foreign claims and not deposits. Furthermore, the consolidated data are based on the principle of nationality instead of residence. In conclusion, the BIS Locational Banking Statistics are preferable.

A cross-border deposit is made when a customer who resides in country A deposits money at an office of a bank that is located in country B. As long as the bank's office is located in country $B$, such a deposit is cross-border, independent of whether the headquarters of the bank is located in country A or B. Similarly, as long as the depositors resides in country A, such a deposit is cross-border, independent of whether the depositor is a national of country A or B. Critically, our definition is based on the residence and not the nationality of the bank and depositor. Therefore, residents' deposits in local branches of foreign banks are counted as domestic deposits. Thus, we are exactly examining those cases where a depositor crosses a national border. ${ }^{10}$

Our sample covers 22 bank countries and 131 depositor countries from 1998 to 2011 but not all bilateral cross-border deposits $X_{i j t}$ are available for all years. ${ }^{11}$ As such our panel is unbalanced. When testing the Safe Haven, Regulatory Arbitrage and Crisis Hypotheses, we

\footnotetext{
${ }^{10}$ While banks need to adhere to anti money laundering rules and know-your-customer obligations, depositors are generally able to open a deposit account from abroad without being physically present at the bank. Subsequently, cross-border deposits can be managed via internet banking, phone banking, or in person.

${ }^{11}$ The 22 bank countries are Australia, Austria, Belgium, Brazil, Chile, Denmark, Finland, France, Germany, Greece, India, Ireland, Italy, Luxembourg, Macao SAR, the Netherlands, Panama, Spain, Sweden, Switzerland, the United Kingdom, and the United States. Note that the following countries start reporting to the BIS only after 1998: India (2002); Brazil, Chile and Panama (2003); Greece and Macao SAR (2004). For our analyses of hypotheses $\mathrm{H} 1$ to $\mathrm{H} 4$, our maximum possible sample would amount to 28,820 observations (22 bank countries * 131 depositor countries * 10 years). However, our largest sample includes only 20,820 observations due to (1) post-1998 reporting by Brazil, Chile, Greece, India, Macao SAR, and Panama, (2) missing values for our control variables or DI proxies. The latter is the case when depositor countries do not participate in the DI surveys. Our 131 depositor countries are shown in Figure 4 and a list of these countries is available upon request.
} 
only consider a sample period from 1998 to 2007. When testing the Emergency Actions Hypothesis, we rely on a sample period of 1998 to $2011 .^{12}$ The BIS reports unadjusted stocks and exchange rate adjusted flows of cross-border deposits. In order to eliminate any potential exchange rate valuation effects, we calculate annual exchange rate adjusted stocks by taking the initial nominal stocks and successively adding the exchange rate adjusted flows. Figure 2.1 provides a first impression of the evolvement of cross-border deposits over time. Both unadjusted and adjusted stocks show high growth from US\$ 1.3 trillion in 1998 to around US\$ 5 trillion in 2008 before dropping by as much as $25 \%$ as a consequence of the $2008 / 09$ banking crisis. Importantly, about $16 \%$ of the deposit stock volume in 2008 can be attributed to exchange rate valuation effects. Therefore, it is necessary and important to adjust for exchange rate valuation effects. Furthermore, our sample is quite heterogeneous as it covers a wide range of countries with different levels of economic and financial development. Figure 2.2 plots the total annual volume of crossborder deposits that a given bank country receives from all depositor countries, averaged across years. Figure 2.2 reveals how substantial the differences across countries are. In the average year, Chile receives the least cross-border deposits, amounting to only US\$307 million from all depositor countries combined. In contrast, banks in the United Kingdom receive the most cross-border deposits amounting to US\$ 607 billion.

Figure 2.1. Cross-Border Deposits over Time

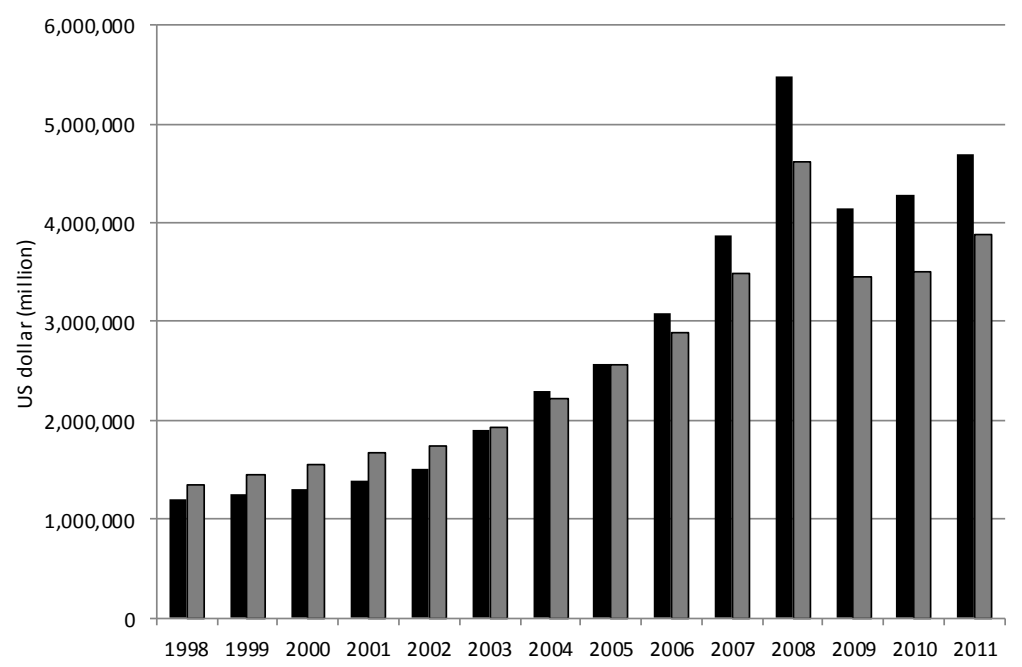

Note: This figure shows the total amount of cross-border deposits (CBD) between all 22 bank countries and all 131 depositor countries in our sample. Black bars represent unadjusted volumes of CBD, grey bars represent $\mathrm{CBD}$ volumes that are adjusted for exchange rate movements.

\footnotetext{
${ }^{12}$ During the 2008/09 financial crisis, many emergency actions have been taken to enhance the DI schemes, both permanently and temporarily. Thus we end our first sample by the third quarter of 2007 and analyze the impact of these emergency actions in 2008 in the following section. Another reason to end our first sample period in 2007 is that before the 2008/09 financial crisis, systemic banking crises only occurred in depositor countries, not in bank countries, in our BIS sample. Thus leaving out the post-2007 period enables us to separate the "old" crises from the "new" crisis, which is more complicated and also occurred in the bank countries in our sample.
} 
Figure 2.2. Cross-Border Deposit Volumes for Different Bank Countries

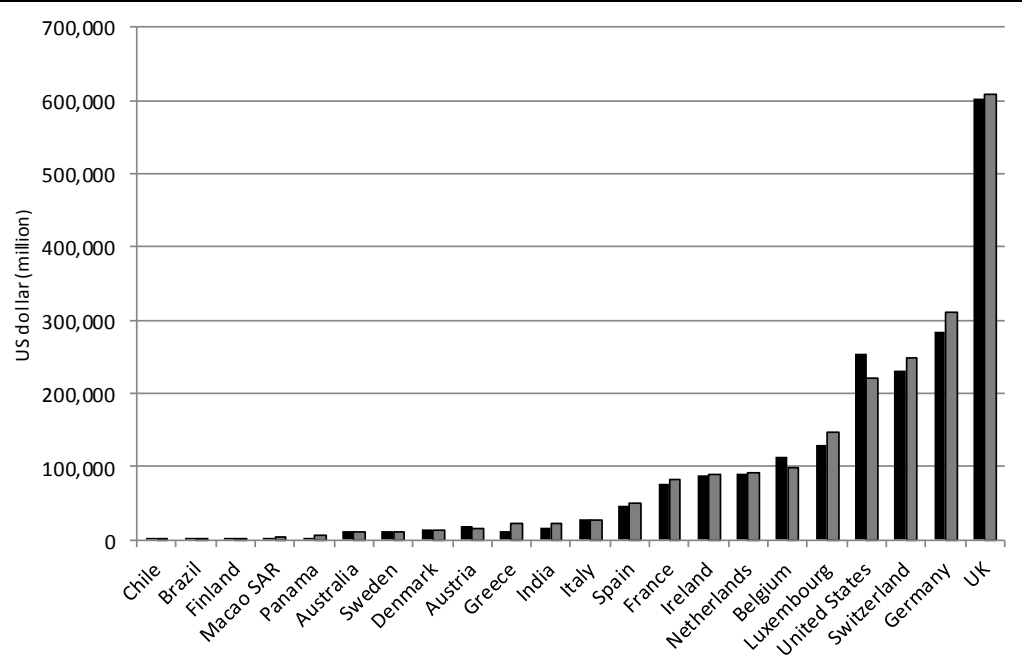

Note: This figure shows the average annual volume of cross-border deposits (CBD) that each of the 22 bank countries in our sample receives from all 131 depositor countries. Black bars represent unadjusted volumes of $\mathrm{CBD}$, grey bars represent $\mathrm{CBD}$ volumes that are adjusted for exchange rate movements.

The main DI data source that we rely on to test our Safe Haven and Regulatory Arbitrage Hypotheses is 'Chapter 8: Depositor (Savings) Protection Schemes' in the World Bank's Bank Regulation and Supervision Database due to its indicator consistency and high survey frequency (see also Barth, Caprio, \& Levine, 2001; Cihak, Demirgüç-Kunt, Martínez Pería, \& Mohseni-Cheraghlou, 2012). Regarding indicator consistency, we are able to not only measure $D_{j t}$ and $D_{i j t}$ as the existence of an explicit DI but are also able to obtain proxies for specific DI characteristics. Regarding the survey frequency, we fill the gap between two consecutive surveys. Specifically, 1998-2001 is filled with data in the survey that was started in 1998. Similarly, 2002-2005 and 2006-2007 are filled with data from the surveys that were conducted in 2002 and 2006 respectively. We only expand the survey data forward so that cross-border deposits are regressed on pre-determined designs of DI systems.

Our proxies for specific DI characteristics capture the insurance benefits for the depositor as well as the moral hazard problem introduced by a poorly designed DI scheme. As argued by Barth, Caprio, \& Levine (2004), the existence of a DI can induce banks to increase their risk taking and a moral hazard problem arises when risk levels become excessive. However, a DI scheme can be designed to limit moral hazard for example by introducing bank funding or risk-based insurance fees. We consider the existence of an explicit DI, the DI power, DI moral hazard mitigation, DI coverage intensity, DI coverage limit and DI repayment history as core features of a DI scheme and will thus focus on them in our empirical analyses. ${ }^{13}$

Among these six DI proxies, the existence of an explicit $D I$ is our most fundamental measure. It is defined as a dummy variable equal to one if a bank country has an explicit DI in place and zero if no DI or only an implicit DI exists in the bank country.

\footnotetext{
${ }^{13}$ Detailed variable definitions and sources are provided in Tables A2.1 and A2.2 in the Appendix.
} 
As our second proxy, we include Barth, Caprio, \& Levine's (2004) DI power measure. This index considers whether the $\mathrm{DI}$ agency has the power to make the decision to intervene in a bank or to cancel/revoke deposit insurance for any participating bank, has the power to take legal action against bank directors or officials, or has ever taken any legal action against bank directors or officers. The index ranges from zero to four, depending on whether the DI agency has none or all four of these powers. A DI agency without these powers might be ineffective, i.e. in cases of political interference or weak relationships between DI agency and the bank supervisors, who instead of the DI agency have the power to resolve bank failures (Garcia, 1999). Note that we code DI power as a missing value for countries without an explicit DI. The same applies to our other proxies for DI design features.

Third, we combine some of the individual DI features to generate a DI moral hazard mitigation index. Here we follow Demirgüç-Kunt \& Detragiache (2002) and consider whether a DI scheme is funded by the banks themselves rather than the government and whether the insurance fees charged to banks vary based on risk assessment. In each case, a value of one is assigned such that the DI moral hazard mitigation index can range from 0 to 2. Demirgüç-Kunt \& Detragiache (2002) argue that moral hazard is stronger under government funding but weaker under bank funding as banks do not bear the cost of their moral hazard. Thus, higher values for the $D I$ moral hazard mitigation index imply greater ability to mitigate moral hazard.

Our remaining DI proxies measure to what extent depositors are covered by the DI scheme. On the one hand, Garcia (1999) argues that limited or restricted DI coverage reduces moral hazard as large, sophisticated depositors remain uninsured and thus have an incentive to monitor and discipline banks by demanding higher deposit rates or refusing to deposit funds altogether. On the other hand, depositors might be more attracted to a banking market where DI coverage is more extensive as the responsibility for monitoring and disciplining is shifted to the DI agency. Thus as our fourth proxy, DI coverage intensity reflects whether there is a coverage limit, whether formal coinsurance explicitly insures depositors for less than $100 \%$ of their deposits and whether foreign currency deposits are excluded. In each case, a value of one is assigned if coverage is not limited. As such, that the DI coverage intensity index can range from 0 to 3 . Fifth, for those DI schemes that have a coverage limit, we measure $D I$ coverage limit as the natural logarithm of US dollar amount at which coverage is limited. Sixth, DI repayment history measures the compensation that depositors received in the past. Looking at prior bank failures, we consider whether insured depositors were fully compensated and whether uninsured depositors were compensated. In each case, a value of one is assigned such that the DI repayment history index can range from 0 to 2 .

DI schemes change over time even before the 2008/09 crisis and vary across countries as the heat maps in Figure 2.3 and the summary statistics in Table A2.3 in the Appendix indicate. Panel A of Figure 2.3 reveals that the number of countries with an explicit $\mathrm{DI}$ increases from 62 in 1998 to 75 in 2006. None of our 131 sample countries removed its explicit DI scheme. For those countries with an explicit DI, we are able to measure our DI design features. Panels $\mathrm{B}$ to $\mathrm{F}$ reveal that depositor protection has generally increased over time. There are however country specific trends. For example, in Sweden DI moral hazard mitigation steadily decreased over time while DI power increased between 1998 and 2002 only to decrease again by 2006 . While a detailed investigation of these country specific 
trends is beyond the scope and focus of this study, we conclude that variations in DI across countries and over time are substantial enough to investigate their potential effect on crossborder depositing.

Figure 2.3. Heat Maps of Deposit Insurance Schemes

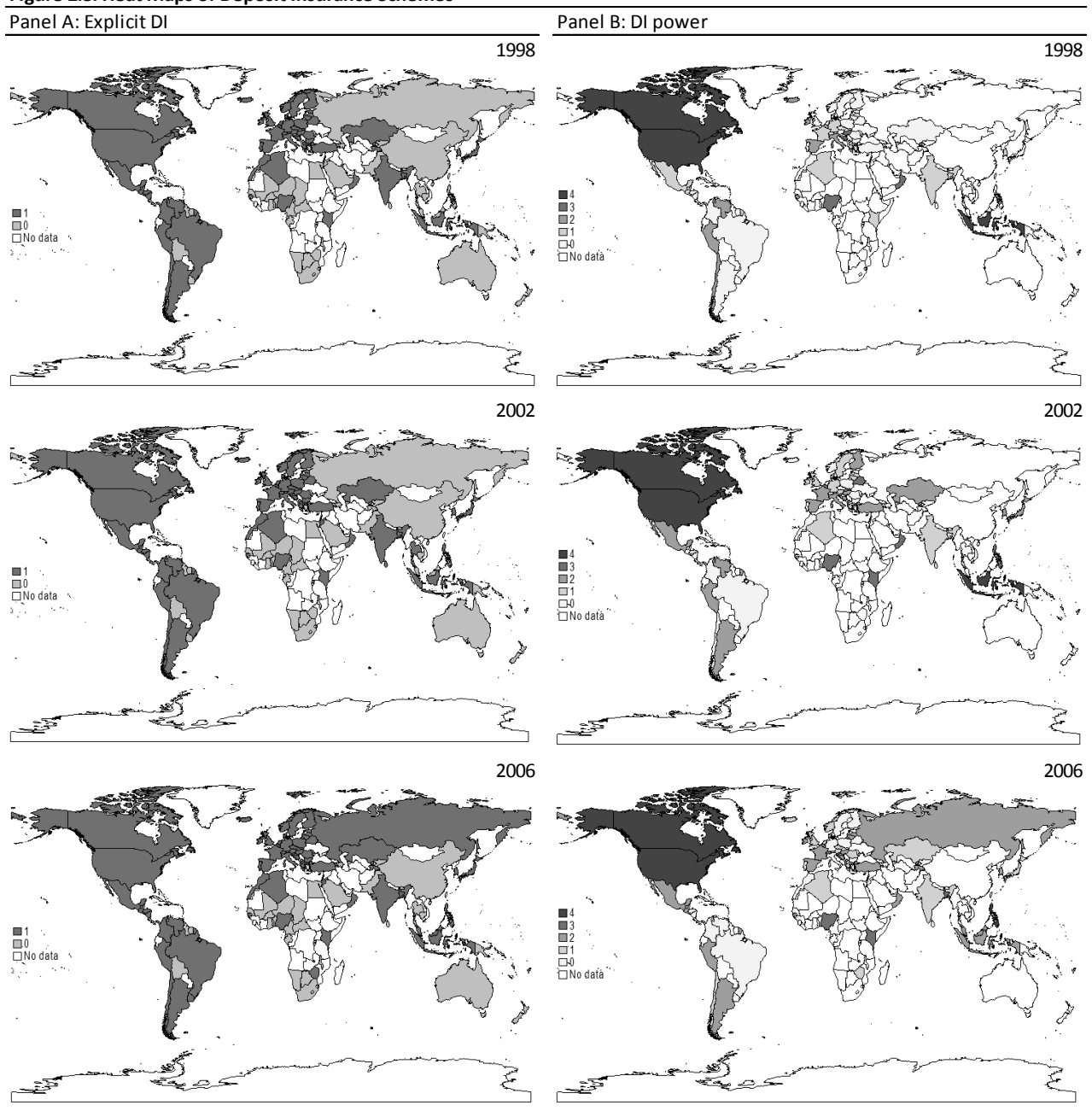

Note: This figure shows heat maps of DI schemes in our 131 sample countries for 1998, 2002 and 2006 respectively. In Panel A, darker blue indicates a country has an explicit DI and lighter blue indicates a country without an explicit DI. In Panel B to Panel $\mathrm{F}$, darker blue indicates higher values respectively for each of the DI design features. 
Figure 2.3 continued. Heat Maps of Deposit Insurance Schemes
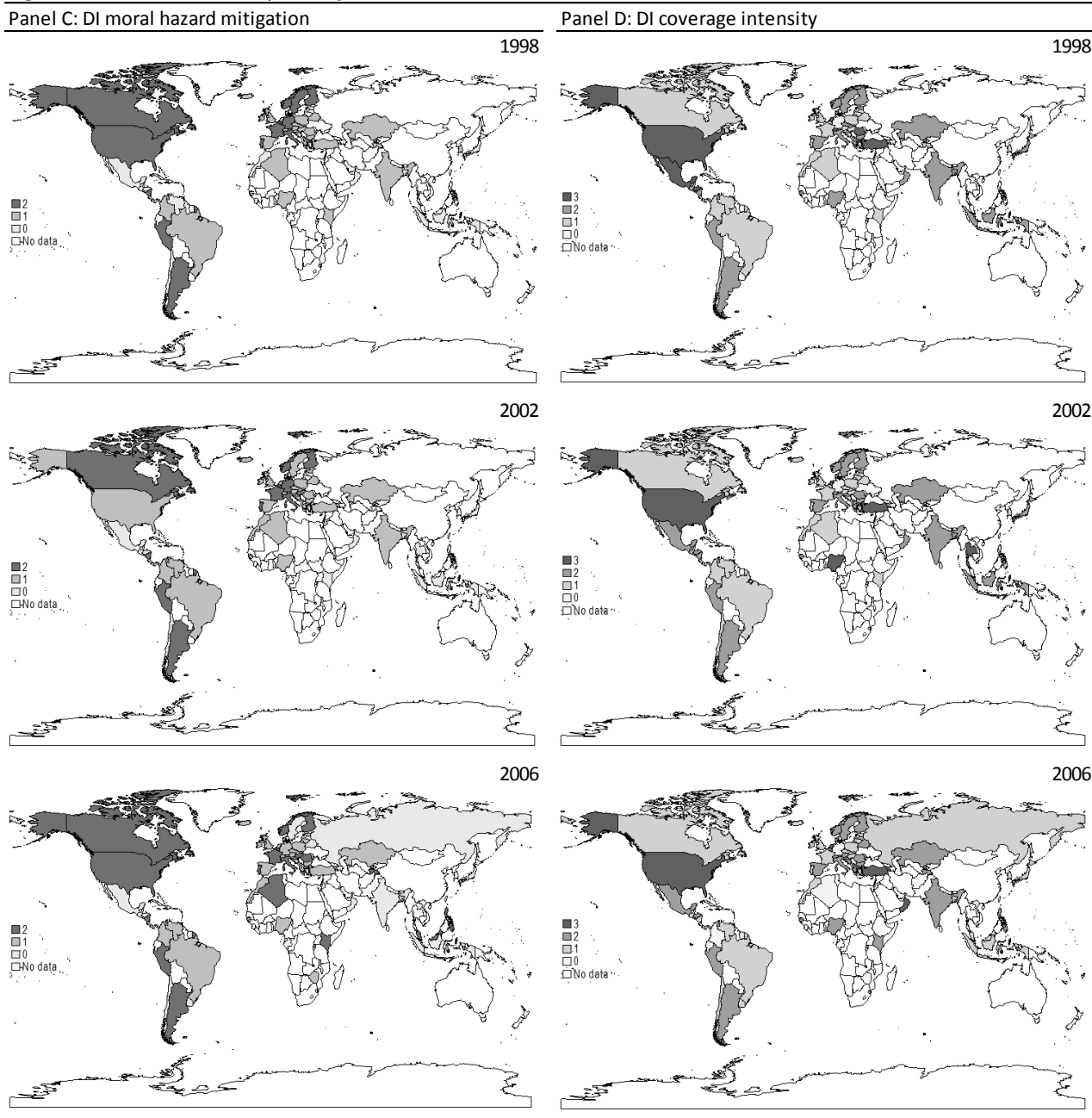
Figure 2.3 continued. Heat Maps of Deposit Insurance Schemes
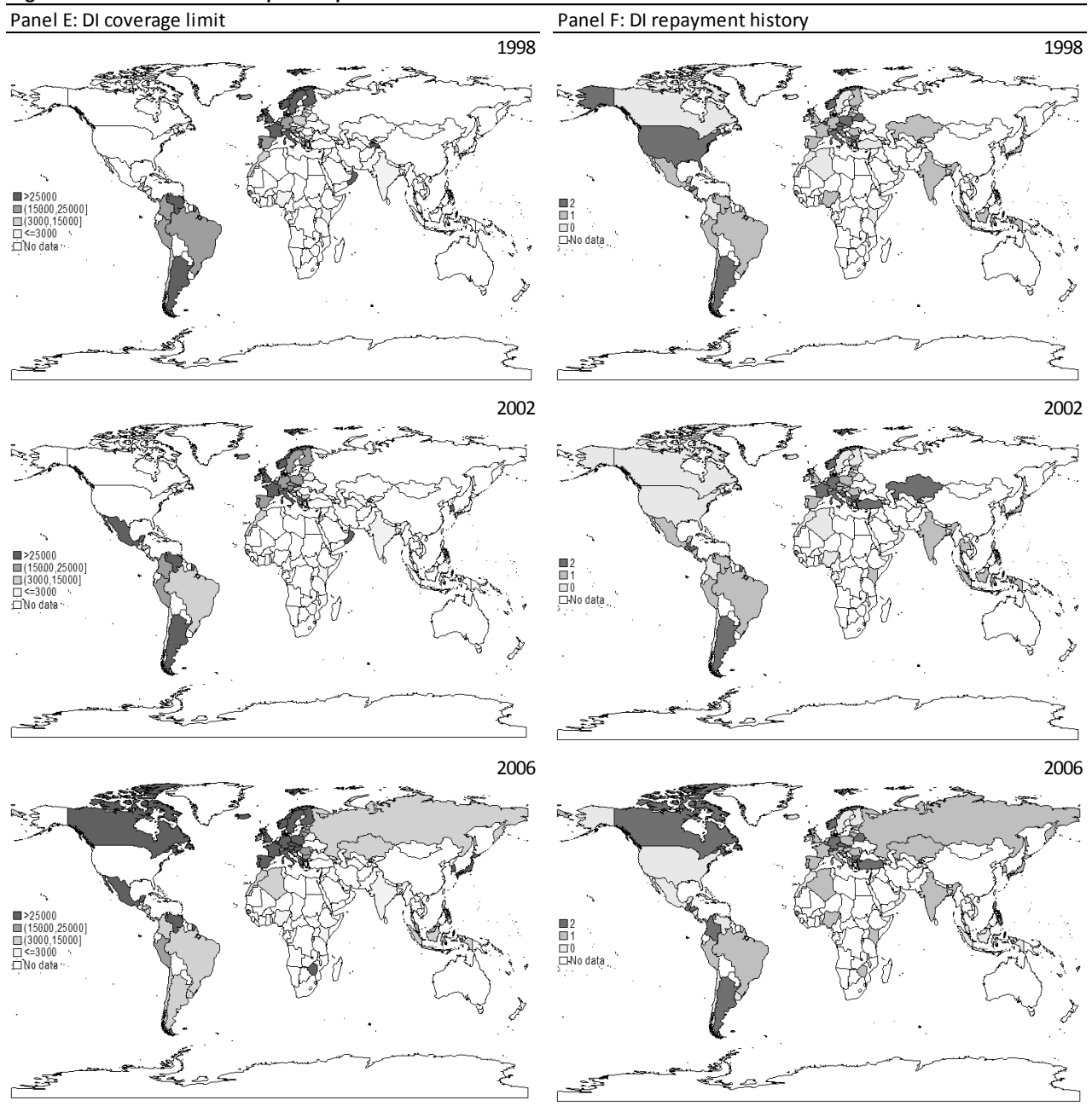

In times of banking crisis or failures, countries might provide implicit DI or increase existing insurance. In particular, during the 2008/09 financial crisis, many countries responded by quickly taking emergency actions in 2008. All emergency actions enhance DI coverage. The data are taken from World Bank's Deposit Insurance Database (see Demirgüç-Kunt, Kane, \& Laeven, 2014) and in line with the IADI's categorization, we differentiate between the introduction of an explicit DI and the provisions of a government guarantee, regardless of the guaranteed amount. Demirgüç-Kunt, Kane, \& Laeven (2014) cover 20 of our 22 bank countries and we thus need to drop Panama and Macao from our sample of bank countries. As Table A2.4 in the Appendix shows, 15 of these 20 countries have undergone the 2008/09 financial crisis. Australia introduced an explicit DI on October $12^{\text {th }}, 2008$. During the $2008 / 09$ financial crisis, six countries (namely Australia, Austria, Denmark, Germany, Ireland, and the United States) extended official guarantees on deposits which are limited in Germany and United States but unlimited in the other four countries. 
To test the effects of crises on cross-border deposits, we employ the Systemic Banking Crises Database by Laeven \& Valencia $(2008,2010,2012)$ which identifies three types of crises, namely banking, currency and sovereign debt crises. A banking crisis is defined as a situation where "a country's corporate and financial sectors experience a large number of defaults and financial institutions and corporations face great difficulties repaying contracts on time. As a result, non-performing loans increase sharply and all or most of the aggregate banking system capital is exhausted". We consider all systemic banking crises during our sample period, that is, 1998-2007. Table A2.5 in the Appendix shows the frequency of banking crises over time and indicates that banking crises are more frequent in 1998-1999 which at least partly reflects the Asian crisis. During the following years, the number of systemic banking crises fluctuates on a relatively low level. The Systemic Banking Crises Database also includes information on the starting and ending year of the systemic banking crises which enables us to cover not only the start of the crises, but also the whole period of it.

Finally, we include a set of control variables that are specific for the bank and depositor country pair and vary over time. Size $e_{i j t}$ is based on the total GDP of both countries obtained from the World Bank's World Development Indicators Database. From the IMF's International Financial Statistics we obtain our proxy for creditijt, e.g. the size of the banking market measured as the two countries' aggregate domestic credit to the private sector as percent of GDP. We employ four measures of openness. First, the KOF Index of Globalization serves as a proxy for de jure openness ( globalization $\left._{i j t}\right)$. Second, we measure de facto openness via trade $_{i j t}$ which reflects the imports and exports between the bank and depositor country and is obtained from the STAN Database. Third, we also control specifically for financial openness $s_{i j t}$ utilizing the Chinn-Ito index to measure a country's degree of capital account openness. Fourth, we include a dummy variable set to one if both countries belong to the same free trade area $\left(F T A_{i j t}\right)$ and we control for exchange rate risk by coding a dummy variable equal to one if the bank and depositor country belong to the same currency union $_{i j t}$. FTA and currency union data are obtained and updated from Sander, Kleimeier, \& Heuchemer (2013) with the original definitions following Rose (2005) and Ilzetzki, Reinhart, \& Rogoff (2008), respectively. Furthermore, we recognize differences in rates of return on deposits as an important determinant of cross-border deposits. Our

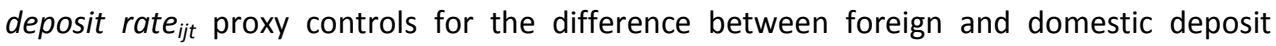
interest rates, with higher values indicating higher returns when depositing abroad. Annual deposit rates are obtained from the IMF's International Financial Statistics. We also include internet $_{i j t}$ access. Sander, Kleimeier, \& Heuchemer (2016) argue that in countries in which a high percentage of the population has internet access, banks have a strong incentive to develop internet banking portals and depositors have low bank transaction costs and can easily and inexpensively deposit across borders. To capture both the bank and depositor side, we obtain data regarding the percentage of individuals with internet access from the UN's World Telecommunication/ITC Indicators dataset and measure internet $t_{i j t}$ as the product of the bank and depositor country. In addition, governance $e_{i j t}$ captures differences in institutional quality between bank and depositor country with data based on the World Bank's Worldwide Governance Indicators and with higher values indicating better institutional quality abroad. Finally, we control for banking market characteristics including the share of foreign banks ${ }_{i j t}$ and net interest margin $_{i j t}$. Heuchemer, Kleimeier, \& Sander (2009) investigate the role of foreign banks in promoting or substituting cross-border 
banking and find that foreign banks promote cross-border lending within the Eurozone. To capture both the bank and depositor side, we obtain data regarding the number of foreign banks in percent of total banks from the World Bank's Global Financial Development Database and measure foreign banks $s_{i j t}$ as the product of the bank and depositor country. Net interest margin $_{i j t}$ serves as a proxy of banking market competition. We obtain our proxy from the World Bank's Global Financial Development Database and measure it as the difference between the bank and depositor country. In sum, this large set of control variables serves two purposes. First, it captures potential determinants of cross-border depositing. Second, it controls for the fact that a country's choice of DI might well be endogenous to the country's economic, political or financial characteristics.

\subsection{Results}

\subsubsection{Safe Haven and Regulatory Arbitrage in Cross-Border Depositing}

In this section we examine the impact of various DI designs on cross-border deposits. We assume that not only the design of the DI system in the bank country matters, but that also the differences in DI design between bank and depositor country matters. In other words, we investigate both the Safe Haven and Regulatory Arbitrage hypotheses.

We start with the Safe Haven Hypothesis by investigating the impact of the existence of an explicit $D I$ in the bank country and its characteristics on cross-border deposits based on our gravity model of equation (1). Results are shown in Table 2.1. Regressions (1) to (6) provide a parsimonious specification in which we only control for size in addition to our various fixed effects. The specification of regressions (7) to (12) is more profligate with a more complete set of control variables. As during our sample period explicit DI does not change over time for any given bank country, we can only include depositor country and year fixed effects in regressions (1) and (7). To compensate for the lack of country pair fixed effects, we instead add gravity country pair controls, e.g. proxies for geographical distance, common border, common language, colony and common legal system. In regression (1), the impact of an explicit $D I$ is highly significant and as expected positive, indicating that bank countries with an explicit DI attract more cross-border deposits than bank countries without an explicit DI. Results regarding the DI agency's power and actions taken to mitigate moral hazard in the DI systems affect cross-border deposits are reported in regressions (2) and (3) and indicate that more deposits flow to countries whose DI agency have more power or take more actions to mitigate moral hazard. Regarding the coverage provided by the DI scheme, regressions (4) to (6) indicate that countries with a higher coverage limit are more attractive to cross-border depositors and there is marginal evidence that depositors care about the DI's coverage intensity. In contrast, repayment history does not matter. Our results are not only statistically significant but also economically relevant. For example, the existence of an explicit $D I$ is associated with $80 \%$ higher cross-border deposits. As the shift from an implicit or non-existent to an explicit DI constitutes a fundamental change in the country's banking system, such a substantial difference in cross-border deposits is not surprising. Furthermore, a one unit increase in the DI's power, moral hazard mitigation and coverage intensity increases cross-border deposits by $4.1 \%, 6.2 \%$ and $3 \%$, respectively. Given the size of the average bilateral cross-border deposits of $\$ 18$ million, these percentages reflect an increase in bilateral cross-border deposits by $\$ 0.7$ million, $\$ 1.1$ million and $\$ 0.5$ million respectively. Finally, a $1 \%$ increase in the coverage limit increases cross-border deposits by $0.55 \%$. This is 
economically meaningful considering that a one standard deviation change in the coverage limit can be associated with a $6.2 \%$ change in cross-border deposits. In regressions (7) to (12) we add more control variables but our DI results are robust with very similar coefficients and significance levels. ${ }^{14}$

However, the introduction of an explicit $D I$ and the relative strength of a DI in terms of its design features may be endogenous. To address this issue, we instrument both explicit $D I$ and the DI design features. Critically, a valid instrument for DI should not be directly correlated with bilateral cross-border deposits. In their seminal study, Demirgüç-Kunt, Kane, \& Laeven (2008) explore how interest-group pressures, outside influences, and politicalinstitutional factors affect DI adoption and design. However, not all DI determinants identified by Demirgüç-Kunt, Kane, \& Laeven (2008) are suitable instruments. In particular, a country's financial, political or legal institutions are likely to be correlated with cross-border deposits. Therefore we select a country's population aged 65 and above as a percentage of the total population as our instrument. Importantly, this measure has been shown to be a significant determinant for DI adoption and design by Demirgüç-Kunt, Kane, \& Laeven (2008) and we can thus use it as a single instrument for all our DI proxies. ${ }^{15}$ In addition, the percentage of population aged 65 and above is not likely to be a direct determinant for cross-border deposits. Therefore, the instrument is arguably valid. The first-stage instrumental variable regressions are reported in Table A2.6 in the Appendix. Notably, the coefficients of our instrumental variable are significant and the test statistics for the weak instrument test are clearly above the critical value. Thus, we indeed have a single, strong, and empirically valid instrument for all DI proxies. In line with the findings of Demirgüç-Kunt, Kane, \& Laeven (2008), an explicit DI is more likely to be adopted in countries with a relatively larger share of elderly people. One possible explanation is that compared to younger people, elderly people usually have more financial assets and are more likely to employ bank deposits as their main savings vehicle. Therefore, elderly people have more demand for explicit DI. Regarding the DI design features, we find that lower power, less moral hazard mitigation, lower coverage intensity and limit are more likely to emerge in countries with more elderly people. This is due to the fact that these safety net subsidies are more likely to be captured by younger people (Demirgüç-Kunt, Kane, \& Laeven, 2008).

The second-stage results are shown in regressions (13) to (17) in Table 2.1. After correcting for potential endogeneity, be it reverse causality or omitted variables, the effects of DI typically come out with more economic and (partially) statistical significance. Thus with the exemption of DI repayment history, the results are in line with our Safe Haven Hypothesis: The existence of explicit DI systems and the strength of the features of the DI schemes attract more cross-border deposits to that country. ${ }^{16}$

\footnotetext{
${ }^{14}$ The unreported control variables generally show the expected coefficients. In particular, cross-border deposits are higher when bank and depositor country are larger, are linked by trade flows or share a common currency. Detailed results are shown in Appendix A2.7 and A2.8.

${ }^{15}$ We do not instrument $D I$ repayment history due to the fact that this measure is based on historical bank failures. Thus, endogeneity is of limited concern.

${ }^{16}$ We conduct robustness checks to allow for the possibility that our match of annual cross-border deposit data to DI data from surveys in 1998, 2002 and 2006 is inaccurate. We therefore restrict our sample period to the three years in which the DI surveys took place. Results are shown in Table A2.9 in the Appendix and are
} 


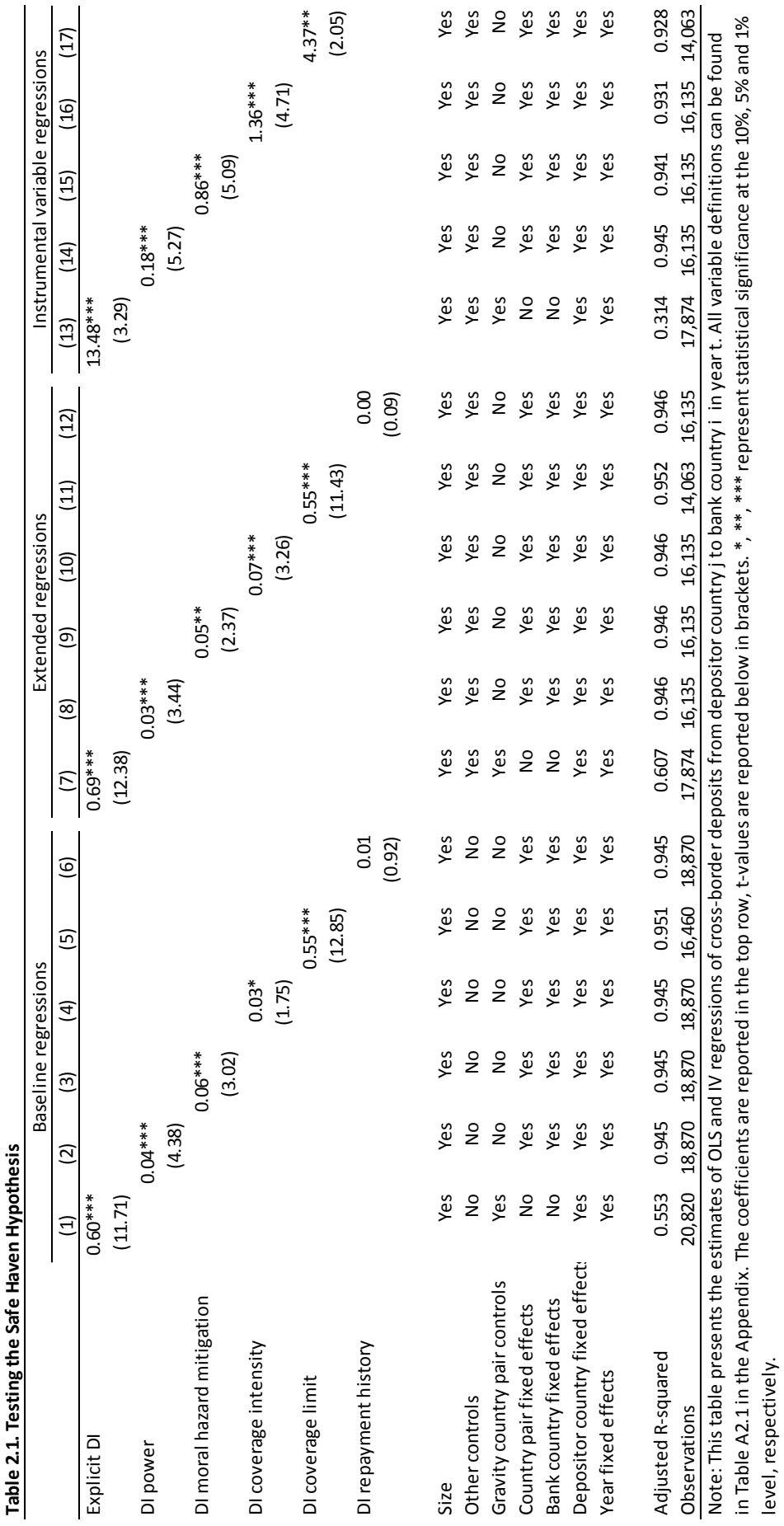

mostly robust. Corresponding robustness checks for Tables 2.2, 2.3, and 2.4 can be found in Tables A2.10, $\mathrm{A} 2.11$, and $\mathrm{A} 2.12$ in the Appendix and also here results are generally robust. 
So far we only examine how the DI systems in the bank countries would impact cross-border deposits. However, the differences in DI schemes between any pair of bank country and depositor country may also matter in a relative way. In this sense, the DI system in the depositor country may serve as a benchmark. Next to the absolute quality of the DI system in the bank country, depositors also care how much better the DI in the bank country is relative to their home country. To test for the Regulatory Arbitrage Hypothesis, we take differences of all the $\mathrm{DI}$ measures between all pairs of bank countries and depositor countries and regress cross-border deposits on these differences in DI schemes as indicated by model (2).

Results are shown in Table 2.2 and we can conclude that depositors hold more funds in bank countries with better DI schemes than they can find in their home country. Specifically, depositors from countries without explicit $D I$ tend to deposit their money in bank countries with explicit $D I$ while depositors from countries with explicit $D I$ are less likely to deposit their money in bank countries without explicit DI. Also relevant in terms of statistical significance are the results that bank countries whose DI authorities have relatively stronger power than the DI authorities in the depositor countries and bank countries with DI schemes designed to mitigate moral hazard more effectively than DI schemes in the depositor countries attract more cross-border deposits. The coefficients of the coverage related DI features are insignificant in the baseline and extended regressions, but both DI coverage intensity and $D I$ coverage limit become significantly positive in the instrumental variable regressions. Hence, the purely exogenous changes in relative DI features as presented in our IV regressions do matter for cross-border depositing. Therefore with the exemption of DI repayment history, the results are overall in accordance with the Regulatory Arbitrage Hypothesis.

\subsubsection{Cross-Border Banking and Home Country Banking Crisis}

In this section we investigate whether the relationships between DI schemes and crossborder deposits change when depositor countries experience a systemic banking crisis. Depositor country banking crises are modelled as indicated in equations (3) and (4) and reported in Tables 2.3 and 2.4 .

In Table 2.3 we examine the Safe Haven in Crisis Hypothesis and utilize F-tests to assess the null hypothesis of equal DI coefficients for stable and crisis periods. For all three regression specifications - the baseline, extended, and instrumental variable regressions - the Fstatistics for explicit DI and DI moral hazard mitigation are at best marginally significant. Thus, these two DI characteristics are equally important during stable and crisis periods and indicate that depositors still trust the foreign DI systems when their home country is undergoing a systemic banking crisis. The F-statistics for the remaining DI design features are statistically significant and indicate that these DI features become more important during a crisis. Next to the statistical significance, the economic significance of our results is most pronounced for DI power and DI repayment history. Firstly, regression (8) indicates that one unit stronger $D I$ power is associated with $7.3 \%$ more cross-border deposits during 


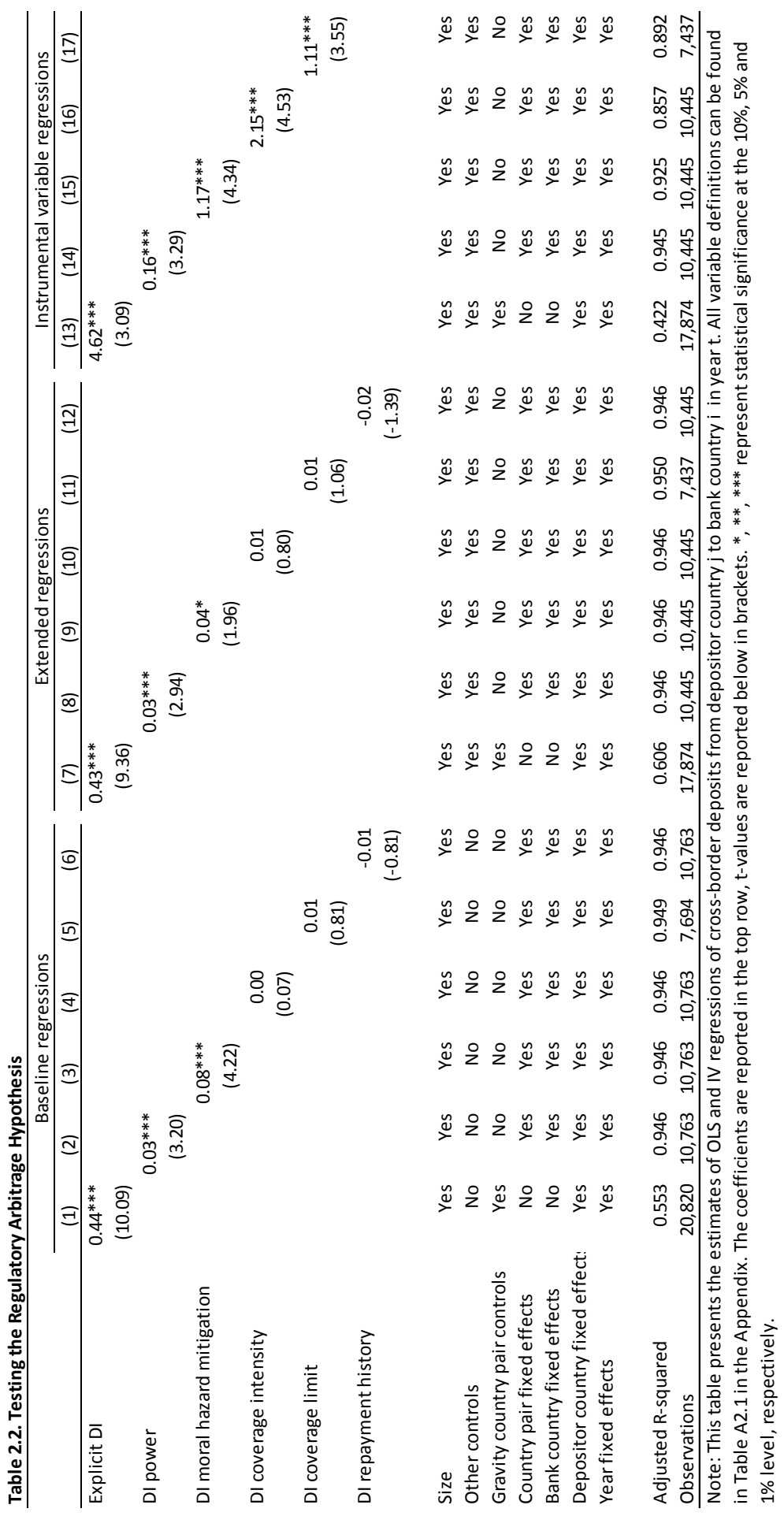


crisis times compared to only $3.0 \%$ during stable times. ${ }^{17}$ Secondly, during a systemic banking crisis, depositors pay attention to the historical record of the DI system as the switch from an insignificant coefficient to a significantly positive coefficient for $D I$ repayment history between stable and crisis times shows. Based on regression (12), a one unit increase in the DI repayment history index is associated with $5.1 \%$ more cross-border deposits during crisis times. When experiencing a crisis in their home countries, depositors thus do not only care about the current features of the DI scheme but also about the historical record of the DI agency during prior bank failures. In sum, these results lend partial support to our Safe Haven in Crisis Hypothesis and indicate that depositors value safe havens at least equally if not more when their home countries are undergoing a systemic banking crisis.

Using model (4) to test our Regulatory Arbitrage in Crisis Hypothesis, Table 2.4 reports the results during stable and crisis times for the differences in DI between bank and depositor countries. Our preferred instrumental variable regressions in Table 2.4 reveal that depositors are willing to chase better explicit DI, DI moral hazard mitigation, and DI coverage limit in stable and crisis times. In contrast, DI power and DI coverage intensity only matter during stable times. This result stands in contrast to the results for Safe Haven in Crisis Hypothesis in Table 2.3 where effects tend to become stronger rather than weaker during a crisis. One possible explanation could be that depositors consider regulatory arbitrage during stable times, but when they are hit by a crisis, they care less about the arbitrage opportunities and only care whether their deposits are safe. Overall, Table 2.4 therefore suggests that regulatory arbitrage behavior partially disappears or becomes less important in times of crisis, i.e. depositors no longer search for better DI power and DI coverage intensity.

In sum, the evidence provided here indicates that safe havens remain important during crisis times while regulatory arbitrage mostly occurs during stable times. One might say, that depositors still search for the best protection in time of crisis and thus locate deposits to safe havens. Only during stable times are depositors willing to consider regulatory arbitrage.

\subsubsection{The Role of Emergency Actions during Global Financial Crisis}

Our analysis so far suggests that during a banking crisis in the home country, foreign safe havens become important to depositors. However, during the 2008/09 financial crisis safe havens were in short supply as bank countries which during our early sample period from 1998 to 2007 had not experienced a banking crisis are now subject to a crisis as well. As a consequence, many bank countries took emergency actions by implementing explicit DI schemes or enhancing government guarantees. To examine the impact of such emergency actions on cross-border deposits, we employ a difference in difference analysis as outlined in model (5) and thereby test our Emergency Actions Hypothesis. However, before

\footnotetext{
${ }^{17}$ We estimate the economic impact for our DI design features based on the coefficients estimated in the extended regressions. While we prefer the instrumental variable regressions for their technical correctness, we rely on the extended regressions and their estimated OLS coefficients due to their simplicity of economic interpretation. In contrast to OLS coefficients, coefficient estimates from instrumental variable regressions capture local average treatment effects. As the estimated coefficients of our instrumental variable regressions exceed those of the extended regression, we are certain not to overestimate importance of the economic impact by resorting to the latter.
} 


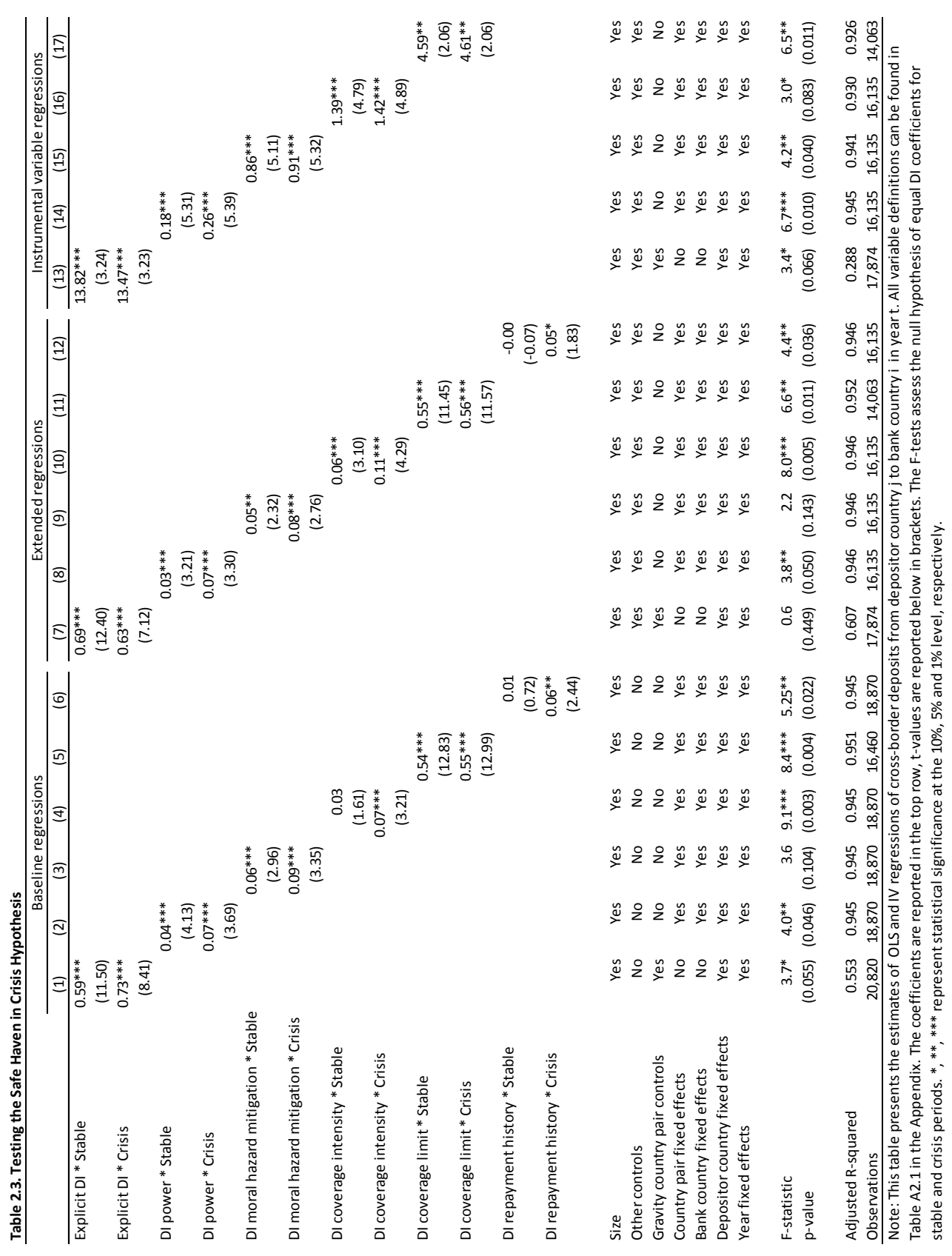




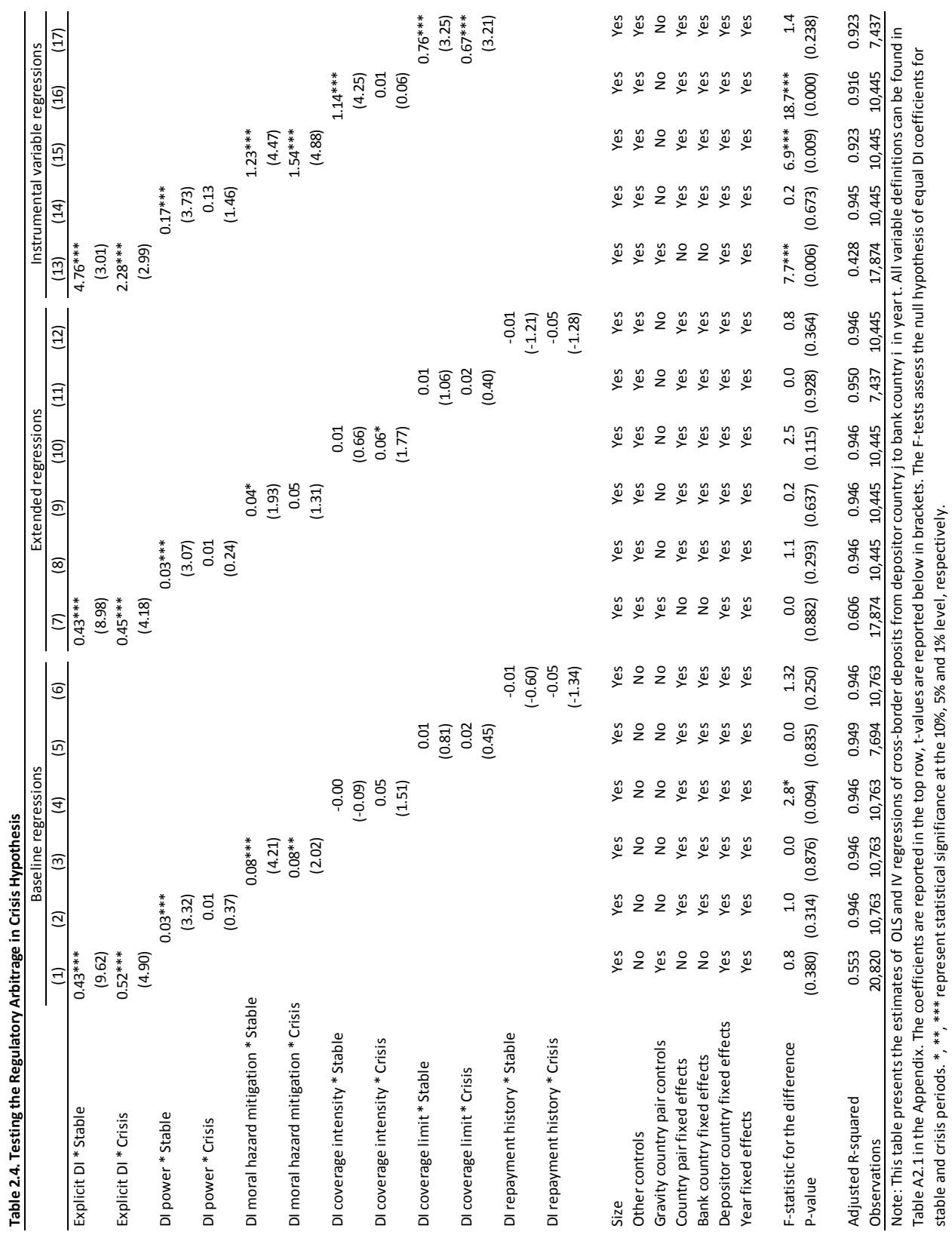


presenting the estimates, we point to Figure 2.4, which provides a vivid illustration comparing cross-border deposit volumes of bank countries that later extend government guarantees to those of bank countries that do not extend such guarantees. Before 2008, both groups of countries show a similar and parallel trend in cross-border deposits. Since 2008, however, the extensions of government guarantees have resulted in a substantial increase in cross-border deposits for countries that extended such government guarantees.

Figure 2.4. Cross-Border Deposits and Emergency Actions Panel A: All bank countries
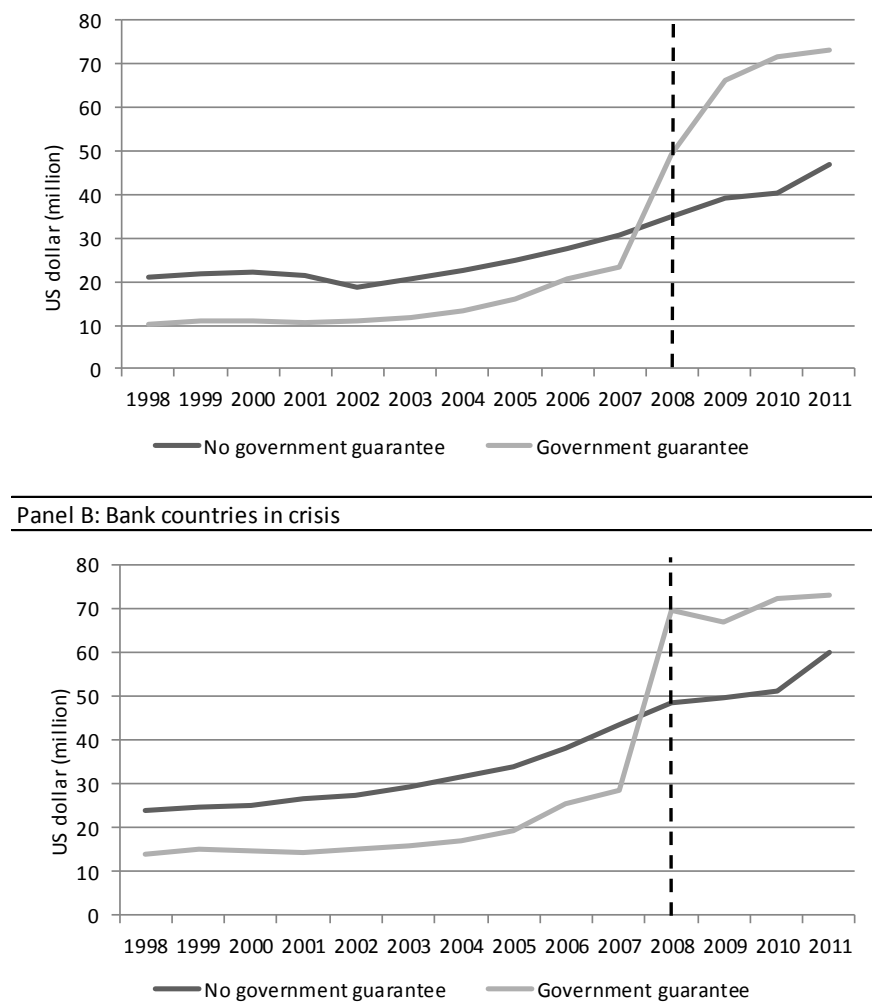

Note: This figure visualizes the difference in difference setting for the emergency actions taken by national governments during the 2008/09 financial crisis. The black lines represent cross-border deposit volumes for countries that did not extend a government guarantee, the grey lines represent cross-border deposit volumes for countries that extended a government guarantee.

Regression results are shown in Table 2.5. It is important to note that we do not only rely on the full sample of country pairs involving all bank countries, but also conduct the difference in difference analysis with a subsample containing only those country pairs for which the bank countries have experienced the 2008/09 crisis. By doing this, we can further narrow down our control groups, thus making our results more precise, i.e. countries that have undergone the 2008/09 crisis have similar characteristics and this similarity is higher within this subgroup than compared to countries that were not exposed to the 2008/09 crisis. We start with regression (1) where we examine the impact of an explicit DI introduction and 
show that this emergency measure significantly increases cross-border deposits. Similarly regressions (2) to (4) show that cross-border deposits increase when government guarantees, whether limited or unlimited, are extended. Regressions (1) to (4) are based on our full sample of country pairs based on all 20 bank countries. Regressions (5) to (7) are based on the subsample of country pairs for which the bank countries have experienced the $2008 / 09$ crisis but we find almost the identical results as in regressions (2) to (4), indicating that our control groups are unbiased. In addition, besides the full time period from 1998 to 2011, we also check the treatment effect with a narrower time window from 2006 to 2009 which captures the 4 years surrounding the introduction of emergency actions in 2008. Results are shown in regressions (8) to (14) and are robust albeit with smaller coefficients. This shorter period mitigates the time trend concern in the sense that the early years of the sample period (1998-2005) could be - for reasons unrelated to the crisis - substantially different than the more recent years and confirms our previous results. In sum, the emergency actions appear to be very successful in terms of providing the safe havens that depositors were looking for during a global financial crisis.

\subsection{Conclusions}

Our results indicate that the existence of an explicit DI, as well as other DI design features, affect cross-border depositing and thus the geography of global banking. The existence of an explicit $D I$ is attractive to foreign depositors in the sense that it provides a higher level of deposit safety. But the design of the DI plays an important role, too. Eisenbeis \& Kaufman (2015) argue that an effective DI system consists of a credible guarantee, effective monitoring by supervisors, and an efficient resolution mechanism. Our results show that the DI power, moral hazard mitigation which encompasses credibility and effective monitoring as well as coverage related DI features matter for cross-border depositing. Our findings regarding these specific DI design features further underline the importance of credibility as depositors identify safe havens as those banking markets with DI schemes that provide high coverage. We further demonstrate that the relationships between DI systems and crossborder deposits vary in stable times and in times of systemic banking crises in depositor countries. In crises times depositors have more incentives to chase a safe haven rather than to engage in regulatory arbitrage. When it comes to a global finance crisis it is the emergency actions of bank country governments, which supply and maintain these safe havens, that matter and can lead substantial relocations of cross-border deposits. As such, these actions do not only rescue the banks and domestic depositors of the countries taking these (credible) emergency actions. They also have measurable and sizeable effects on other countries in a financially interdependent world, which may call for coordinated emergency actions which take possible spillovers across countries into account. However, even in tranquil times, our results show that the design of an effective DI must take the DI's impact on cross-border activities of depositors into account. Our findings add therefore also to the debate on the design of macro prudential instruments in globalized financial markets. This discussion, currently focused on bank lending, questions their effectiveness when banks and borrowers are able to circumvent these measures via regulatory arbitrage and calls for coordination among national regulators (Houston, Lin, \& Ma, 2012; Ongena, Popov, \& Udell, 2013; Reinhardt \& Sowerbutts, 2015). Likewise, our findings, documenting a novel pattern of save haven and regulatory arbitrage driven behavior by depositors, stresses the need for a coordinated regulatory strategy with respect to deposit insurance schemes. 


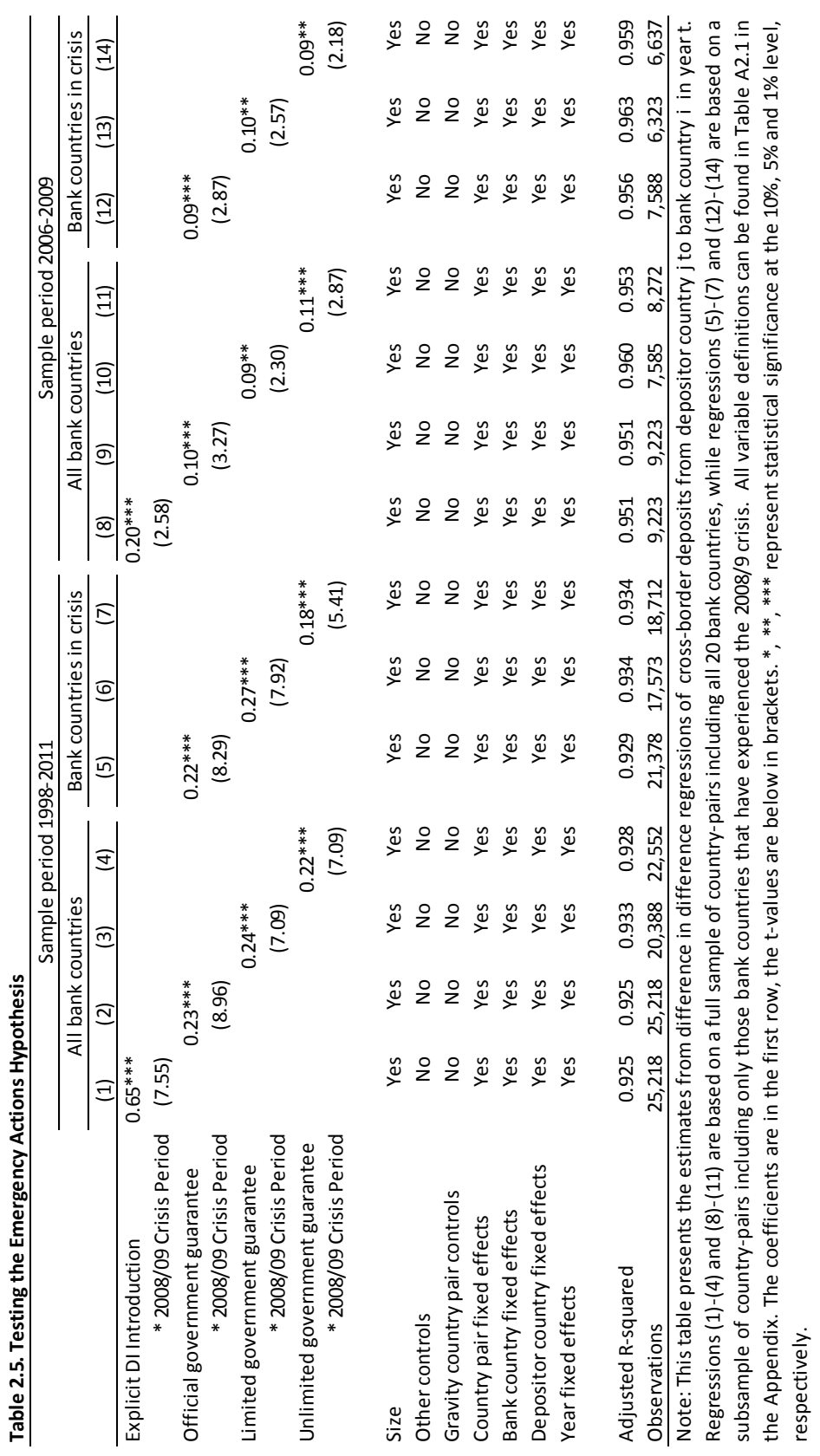




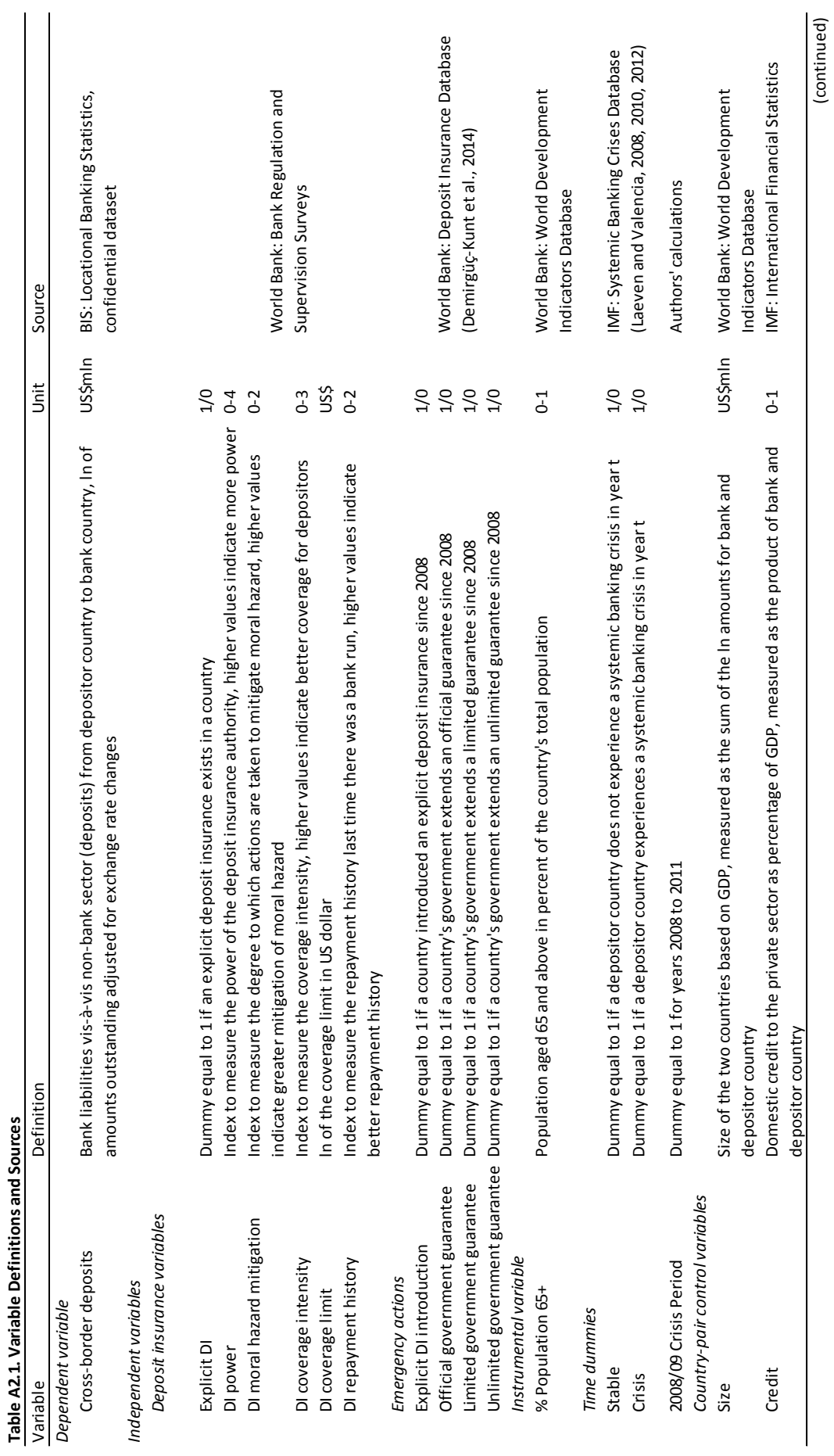




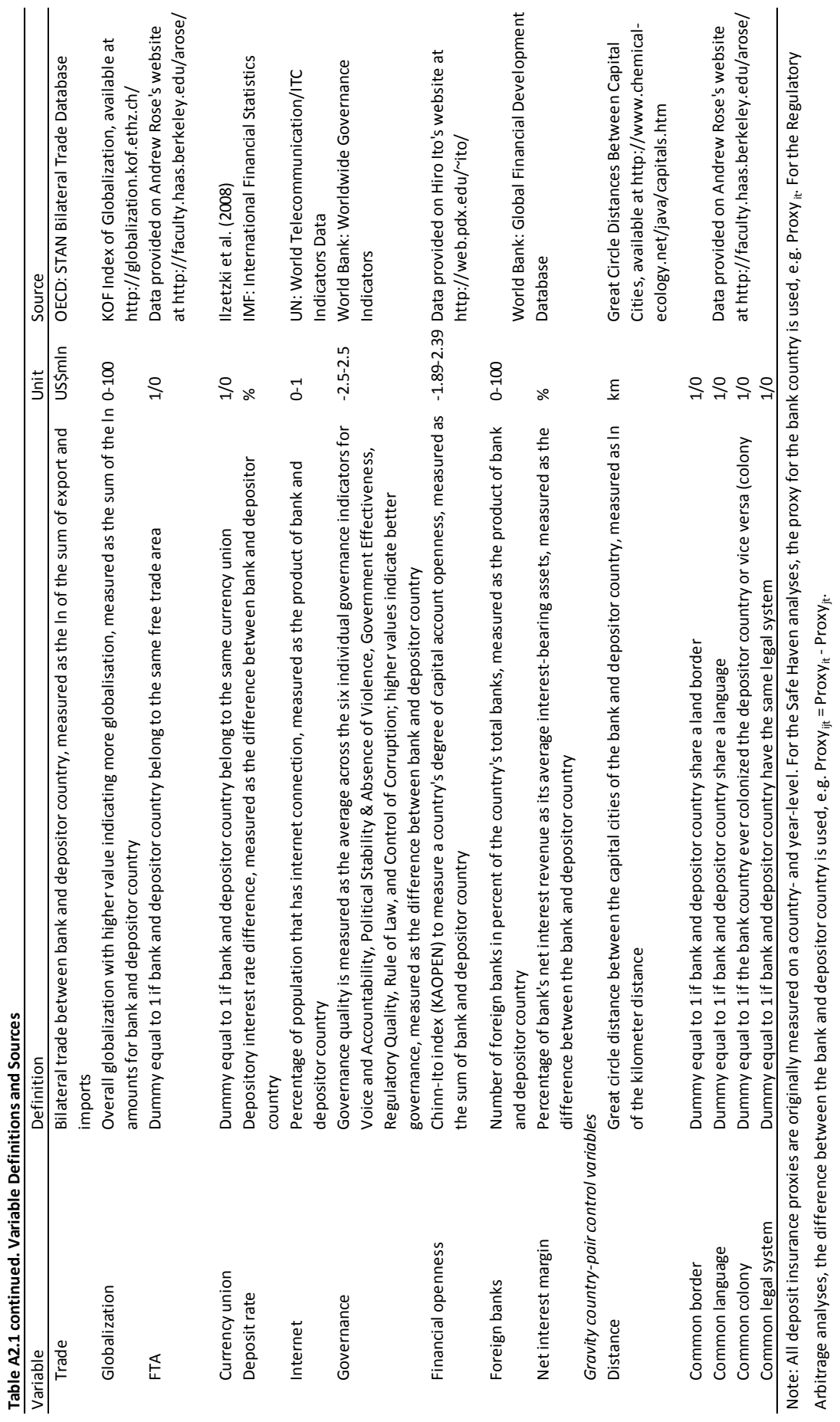


Table A2.2. Deposit Insurance Indices

\begin{tabular}{|c|c|c|}
\hline Variable & Questions & Index \\
\hline DI power & $\begin{array}{l}\text { (1) Does the deposit insurance authority make the decision to } \\
\text { intervene a bank? } \\
\text { (2) Does the deposit insurance authority have the legal power to } \\
\text { cancel or revoke deposit insurance for any participating bank? } \\
\text { (3) Can the deposit insurance authority take legal action for } \\
\text { violations against laws, regulations, and bylaws against bank } \\
\text { officials? } \\
\text { (4) Has the deposit insurance authority ever taken legal action for } \\
\text { violations against laws, regulations, and bylaws against bank } \\
\text { officials? }\end{array}$ & $(1)+(2)+(3)+(4)$ \\
\hline $\begin{array}{l}\text { DI moral hazard } \\
\text { mitigation }\end{array}$ & $\begin{array}{l}\text { (1) Is the deposit insurance funded by banks? } \\
\text { (2) Do deposit insurance fees charged to banks vary based on some } \\
\text { assessment of risk? }\end{array}$ & $(1)+(2)$ \\
\hline $\begin{array}{l}\text { Dl coverage } \\
\text { intensity }\end{array}$ & $\begin{array}{l}\text { (1) Is there a no limit per person? } \\
\text { (2) Is there no formal coinsurance? } \\
\text { (3) Does the deposit insurance scheme include coverage of foreign } \\
\text { currency deposits? }\end{array}$ & $(1)+(2)+(3)$ \\
\hline $\begin{array}{l}\text { DI repayment } \\
\text { history }\end{array}$ & $\begin{array}{l}\text { (1) Were insured depositors wholly compensated (to the extent of } \\
\text { legal protection) the last time a bank failed? } \\
\text { (2) Were any deposits not explicitly covered by deposit insurance } \\
\text { at the time of the failure compensated when the bank failed? }\end{array}$ & $(1)+(2)$ \\
\hline
\end{tabular}

Note: If a question is answered with yes, a value of 1 is assigned. If a question is answered with no, a value of 0 is assigned. The index for each deposit insurance characteristic equals the sum of the values to all relevant questions. 
Table A2.3. Summary Statistics

\begin{tabular}{|c|c|c|c|c|c|}
\hline \multirow{2}{*}{$\begin{array}{l}\text { Variable } \\
\text { Cross-border deposits }\end{array}$} & \multirow{2}{*}{$\begin{array}{r}\text { Obs } \\
20,820\end{array}$} & \multicolumn{2}{|c|}{ Mean Std. Dev. } & \multirow{2}{*}{$\frac{\text { Min }}{0}$} & \multirow{2}{*}{$\frac{\text { Max }}{13.13}$} \\
\hline & & 2.89 & 2.74 & & \\
\hline \multicolumn{6}{|l|}{ Bank country } \\
\hline Explicit DI & 20,820 & 0.91 & 0.29 & 0 & 1 \\
\hline DI power & 18,870 & 1.10 & 0.95 & 0 & 4 \\
\hline DI moral hazard mitigation & 18,870 & 1.28 & 0.55 & 0 & 2 \\
\hline DI coverage intensity & 18,870 & 1.61 & 0.86 & 0 & 3 \\
\hline DI coverage limit & 16,460 & 10.04 & 0.95 & 7.60 & 11.77 \\
\hline DI repayment history & 18,870 & 0.99 & 0.63 & 0 & 2 \\
\hline \% Population $65+$ & 20,820 & 0.14 & 0.04 & 0.04 & 0.20 \\
\hline \multicolumn{6}{|l|}{ Country-pair differences } \\
\hline Explicit DI & 20,820 & 0.33 & 0.58 & -1 & 1 \\
\hline DI power & 10,763 & 0.02 & 1.51 & -4 & 4 \\
\hline DI moral hazard mitigation & 10,763 & 0.29 & 0.91 & -2 & 2 \\
\hline DI coverage intensity & 10,763 & 0.10 & 1.13 & -3 & 3 \\
\hline DI coverage limit & 7,694 & 0.36 & 1.97 & -9.79 & 6.44 \\
\hline DI repayment history & 10,763 & 0.10 & 0.97 & -2 & 2 \\
\hline \% Population 65+ & 20,820 & 0.05 & 0.07 & -0.16 & 0.19 \\
\hline Size & 20,820 & 23.53 & 2.78 & 14.12 & 35.37 \\
\hline Credit & 20,820 & 0.57 & 0.55 & 0.00 & 5.95 \\
\hline Trade & 20,820 & 5.19 & 2.88 & 0.00 & 13.25 \\
\hline Globalisation & 20,820 & 8.49 & 0.41 & 5.06 & 9.07 \\
\hline FTA & 20,820 & 0.07 & 0.26 & 0 & 1 \\
\hline Currency union & 20,820 & 0.05 & 0.22 & 0 & 1 \\
\hline Deposit rate & 20,820 & -3.80 & 10.74 & -202.63 & 27.73 \\
\hline Internet & 20,820 & 0.08 & 0.11 & 0.00 & 0.71 \\
\hline Governance & 20,820 & 1.04 & 1.09 & -2.21 & 3.50 \\
\hline Financial openness & 20,820 & 2.75 & 1.82 & -3.79 & 4.78 \\
\hline Foreign banks & 18,230 & 1062 & 1419 & 0 & 8640 \\
\hline Net interest margin & 19,365 & -2.56 & 3.49 & -23.05 & 8.07 \\
\hline Explicit DI introduction & 25,218 & 0.04 & 0.20 & 0 & 1 \\
\hline Official government guarantee & 25,218 & 0.30 & 0.46 & 0 & 1 \\
\hline Limited government guarantee & 25,218 & 0.11 & 0.31 & 0 & 1 \\
\hline Unlimited government guarantee & 25,218 & 0.19 & 0.39 & 0 & 1 \\
\hline
\end{tabular}


Chapter 2. Deposit Insurance and Cross-Border Deposit

Table A2.4. Emergency Actions

\begin{tabular}{lccccc}
\hline Country & $\begin{array}{c}\text { Experienced } \\
\text { banking crisis }\end{array}$ & $\begin{array}{c}\text { Explicit DI } \\
\text { introduction }\end{array}$ & $\begin{array}{c}\text { Official } \\
\text { government } \\
\text { guarantee }\end{array}$ & $\begin{array}{c}\text { Limited } \\
\text { government } \\
\text { guarantee }\end{array}$ & $\begin{array}{c}\text { Unlimited } \\
\text { government } \\
\text { guarantee }\end{array}$ \\
\hline Australia & 0 & 1 & 1 & 0 & 1 \\
Austria & 1 & 0 & 1 & 0 & 1 \\
Belgium & 1 & 0 & 0 & 0 & 0 \\
Brazil & 0 & 0 & 0 & 0 & 0 \\
Chile & 0 & 0 & 0 & 0 & 0 \\
Denmark & 1 & 0 & 1 & 0 & 1 \\
Finland & 0 & 0 & 0 & 0 & 0 \\
France & 1 & 0 & 0 & 0 & 0 \\
Germany & 1 & 0 & 1 & 1 & 0 \\
Greece & 1 & 0 & 0 & 0 & 0 \\
India & 0 & 0 & 0 & 0 & 0 \\
Ireland & 1 & 0 & 1 & 0 & 1 \\
Italy & 1 & 0 & 0 & 0 & 0 \\
Luxembourg & 1 & 0 & 0 & 0 & 0 \\
Netherlands & 1 & 0 & 0 & 0 & 0 \\
Spain & 1 & 0 & 0 & 0 & 0 \\
Sweden & 1 & 0 & 0 & 0 & 0 \\
Switzerland & 1 & 0 & 0 & 0 & 0 \\
UK & 1 & 0 & 0 & 0 & 0 \\
United States & 1 & 0 & 1 & 1 & 0 \\
\hline Note: Thistable & 1 & 0 & 0 & 0 & 0 \\
\hline
\end{tabular}

Note: This table lists our sample of bank countries for which emergency action data are available. Thus, in contrast to our full sample of 22 bank countries, Panama and Macao SAR are excluded here. All variable definitions can be found in Table A2.1 in Appendix.

Table A2.5. Systemic Banking Crises

\begin{tabular}{cc}
\hline Year & $\begin{array}{c}\text { Number of countries in } \\
\text { crisis }\end{array}$ \\
\hline 1998 & 16 \\
1999 & 11 \\
2000 & 9 \\
2001 & 7 \\
2002 & 3 \\
2003 & 3 \\
2004 & 2 \\
2005 & 1 \\
2006 & 0 \\
2007 & 2 \\
2008 & 22 \\
2009 & 23 \\
2010 & 23 \\
2011 & 23 \\
\hline Note: Borderline systemic banking \\
crises are included.
\end{tabular}

crises are included. 


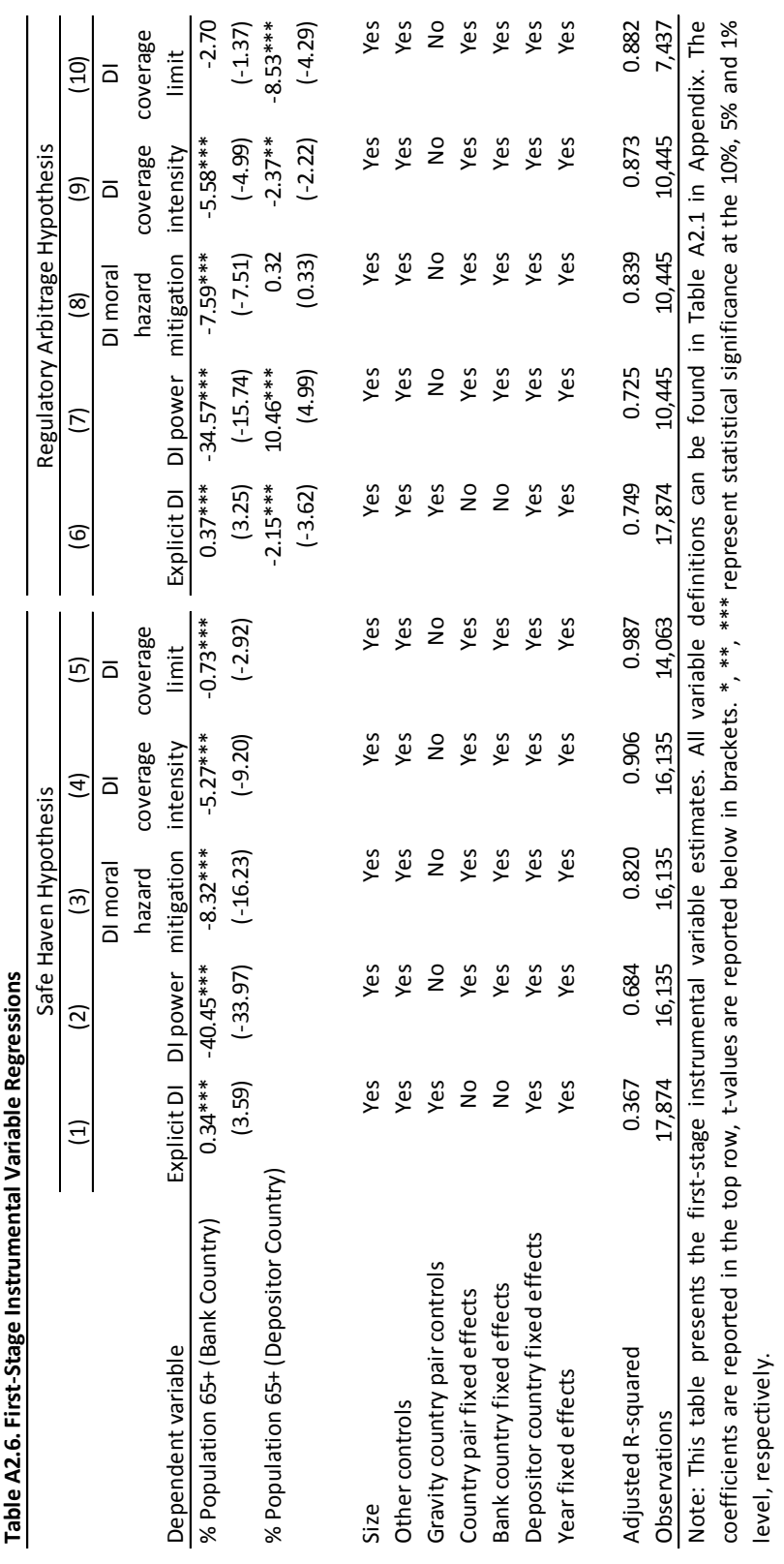




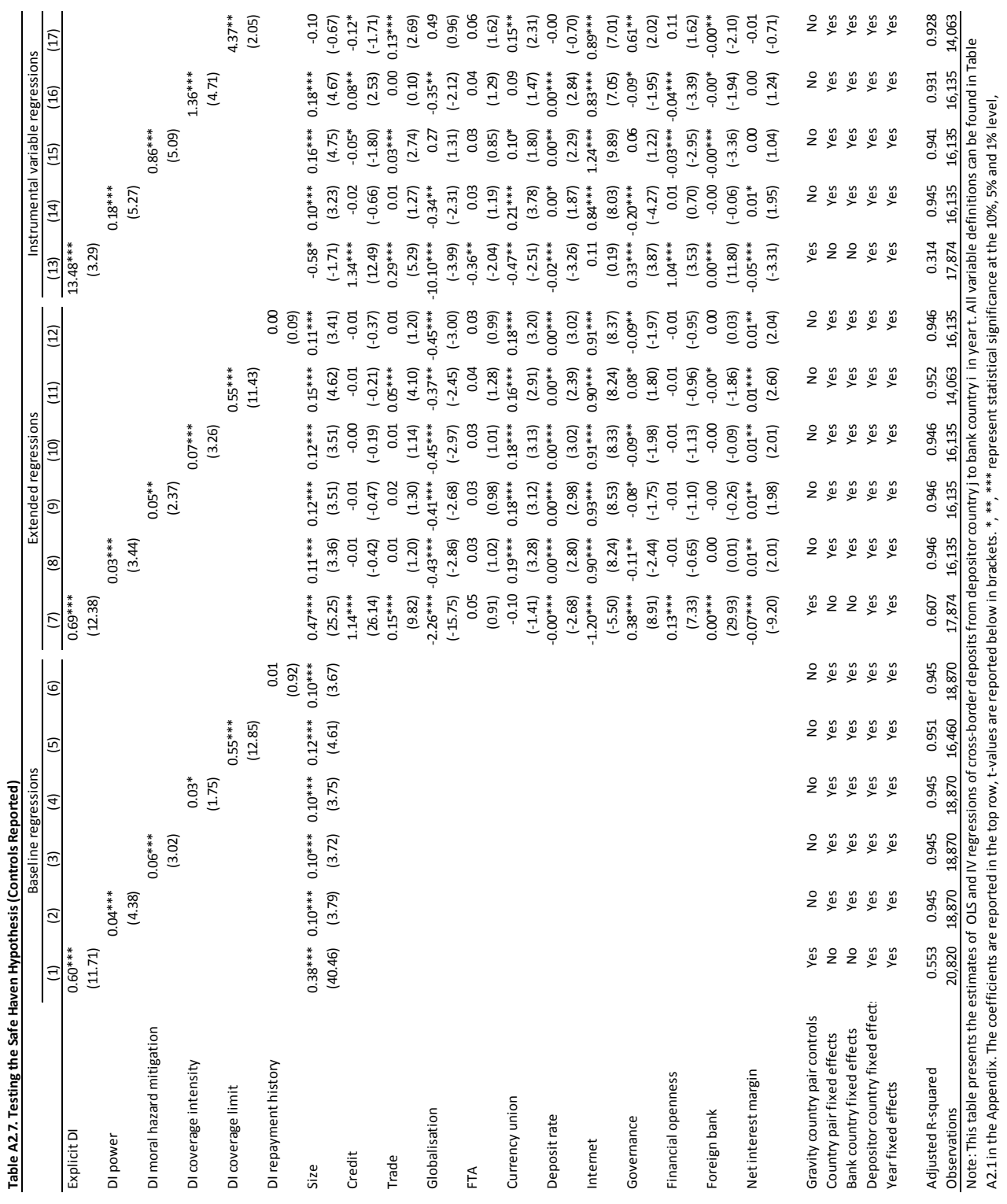




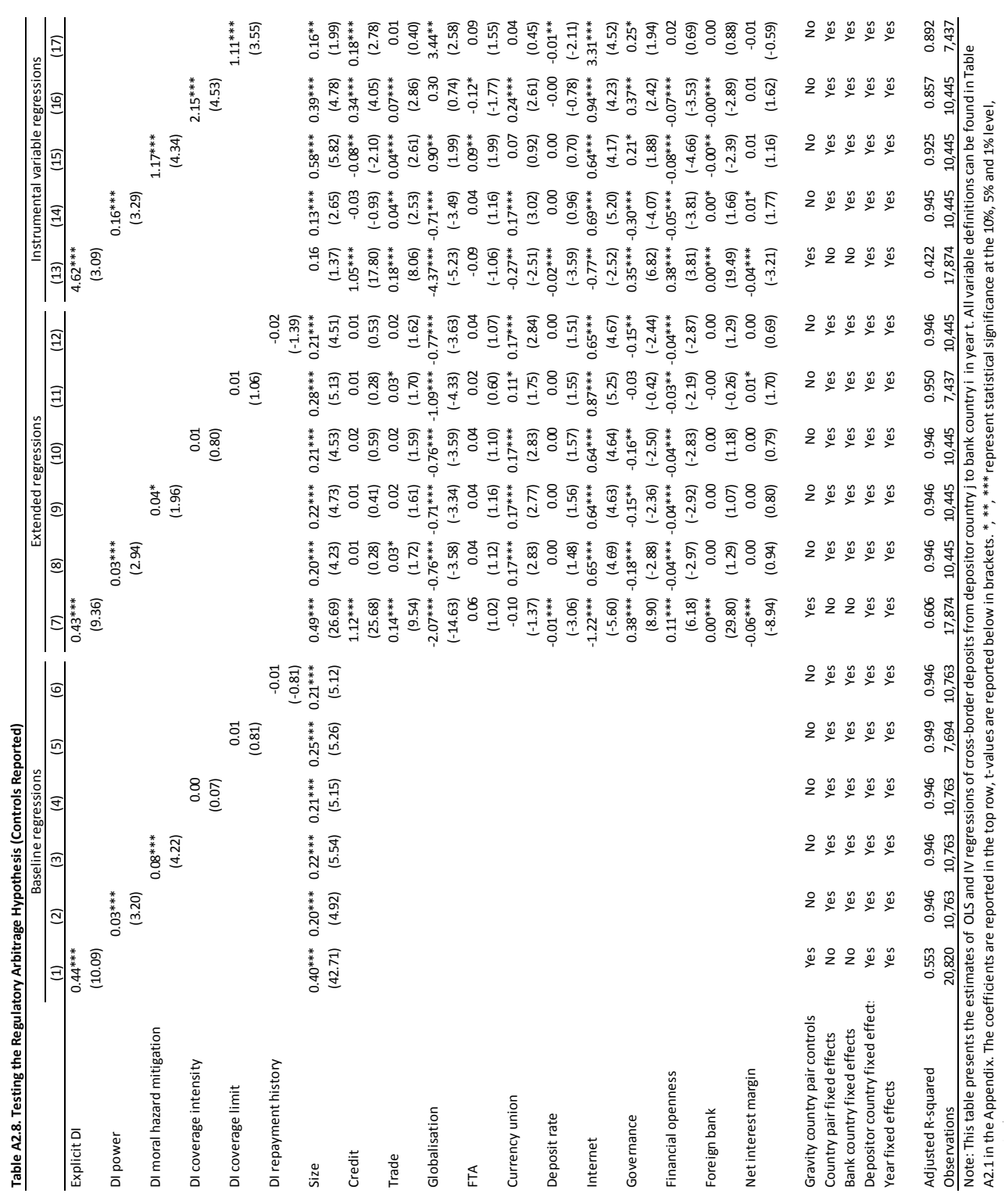




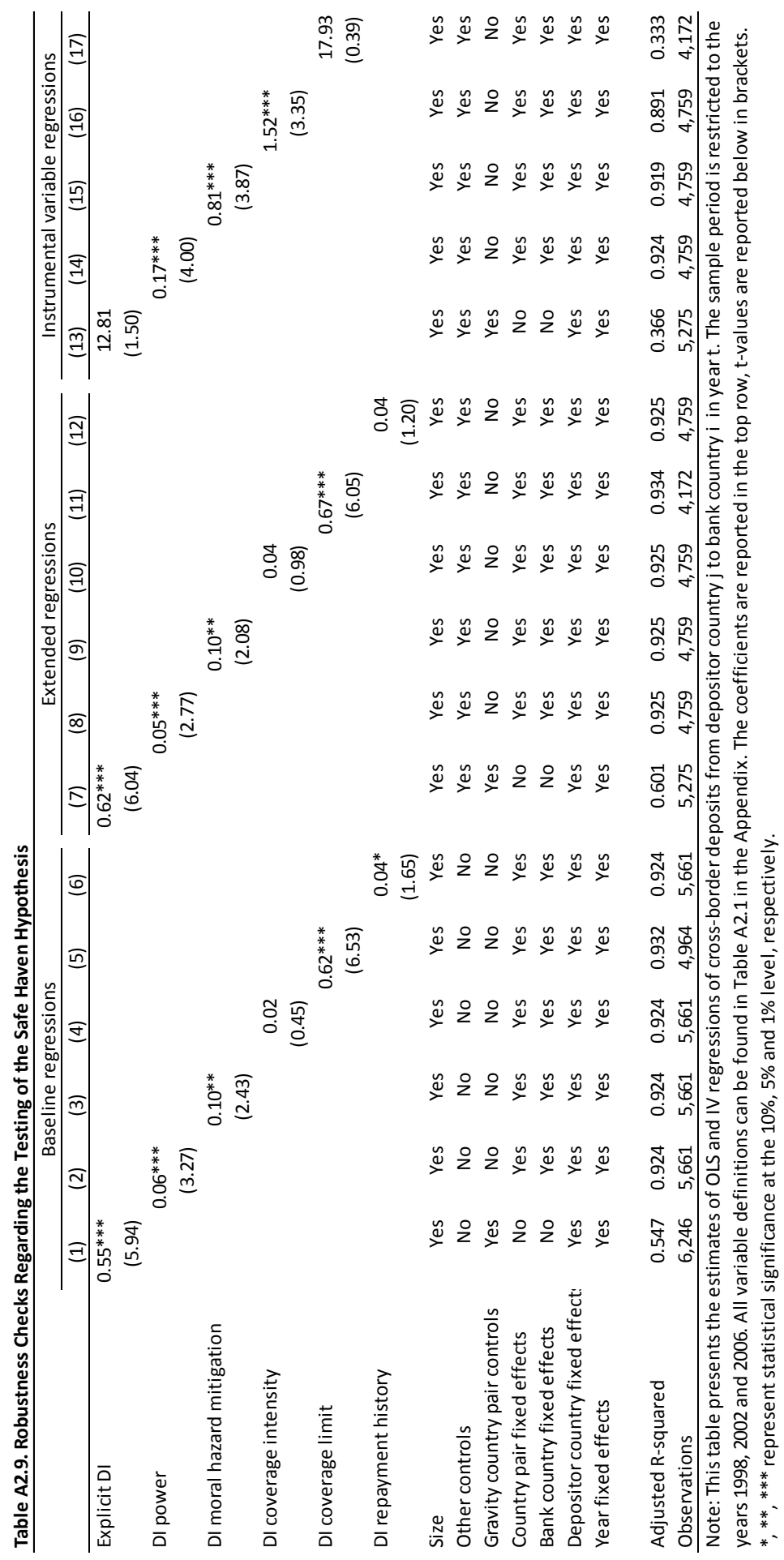




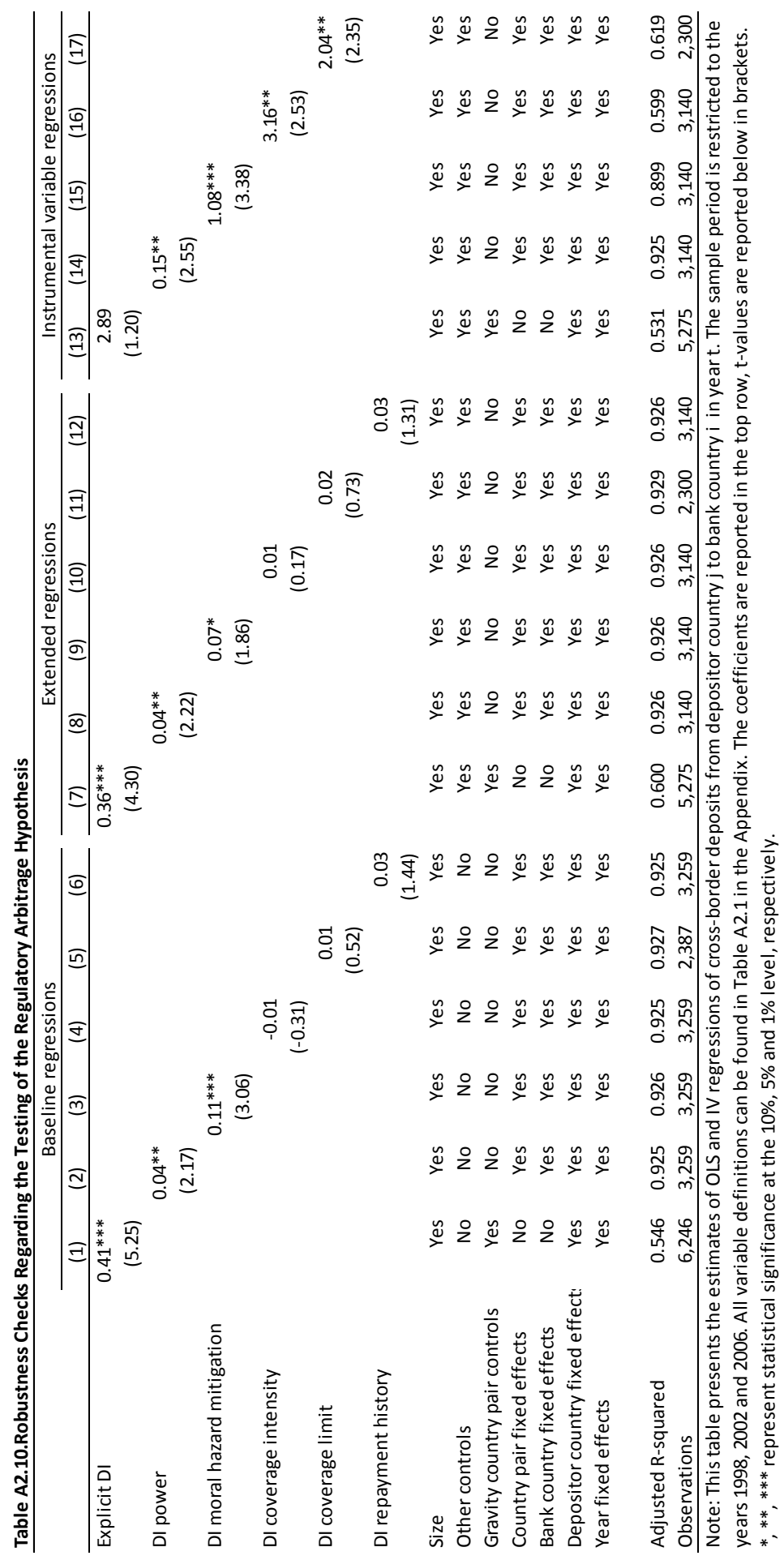




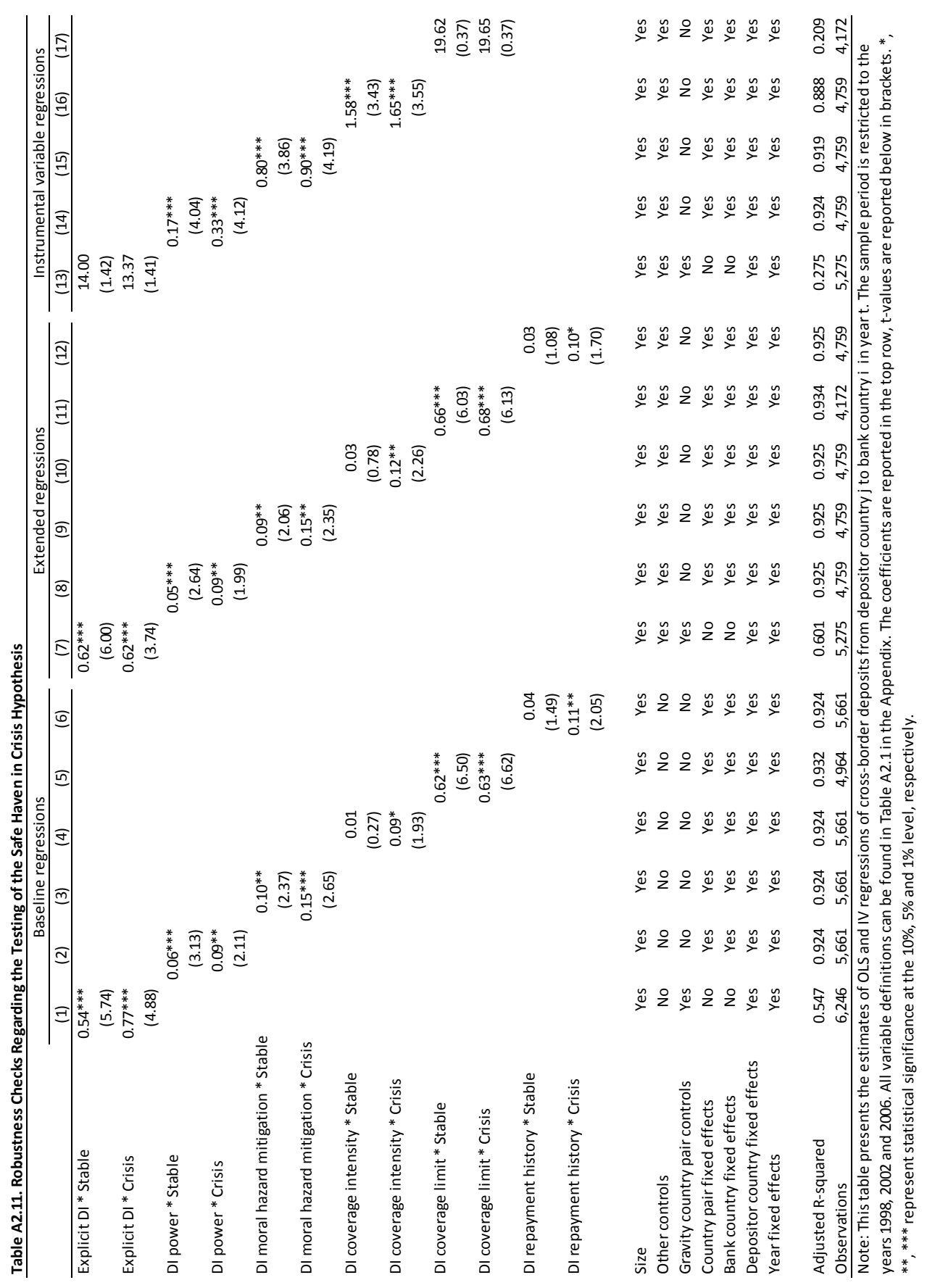




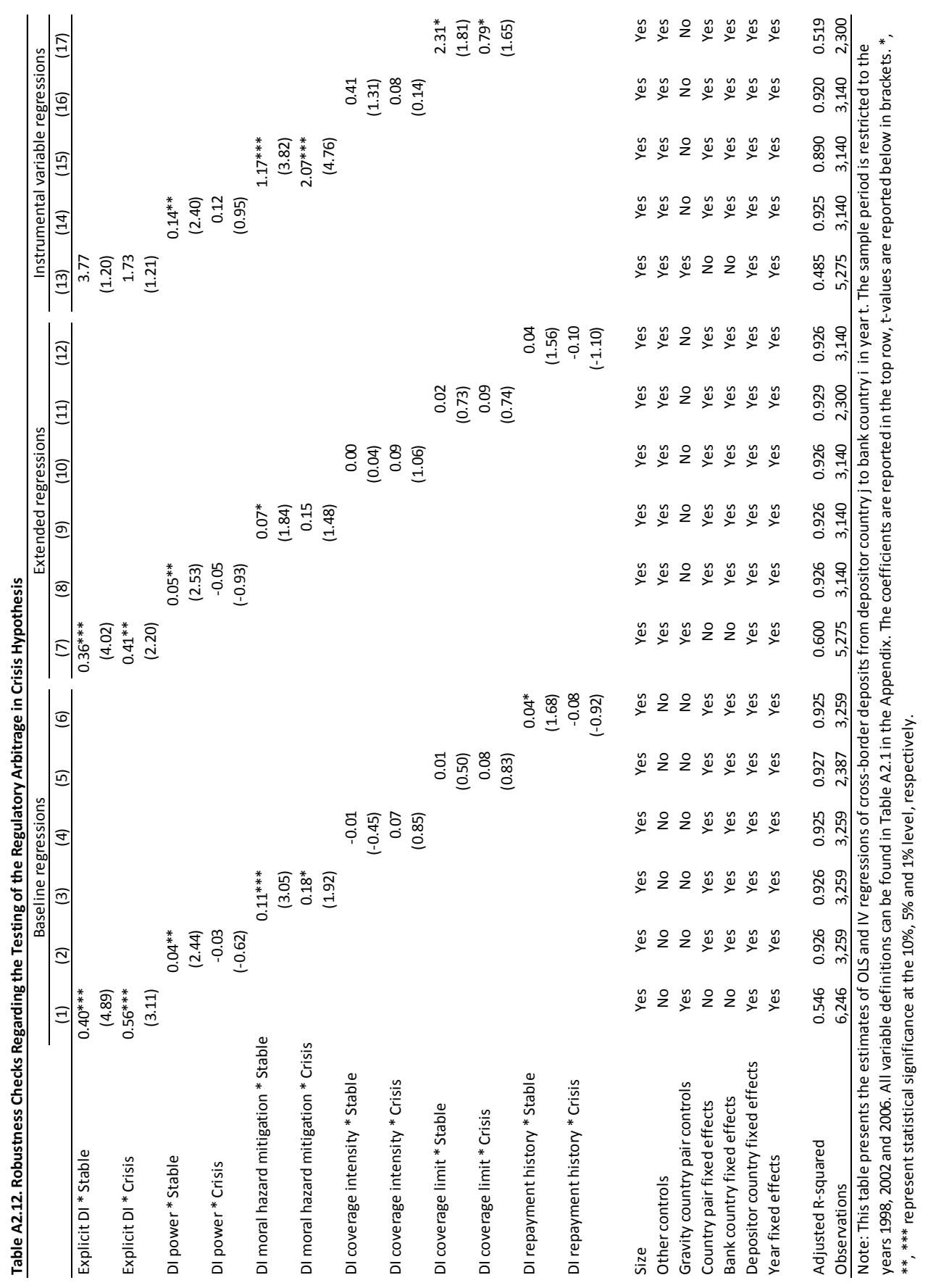




\section{Chapter 3}

\section{Information Sharing and Bank Branching ${ }^{18}$}

\subsection{Introduction}

Over the past two decades, banks across the world have adjusted their branch networks in response to regulatory changes, increased competition, and progress in information and communication technology. More recently, many American and European banks have also pruned their branch networks in the aftermath of the Great Recession. Figure 3.1 illustrates how branch networks in a variety of countries have evolved over time.

Figure 3.1. Aggregate Bank Branch Dynamics in the U.S. and Europe: 2001-2014

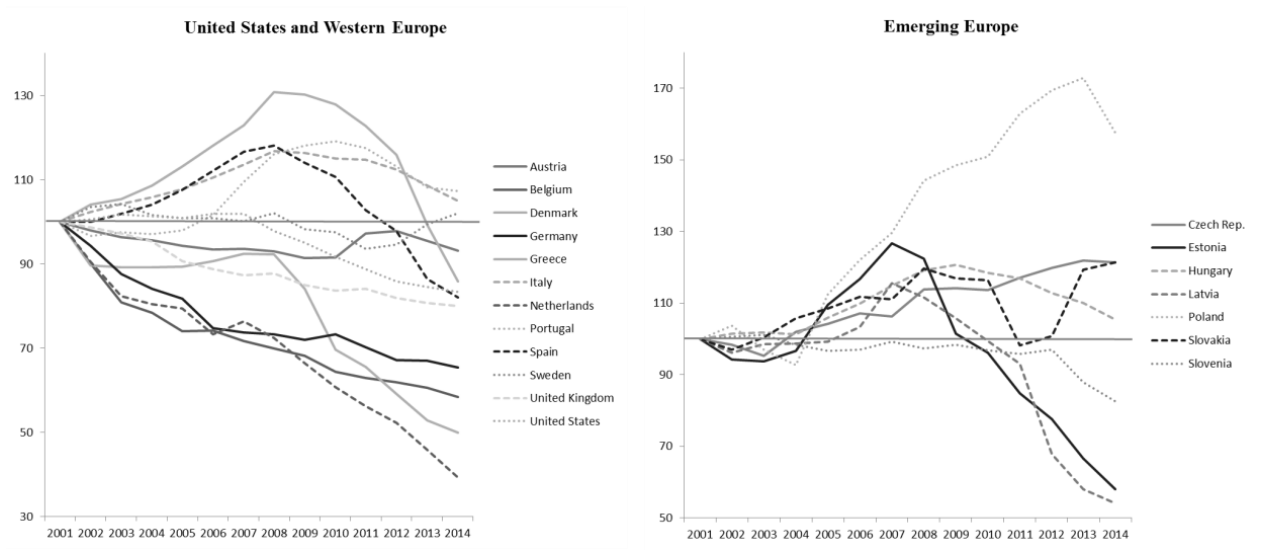

Note: These charts show the development of the total number of bank branches by country. If a foreign bank has several branches in a host country then these are counted as a single branch in the case of European countries (in line with ECB methodology). Source: FDIC and ECB.

Importantly, these dynamics do not play out in a geographically uniform way within countries. Branches increasingly cluster together as banks close branches in sparsely populated areas while opening new ones in economically stronger population centers. For example, of the 600 branches that British banks closed between April 2015 and April 2016, over 90 percent were in areas with a below-median household income. In contrast, about two-thirds of all branch openings occurred in wealthier neighborhoods, especially in London (Reuters, 2016). A similar trend can be observed in the United States, where branch clustering is mirrored by an increase in "banking deserts": localities entirely devoid of bank branches (Morgan, Pinkovsky, \& Yang, 2016). ${ }^{19}$

\footnotetext{
${ }^{18}$ This chapter is co-authored with Ralph De Haas (EBRD; Tilburg University), Steven Ongena (University of Zurich; Swiss Finance Institute; CEPR) and Stefan Straetmans (Maastricht University). The views expressed are those of the authors and not necessarily of the EBRD.

${ }^{19}$ Nguyen (2015) finds that (merger-related) branch closures in the U.S. result in prolonged declines in smallbusiness lending and a related reduction in employment growth. These impacts are highly local and dissipate within six to eight miles.
} 
Despite this observed increase in geographic (spatial) branch clustering, hardly any theoretical and empirical research exists on what drives the physical location of bank branches. The main contribution of this paper is to at least partially fill this gap. The departure point of our analysis is the assumption that spatial branch clustering intensifies price competition and lowers loan rates because loans from different banks are (imperfect) substitutes. But why then do bank branches cluster to start with?

The scarce existing literature on the determinants of spatial bank clustering is either of a rational or behavioral nature (Deller \& Sundaram-Stukel, 2012). Clustering is rational when locating near other banks generates external economies of scale or when the demand for banking services is spatially clustered itself. In contrast, behavioral explanations regard clustering as the result of "groupthink" or of banks following first-movers in an informational cascade model. Due to reputational concerns, bank managers may open a new branch in a neighborhood with pre-existing branches rather than venture into virgin territory. In line with such herding, Chang, Chaudhuri, \& Jayaratne (1997) find that branch openings follow existing branches even if this hurts the profitability of the new branch.

Both explanations for geographical branch clustering are hard to test empirically. It is, for instance, challenging to evaluate current and expected credit demand across regions. Moreover, bank managers are compensated based on multiple criteria so that branch locational decisions are hard to evaluate separately. It is also problematic to directly measure and compare banks' informational awareness.

As a first step towards a better understanding of branch clustering, we build a spatial oligopoly model that can both explain clustering behavior and be tested empirically. ${ }^{20}$ To the best of our knowledge we are the first to develop such a stylized model, in which bank branch clustering arises in an intuitive way. For example, suppose an entrepreneur needs credit to expand her business. She needs to visit a bank branch and talk to a loan officer to know whether she will get a loan or not. Suppose the probability of getting a loan from any local bank branch is 20 percent. Moreover, assume that the success probabilities across different bank branches are unrelated. ${ }^{21}$ If the entrepreneur visits a locality with only one bank branch, the probability of getting a loan is 20 percent. Yet, if another locality has six bank branches, then the probability of getting a loan is almost 74 percent. Given this much higher probability, the entrepreneur will be tempted to visit the second locality. At the same time, the higher inter-bank competition in this locality will lower banks' lending rates and profit margins. An important intuition of our model is therefore that while branch clustering increases the size of the local banking market (a "market-size" effect), inter-bank proximity also implies more vigorous competition (a "price-cutting" effect). If the first effect dominates, bank branches earn higher profits by locating closer to each other.

We use this theoretical framework to make predictions about the impact of a reduction in information asymmetries between banks and borrowers on branch clustering. As

\footnotetext{
${ }^{20}$ Our assumptions are less stringent than those in the Salop (1979) model that is used extensively in the literature on bank competition (see Barros, 1999; Dell'Ariccia, 2001; Kim, Lozano-Vivas, \& Morales, 2007). In our model, borrowers are uniformly distributed on a two-dimensional plane and banks can cluster in a locality (in contrast to the Salop model where banks are equidistant).

${ }^{21}$ We later relax this assumption so that success probabilities are correlated across banks.
} 
information asymmetries typically increase with distance, geographical credit rationing makes it difficult for entrepreneurs to successfully apply for a loan at a branch that is further away (Petersen \& Rajan, 2002; Hauswald \& Marquez, 2006). Such distance constraints are less binding when banks can credibly share information about loan applicants, either voluntarily through private credit bureaus or in the form of mandatory public credit registries. In our model, information sharing therefore allows banks to lend to more distant entrepreneurs. This allows us to derive three testable hypotheses.

First, our model predicts that information sharing increases competition and bank branch clustering. Banks can now attract more distant borrowers that were previously too opaque to lend to. Second, the model predicts that information sharing reduces the likelihood that banks open branches in localities where they already operate one or more branches. Third, information sharing synchronizes different banks' loan-approval decisions. This dampens the market-size effect of branch clustering and our model accordingly predicts that when information sharing becomes more efficient, branch clustering gradually becomes less pronounced.

To empirically test our model, we use detailed bank branch data - geographical coordinates and the dates of establishment and possible closure of each branch - from 22 Eastern European countries. Our sample covers 59,333 branches that were active for (part of) the period 1995-2012. The dataset further contains information on the banks that own these branches, which enables us to distinguish between branches of domestic versus foreign banks. Eastern Europe constitutes a natural testing ground for our model because information asymmetries are pervasive in this region while creditor rights remain weak (Brown, Jappelli, \& Pagano, 2009).

Moreover, many Eastern European countries institutionalized information sharing among lenders - either through a public credit registry or a private credit bureau - during our sample period. We use the introduction of such information-sharing regimes as countrylevel exogenous shocks that push banks towards a new branch clustering equilibrium. We implement a difference-in-differences estimation approach to evaluate the impact of the introduction of information sharing in some countries compared with other sample countries where information sharing had not yet been introduced. This strategy enables us to mitigate selection biases and, by allowing for country and time fixed effects, alleviates concerns about omitted variables.

To preview our results, we find that the introduction of information sharing has a strongly positive effect on bank branch clustering. The impact is larger for domestic banks. We also find that information sharing makes it more likely that banks open new branches in localities where they did not yet operate branches. Finally, and in line with our model, we show that in countries with more efficient credit information sharing systems, bank clustering becomes less pronounced over time.

This paper contributes to two strands of the literature. First, there is a clear lack of research that theoretically explains and empirically identifies the fundamental factors that drive the physical location of bank branches. In contrast, a rich empirical literature exploits plausibly exogenous spatial diversity in the presence of bank branches - reflecting historical 'quirks' 
or waves of financial deregulation - to identify the impact of bank density on various real outcomes. ${ }^{22}$ While useful for identification purposes, one ought to bear in mind that outside of these settings, bank branches are unlikely to be spread quasi-randomly across space. Moreover, the limited literature that does investigate banks' decisions concerning their branch network mainly focuses on the size of these networks rather than their geographical distribution. ${ }^{23}$ Our contribution is to develop a simple and intuitive framework in which banks rationally trade off the market-size and price-cutting effects of geographical bank clustering. We then test our model predictions in an international context, using the introduction of information sharing as country-level exogenous shocks that move banks towards a new clustering equilibrium.

Second, we add to the literature on the economic impacts of information sharing. Theoretical contributions explore how information sharing reduces moral hazard and adverse selection, improves loan quality, and lowers interest rates (Padilla \& Pagano, 1997; 2000). On the empirical side, cross-country evidence indicates that information sharing is associated with more lending to the private sector, fewer defaults and lower interest rates (Jappelli \& Pagano, 2002). Recent evidence suggests that (voluntary) private credit bureaus tend to be more effective than (mandatory) public registries in this regard (Martinez-Peria \& Singh, 2014). Yet, exactly how information sharing affects bank behavior remains unclear. This paper uncovers an important mechanism: the central availability of borrower information leads to different equilibrium levels of branch clustering which may be associated with a reduction in spatial credit rationing.

The remainder of the paper proceeds as follows. Section 2 introduces a simple spatial oligopoly model of bank branch clustering after which Section 3 describes our data in more detail. Section 4 then sets out our methodology and Section 5 reports the empirical findings. Section 6 concludes.

\subsection{Theoretical Model}

We develop a spatial oligopoly model to formalize the trade-off between the market-size and price-cutting effects of bank clustering. ${ }^{24}$ Specifically, we determine both the number of borrowers who visit a locality (the market size) and the equilibrium loan rate prevailing in that locality (the price). This section sets out the main intuition of the model while Appendix 1 provides a more formal discussion.

In our model both entrepreneurs and banking localities (towns or cities) are uniformly distributed across a two-dimensional plane. Each entrepreneur has identical project returns $r$ and wants to obtain a single loan for which she can apply by travelling to any locality with at least one bank branch. Entrepreneurs face a probability $p$ of not obtaining a loan when

\footnotetext{
${ }^{22}$ See Jayaratne \& Strahan (1996), Beck, Levine, \& Levkov (2010), Rice \& Strahan (2010), Kroszner \& Strahan (2014), and Favara \& Imbs (2015) for the U.S.; Guiso, Sapienza, \& Zingales (2004), Herrera \& Minetti (2007) and Benfratello, Schiantarelli, \& Sembenelli (2008) for Italy and Berkowitz, Hoekstra, \& Schoors (2014) for Russia.

${ }^{23}$ Cerasi, Chizzolini, \& Ivaldi (2002) and Cohen \& Mazzeo (2010) investigate the impact of competition on the size of branch networks. Temesvary (2014) shows both theoretically and empirically that locational market power allows banks with larger branch networks to charge an interest-rate premium, while Coccorese (2012) incorporates branch decisions in a price competition model.

${ }^{24}$ We build on Konishi (2005) who models the spatial concentration of retail stores.
} 
applying. This probability is correlated across branches with correlation $\varphi$. We assume this correlation is the same for different localities.

Loan size is homogeneous across entrepreneurs and normalized to one. Entrepreneurs need to pay the commuting cost to their locality of choice and this cost equals the distance times a positive transportation cost coefficient $t$. In addition, entrepreneurs pay the equilibrium loan rate prevailing in this locality if they successfully obtain a loan there.

The model consists of three stages. In Stage I, banks open a finite number of branches across the localities on the two-dimensional plane. They cluster these branches based on expected profits. In Stage II, entrepreneurs observe the locations of the branches and consequently receive a signal about the loan rate in each locality. ${ }^{25}$ They now decide, based on the expected return of borrowing in each locality, which locality to visit. The expected return depends on the distance to the locality (and the associated transportation costs), the probability of successfully applying for a loan there, and the interest rate in case the borrower receives credit. Each entrepreneur visits at most one locality: the one that in expectation gives the highest (positive) net return. If no locality yields a positive expected return, the entrepreneur does not apply for a loan.

Critically, without information sharing among banks, information asymmetries between entrepreneurs and banks cause a discrete distance threshold beyond which the probability $p$ of an unsuccessful loan application is 1 . Stated otherwise, due to geographical credit rationing entrepreneurs know for sure that they will be rejected when applying for a loan at branches located beyond the distance threshold. ${ }^{26}$ Only below this threshold does the entrepreneur face the usual rejection probability $p<1$ and trades off the higher transportation costs of more distant bank localities against the higher probability of receiving a loan (at a relatively low cost) in distant localities with more branches.

Finally, in Stage III of the model, bank branches in the same locality compete the loan rate down to a local equilibrium level. ${ }^{27}$ We assume that bank branches grant loans at zero marginal cost.

In our model, branch clusters increase an entrepreneur's expected return for two reasons: a higher chance of getting a loan and loans being cheaper. These advantages may be (partially) offset if the locality is distant and transportation costs are high. For the bank, there is a trade-off too. On the one hand, branch clustering increases the local market size because entrepreneurs prefer denser banking markets (the market-size effect). On the other hand, branch density and the associated competition reduces loan rates (the price-cutting effect). This trade-off determines the optimal level of clustering and makes the relationship between clustering and the expected profit of a branch follow an inverse U-shape. Denser

\footnotetext{
${ }^{25}$ The local loan rate depends on the number of branches and hence the intensity of bank competition.

${ }^{26}$ According to the president of the Italian Bankers' Association "the banker's rule of thumb is to never lend to a client located more than three miles from his office" (quoted in Guiso, Sapienza, \& Zingales, 2004). The median Belgian SME borrower in Degryse \& Ongena (2005) is located 2.5 kilometers (1.6 miles) from the lending branch. In the U.S. data of Petersen \& Rajan (2002) and Agarwal \& Hauswald (2010) this median distance is $3.7 \mathrm{~km}$ ( 2.3 miles) and $4.2 \mathrm{~km}$ ( 2.6 miles), respectively.

${ }^{27}$ We assume that the equilibrium lending rate is determined by within-locality competition and is not affected by distant banks. See Ho \& Ishii (2011) for empirical evidence.
} 
branching initially leads to higher profits as the positive market-size effect dominates the negative price-cutting effect. After some optimum, however, opening another branch in a locality drives down profits as the price-cutting effect more than offsets the increase in market size.

Information sharing among banks impacts the equilibrium level of branch clustering in our model as it eliminates the distance threshold beyond which entrepreneurs cannot successfully apply for loans. That is, when borrower information is shared, entrepreneurs can in principle apply in each locality - as long as transportation costs are not prohibitive. Realizing this, banks start to cluster in order to attract more distant entrepreneurs that are in search of deeper credit markets in which they can apply for a loan from a wider variety of banks. This yields our first testable hypothesis:

HYPOTHESIS 1: After the introduction of information sharing, different banks increasingly cluster their branches in the same localities.

Our model also predicts that banks exploit the opportunities of sharing borrower information by extending their branch network to localities where adding a branch of their own increases the number of different banks that entrepreneurs can choose from. In contrast, adding more branches from the same bank to localities where this bank is already present would not make this locality a more attractive 'shopping' destination for (distant) entrepreneurs because loan rejection rates are perfectly correlated among branches of the same bank. That is, if an applicant gets rejected by a branch of Bank $A$ it will get rejected by all branches of Bank $A$ in the same locality. Our second hypothesis is therefore:

HYPOTHESIS 2: After the introduction of information sharing, banks are more likely to open new branches in localities with no (or fewer) existing branches of their own.

Third, our model predicts that information sharing affects domestic banks and foreign banks differently. Domestic banks may depend more on developing long-term lending relationships with borrowers and on extracting proprietary information in the process while foreign banks focus more on transactional lending based on publicly available information (Mian, 2006; Beck, loannidou, \& Schäfer, 2017). If this is the case, distance thresholds due to informational asymmetries may be more binding for domestic as compared with foreign banks in the absence of borrower information sharing. The introduction of the sharing of such information may consequently affect domestic banks more and make them cluster their branches in particular. At the same time, information sharing allows foreign banks in particular to expand into new localities. Our third hypothesis is therefore:

HYPOTHESIS 3: The impact of information sharing on bank clustering is stronger for domestic banks while it helps foreign banks in particular to expand into new localities.

Finally, in our model the introduction of information sharing increases the correlation across banks of declining a loan application and this gradually reduces the market-size effect. This implies that when information sharing becomes increasingly effective (and the correlation becomes high enough) there will be a gradual reduction in bank branch clustering. Our fourth and last hypothesis is therefore: 
HyPOTHESIS 4: Very effective information sharing, characterized by a sufficiently high correlation among banks' loan-approval decisions, will reduce branch clustering.

Specifically, the numerical model set-up and analysis are introduced in the following paragraphs in detail.

\section{Basic set-up}

We assume there are two nearby bank localities $d$ and $s$ as well as a more distant bank locality $w$. Each entrepreneur visits at most one of these three localities to apply for a loan. We focus on branch clustering in locality $d$, treating the situation in localities $s$ and $w$ as given, and then proceed by backward induction.

Stage III: In locality $d$ with $k$ bank branches the equilibrium loan rate is:

$$
i_{d}=i_{0}+i_{1} / k
$$

Where $i_{o}$ stands for the minimum loan rate and $i_{1}$ is the oligopoly rent that banks can extract from nearby borrowers. With more bank branches, the equilibrium loan rate decreases in line with the price-cutting effect of branch clustering.

To determine the probability that a loan application gets rejected, we start from the case of two bank branches. The probability of rejection at the first and the second branch is $p$ and $\varphi$, respectively, and the joint probability of rejection at both branches equals (Gupta and Tao, 2010):

$$
\operatorname{Prob}(2)=p * p+\varphi * \sqrt{p * p *(1-p) *(1-p)}=p^{2}+\varphi * p *(1-p)
$$

In the case of three branches, we can compare the third branch with the first two branches while treating those first two as one unit. The joint probability of rejection at all three branches then equals:

$$
\operatorname{Prob}(3)=p * \operatorname{Prob}(2)+\varphi * \sqrt{p * \operatorname{Prob}(2) *(1-p) *(1-\operatorname{Prob}(2))}
$$

Likewise, if there are $k$ bank branches in locality $d$, then the joint probability of rejection in locality $d$ is:

$$
\operatorname{Prob}(k)=p * \operatorname{Prob}(k-1)+\varphi * \sqrt{p * \operatorname{Prob}(k-1) *(1-p) *(1-\operatorname{Prob}(k-1))}
$$

Stage II: Given the expected loan rates at each bank locality, an entrepreneur decides which locality to visit by maximizing the expected profit:

$$
E P_{d}=(1-\operatorname{Prob}(k))\left(r-i_{d}\right)-t * \text { radius }
$$

Where radius is a threshold distance between the borrower location and locality $d$. 
If we assume for now that there is no overlap between localities $d$ and $s$, then the marginal entrepreneur should satisfy $E P_{d}=0$ and we have:

$$
\text { radius }=(1-\operatorname{Prob}(k))\left(r-i_{d}\right) / t
$$

This means that all entrepreneurs for whom the distance to $d$ is less than radius choose to go to locality $d$ to apply for a loan. In other words, the market area for locality $d$ encompasses a circle around locality $d$ with a radius of radius. Therefore, if all bank branches in locality $d$ equally share the total market, then the market size of each branch in locality $d$ is:

$$
S_{d}=\left(\pi * \operatorname{radius}^{2}\right) / k=\left[(1-\operatorname{Prob}(k))\left(r-i_{d}\right) / t\right]^{2} / k
$$

The expected profit of each branch in locality $d$ is then:

$$
E_{d}=S_{d} * i_{d}
$$

Stage I: In this stage, banks determine the clustering of their branches based on expected profits. They will not open a branch in locality $d$ if the expected profit is below the expected profit of opening a stand-alone branch in a new locality.

\section{Information sharing}

In the absence of information sharing, entrepreneurs can only apply for a loan in nearby localities $d$ and $s$. Due to geographical credit rationing the loan-rejection probability in distant locality $w$ is 1 . However, when information sharing is introduced the entrepreneur can also choose to apply for a loan in locality $w$. The establishment of information sharing thus increases competition in each banking locality and both the market size and the equilibrium price decrease. Banks in nearby localities now have more incentives to cluster their branches in order to attract (or retain) borrowers who may be tempted to travel to a distant locality and apply there.

Assume there are $n$ branches located in distant locality $w$ and there is a positive additional cost component $c$. These costs include higher expenses due to long-distance travel as well as agency costs that result from the serious information asymmetries between bank branches and very distant entrepreneurs. The marginal entrepreneur who chooses the far-away locality $w$ should hence satisfy:

$$
E P_{n}=(1-\operatorname{Prob}(n))\left(r-i_{n}\right)-c \geq 0
$$

It is important to note that with information sharing, the inter-branch correlation of the probability that an entrepreneur cannot get a loan at any branch increases. This is because different branches now have similar information about each borrower, which reduces the benefit of branch clustering and decreases the market-size effect.

If the transaction cost $c$ is sufficiently small, then the fraction of entrepreneurs that still visits bank locality $d$ declines. The marginal entrepreneur who is indifferent between going to locality $d$ and locality $w$ should satisfy: 


$$
E P_{d}=E P_{n}
$$

This gives us the new radius, which should be strictly positive. This implies that there are still some borrowers who visit bank locality $d$ to get a loan:

$$
\text { radius }=\left[(1-\operatorname{Prob}(k))\left(r-i_{d}\right)-(1-\operatorname{Prob}(n))\left(r-i_{n}\right)+c\right] / t \geq 0
$$

Due to the introduction of information sharing, the oligopoly rent decreases. The equilibrium loan rate in locality $d$ is now:

$$
i_{d}=i_{0}+i_{1}^{\text {new }} / k
$$

This situation is depicted in Figure A3.1. We assume that there is no overlap between the market areas of locality $d$ and nearby locality $s$. The larger circle in light grey represents the market area of locality $d$ and $s$ before there is information sharing, while the smaller dark circle is the market area afterwards. The market size shrinks as some entrepreneurs - those already at the outer margins of localities $d$ and $s$-decide to apply for a loan in locality $w$.

\section{Comparative statics}

We now provide some numerical simulations of our model. We assume that the probability of loan rejection is 70 per cent, both the minimal loan rate and the oligopoly rent is 2 percent without information sharing and 0.5 percent with information sharing, the project return is 10 percent, the commuting cost coefficient equals 1 per cent and the commuting cost of applying for a loan in the distant locality $w$ is 3.2. There are 10 bank branches in this distant locality. After the establishment of information sharing, the correlation among bank branches of a loan rejection increases from 0.2 to 0.5 . Appendix Table A3.6 shows the simulation results.

The comparative statics show that before the establishment of information sharing, banks cluster together until there are 6 branches in locality $d$. The expected profit of each of these six branches is then 41.8 , which is still higher than the expected profit of operating alone (40.7). Adding a $7^{\text {th }}$ branch would, however, push expected profit below the profit that could be had when opening that additional branch in a new locality instead. After the introduction of information sharing (which introduces competition from distant bank localities) branch clustering increases significantly to 26 (until the profit of operating alone is higher than clustering).

We now generalize the model to allow for competition among nearby bank localities: that is, the market areas of locality $d$ and $s$ overlap. We assume that around locality $d$ there is an infinite number of localities $s$. The distance between all these localities $s$ and locality $d$ is $m$. Each locality $s$ has the same number of bank branches $j$. The expected profit in locality $s$ is then:

$$
E P_{s}=(1-\operatorname{Prob}(j))\left(r-i_{s}\right)-t(m-\text { radius })
$$

The equilibrium loan rate at locality $s$ equals: 


$$
i_{s}=i_{0}+i_{1} / j
$$

Assume that locality $d$ and $s$ are close enough so that the expected profit of visiting each locality is positive. The borrowers then compare the expected profit of both options and the marginal borrower is indifferent between locality $d$ and $s$ :

$$
E P_{d}=E P_{s}
$$

This gives us the radius of locality $d$ :

$$
\text { radius }=\left[(1-\operatorname{Prob}(k))\left(r-i_{d}\right)-(1-\operatorname{Prob}(j))\left(r-i_{s}\right)\right] / 2 t+m / 2
$$

The introduction of information sharing reduces both the equilibrium loan rate and the market size. The calculations are similar as before and Figure A3.2 depicts the situation with competition among nearby bank localities. The dashed line circumference around locality $d$ represents all the possible nearby localities $s$. Comparative statics in Table A3.7 show again that our model predicts a certain amount of bank clustering and that clustering increases (from 12 to 19 branches in locality $d$ ) once information sharing is introduced (we assume that the number of bank branches in locality $s$ is 5 and that the distance $m$ between locality $d$ and $s$ is 5). That is, the increase in branch clustering happens regardless of whether there is overlap in nearby banking markets.

Figure A3.3 shows, for the case of no overlap among nearby banking localities and with information sharing in place, that the relationship between bank clustering and expected profit is inversely $\mathrm{U}$-shaped. While the maximum expected profit per branch occurs when there are only 4 bank branches in locality $d$, new bank branches will continue to enter until there are 26. Each additional branch that opens after the initial 4 branches, decreases the expected profit of existing branches. If we assume that clustering is in equilibrium ex ante (6 branches in place), then ex post a new branch decreases the expected profit of existing branches. Therefore, our model predicts that information sharing will lead banks to locate their new branches in localities with fewer or no own existing branches.

The impact of information sharing on branch clustering may be more pronounced for domestic banks that are more vulnerable to the additional competition due to the establishment of information sharing. When information sharing is established, the borrowers of these less competitive banks have more offers from distant banks. To analyze this in our set-up, we assume that clients of domestic banks experience lower additional costs (3.2 compared to 3.3) when applying for a loan in distant locality w. Such borrowers may for instance be held up to a lesser extent by their incumbent lender and therefore find it less costly to switch to a distant locality that has become within reach due to information sharing. Table A3.8 shows that domestic banks cluster until 26 branches are opened in a locality whereas for foreign banks this number is only 20 . These numbers are 19 and 13 , respectively, in case there is overlap among nearby localities.

Finally, recall that we assume that with information sharing the inter-branch correlation of loan rejections increases so that the market-size effect is less pronounced. This implies that the more effective information sharing is, the smaller the additional bank clustering that we observe. To see this in our calibration exercise, we gradually increase the correlation from 
0.5 to 0.6 and compare the equilibrium clustering level of bank branches (Table A3.9). We indeed observe a decrease in the market-size effect and therefore branch clustering.

\subsection{Data}

Table 3.1 provides summary statistics of the dependent (branch data) and independent variables used in the empirical analysis. Appendix Table A3.1 provides all definitions. ${ }^{28}$

\subsubsection{Branch Data}

To test our hypotheses, we require time-varying data on branch locations for countries in which information sharing - either through a public credit registry or through a private credit bureau - is introduced at different points in time. To this end, we collect information on the geographical coordinates of 59,333 branches operated by 676 banks across 22 emerging European countries. ${ }^{29}$ These data paint a precise and gradually changing picture reflecting branch openings and closures - of the banking landscape during the years 19952012. Figure 3.2 shows the geographical branch distribution in these countries at the start and the end of our sample.

Appendix Table A3.3 summarizes the number of branches that opened or closed by year and country: $33,716(1,368)$ branches opened (closed) during our sample period. Many new branches were established during 2001-07, a period of rapid credit growth. The expansion of branch networks slowed down after the global financial crisis when fewer branches opened while branch closures (rare before the crisis) accelerated.

For each branch, we know the identity of the parent bank. By merging our data with the bank ownership data in Claessens \& Van Horen (2014) we can distinguish between foreign and domestic branches. A bank is classified as foreign if at least half of its equity is in foreign hands. We further distinguish between greenfield foreign banks (de novo banks established from scratch) and take-over banks that were formed when a foreign bank acquired a domestic one.

To empirically assess the impact of information sharing on bank branch clustering, we take the 33,716 branch openings during our sample period as our main unit of observation. ${ }^{30}$ This allows us to test whether the introduction of information sharing encouraged banks to open branches in different localities compared to before the introduction of information sharing.

Table 3.1 shows that slightly over half of all branch openings took place when a country had a credit registry or bureau in place (Information sharing). 44 per cent of all branch openings were by a foreign bank and about a third of these were by greenfield foreign banks.

\footnotetext{
${ }^{28}$ Appendix Table A3.2 contains a correlation matrix of all variables.

${ }^{29} \mathrm{~A}$ team of consultants with extensive banking experience collected the data by contacting banks or downloading data from bank websites. This data-collection exercise was part of the second Banking Environment and Performance Survey (BEPS II). For more information, see http://www.ebrd.com/what-wedo/economics/data/banking-environment-and-performance-survey.html.

${ }^{30}$ Our dataset contains 59,333 branches (owned by 676 banks) of which 33,716 (owned by 532 banks) opened during 1995-2012. The remaining 144 banks did not open branches during this period.
} 
Figure 3.2. Distribution of Localities with Bank Branches in 1995 and in 2012

Panel A. This map plots all localities in our dataset with at least one bank branch in 1995.

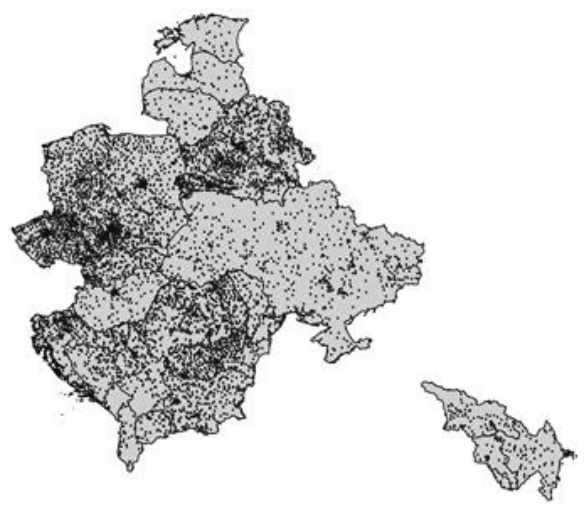

Panel B. This map plots all localities in our dataset with at least one bank branch in 2012.

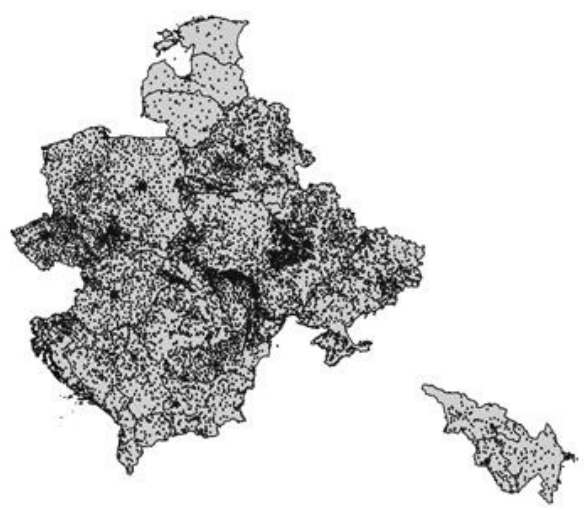

Our main dependent variables capture the clustering of banks across countries and over time. No. branches all banks measures the number of pre-existing bank branches around a newly opened branch. For this and all other dependent variables, we use two methods to match a new branch with all nearby existing branches. First, we draw circles with a 2 or $5 \mathrm{~km}$ radius around the geo-coordinates of the new branch and count the number of existing bank branches within that circle. Second, we count the number of existing branches within the same locality (town or city) as where the new branch is located. Table 1 shows that the median new branch is surrounded by 17 pre-existing branches within a 2-km radius; 23 branches within a $5-\mathrm{km}$ radius and 25 branches within the same locality. This indicates that most of the localities are medium-sized towns and cities.

Branch same bank is a dummy that indicates whether the bank that opens a new branch already operated one or more branches in the same area (circle or locality). The probability of pre-existing branches of the same bank being present is 33 (37) per cent when the surrounding area is measured as a circle with a $2 \mathrm{~km}(5 \mathrm{~km})$ radius and 38 per cent when branches are matched by locality. While the median number of pre-existing branches is zero, there is wide variation and the average number is three. 
Table 3.1. Summary Statistics

\begin{tabular}{lcccccc}
\hline Variable & Obs. & Mean & Median & St. Dev. & Min. & Max. \\
\hline Year of branch opening & 33,716 & 2004 & 2005 & 4.06 & 1995 & 2012 \\
Year of bank establishment & 33,716 & 1992 & 1992 & 14.26 & 1873 & 2011 \\
Dependent variables & & & & & & \\
No. branches all banks w/i $2 \mathrm{~km}$ & 33,716 & 90 & 17 & 202 & 0 & 1,575 \\
No. branches all banks w/i $5 \mathrm{~km}$ & 33,716 & 109 & 23 & 209 & 0 & 1,575 \\
No. branches all banks w/i same locality & 33,716 & 129 & 25 & 232 & 0 & 1,574 \\
Branch same bank w/i 2 km & 33,716 & 0.33 & 0 & 0.47 & 0 & 1 \\
Branch same bank w/i 5 km & 33,716 & 0.37 & 0 & 0.48 & 0 & 1 \\
Branch same bank w/i same locality & 33,716 & 0.38 & 0 & 0.49 & 0 & 1 \\
No. branches same bank w/i 2 km & 33,716 & 3 & 0 & 9.35 & 0 & 202 \\
No. branches same bank w/i 5 km & 33,716 & 3 & 0 & 10.12 & 0 & 202 \\
No. branches same bank w/i same locality & 33,716 & 4 & 0 & 11.95 & 0 & 202 \\
HHI w/i 2 km & 33,716 & 0.21 & 0.13 & 0.24 & 0 & 1 \\
HHI w/i 5 km & 33,716 & 0.21 & 0.13 & 0.24 & 0 & 1 \\
HHI w/i same locality & 33,716 & 0.23 & 0.14 & 0.24 & 0 & 1 \\
Independent variables & & & & & & \\
Information sharing & 33,716 & 0.55 & 1 & 0.50 & 0 & 1 \\
Quality information sharing & 17,807 & 1.45 & 0 & 2.16 & 0 & 6 \\
Branch by foreign bank & 33,716 & 0.44 & 0 & 0.50 & 0 & 1 \\
Branch by greenfield foreign bank & 33,716 & 0.14 & 0 & 0.35 & 0 & 1 \\
\hline Note: This table provides the number & of observations, mean, median, standard deviation, \\
minimum and maximum for all variables used in the analysis. & & & &
\end{tabular}

Lastly, we measure local credit market concentration by constructing a Herfindahl Hirschman Index (HHI) for each circle or locality around a new branch:

$$
H H I_{i}=\sum_{i=1}^{N} s_{i}^{2}
$$

Where $s_{i}$ stands for the market share, measured in branches, of bank $i$ in the market and $N$ is the number of banks.

\subsubsection{Data on Information Sharing}

Data on the introduction of information-sharing regimes are from the World Bank Doing Business database, the EBRD and various on-line sources. Appendix Table A3.4 shows that during the period 1995-2012, fifteen countries introduced a public credit registry and eighteen a private credit bureau. There exists substantial variation in the timing of the introduction of information sharing which is helpful for our empirical identification.

The upper bar chart in Figure 3.3 shows the average number of pre-existing branches of the same bank around newly opened branches in the four years before and the four years after the establishment of information sharing at $t=0$ (where $t=0$ differs across countries). In line with our second hypothesis, after the introduction of information sharing, new branches open in localities where banks have fewer pre-existing branches of their own (that is, banks spread out their own branch network). The second and third chart show that, in line with our first hypothesis, these new branches tend to cluster in more competitive markets (with more existing bank branches and hence a lower $\mathrm{HHI}$ ). 
No. branches same bank $\mathrm{w} / \mathrm{i} 2 \mathrm{~km}$

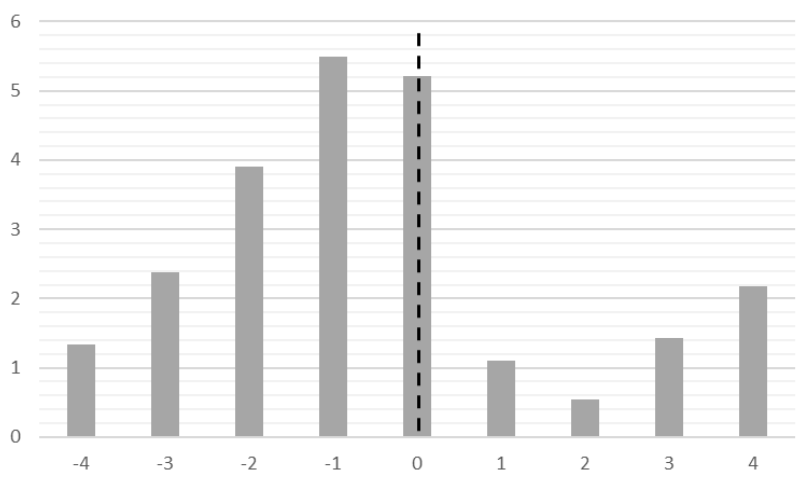

No. branches all banks w/i $2 \mathrm{~km}$

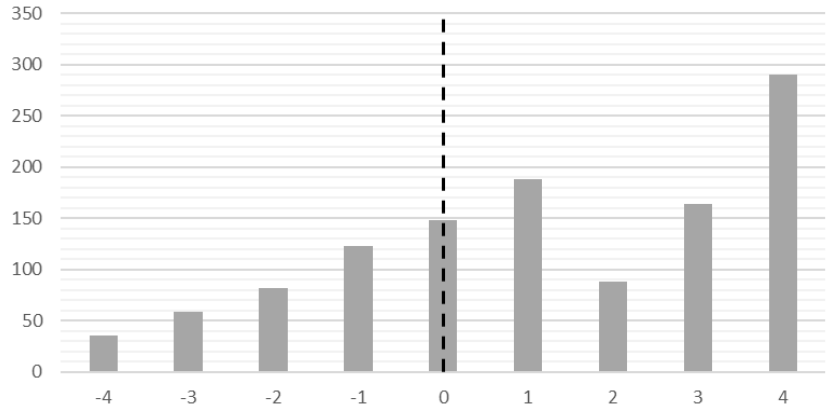

$\mathrm{HHI} / \mathrm{i} 2 \mathrm{~km}$

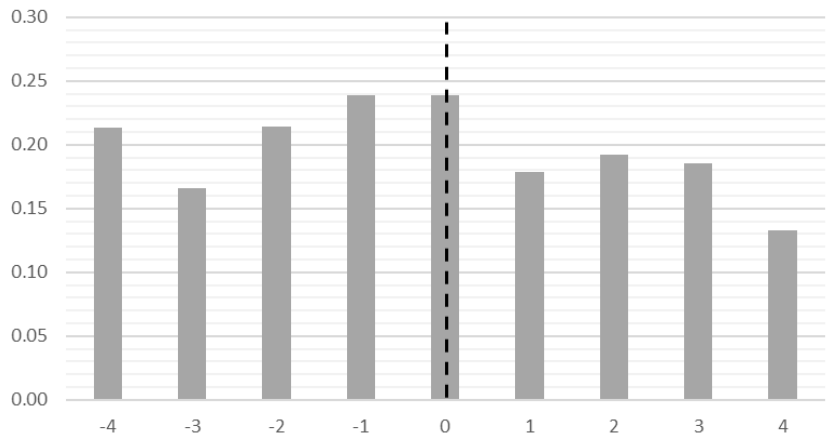

Note: The first two charts show the trend in the number of pre-existing branches of the same bank and all banks, respectively, within a $2 \mathrm{~km}$ radius around newly opened branches in the four years before and the four years after the establishment of information sharing at $\mathrm{t}=0$. The third chart shows the same for the $\mathrm{HHI}$ index in the $2 \mathrm{~km}$ around newly opened branched. Table A3.1 contains all variable definitions. 
Lastly, we proxy the quality of the information-sharing regime in a country by means of the World Bank Doing Business credit information index. The index ranges from 0 to 6 and reflects rules and practices affecting the coverage, scope and accessibility of credit information from either a public credit registry or a private credit bureau (higher values indicate more effective information sharing). A score of 1 is assigned for each of the following six features: (1) Both positive credit information (outstanding loan amounts and pattern of on-time repayments) and negative information (late payments, defaults and bankruptcies) are distributed; (2) Data on both firms and individuals are distributed; (3) Data from retailers and utility companies as well as financial institutions are distributed; (4) More than two years of historical data are distributed; (5) Data on loan amounts below 1 percent of income per capita are distributed; and (6) By law, borrowers have the right to access their data in the largest credit bureau or registry.

Among our 22 countries the average value of Quality information sharing is 1.45 but there is wide variation with a standard deviation of 2.16 (Table 1). Annual data on the quality of information sharing is only available from 2005 onwards, which reduces the number of observations. The quality of information-sharing regimes has increased significantly over time, from an average of 0.31 in 2005 to 5.11 in 2012.

\subsection{Methodology}

To test our hypotheses, we apply a difference-in-difference framework with multiple groups (countries in our case) and time periods (Wooldridge, 2007). To test Hypothesis 1, we estimate the following benchmark model:

$$
N_{i j c t}=\alpha_{c}+\alpha_{t}+\beta_{1} T_{c t}+\varepsilon_{i j c t}
$$

Where $i$ indicates a new bank branch; $j$ the locality in which the new branch opens (circle or town/city); $c$ indicates the country and $t$ refers to the year. $N_{i j c t}$ is the number of preexisting branches when branch $i$ opens in locality $j$ (No. of branches all banks). $T_{c t}$ (Information sharing) is a dummy equal to 1 if banks in country $c$ share borrower information in year t. $\alpha_{c}$ and $\alpha_{t}$ are country and year fixed effects. According to our model, $\beta_{1}$ is expected to be positive as the introduction of information sharing induces bank branches to cluster so as to attract more borrowers. We also run this model with the locality-level $\mathrm{HHI}$ index on the left-hand side $\left(H H I_{i j c t}\right)$. We then expect $\beta_{1}$ to be negative as smaller information asymmetries due to information sharing mean that new branches tend to open in more competitive local markets with a lower pre-existing HHI.

To test Hypothesis 2, we measure the number of existing bank branches of the same bank in the locality where a branch opens (No. branches same bank): $N_{i j c t}^{\text {own }}$. We also construct a dummy version of this variable $\left(D_{i j c t}^{o w n}\right)$ that is equal to 1 if $N_{i j c t}^{o w n}>0$ and 0 otherwise (Branch same bank). We run the following regression model:

$$
N_{i j c t}^{\text {own }}=\alpha_{c}+\alpha_{t}+\beta_{1} T_{c t}+\varepsilon_{i j c t}
$$

With information sharing, banks are less likely to open new branches in localities where they already operate branches themselves. We therefore expect $\beta_{1}$ to be negative. 
To examine whether information sharing differentially impacts domestic and foreign banks, we also run a set of interaction regressions. We expect that less domestic banks are more affected by the introduction of information sharing and therefore have more incentives to cluster. Let $D_{i}$ be a dummy equal to ' 1 ' if a branch belongs to a domestic bank. The sum of $\beta_{1}$ and $\beta_{3}$ is now the treatment effect for domestic banks:

$$
N_{i j c t}=\alpha_{c}+\alpha_{t}+\beta_{1} T_{c t}+\beta_{2} D_{i}+\beta_{3} T_{c t} * D_{i}+\varepsilon_{i j c t}
$$

Lastly, we investigate the extent to which the effectiveness of information sharing matters (Hypothesis 4). The time-varying variable Quality $c$ measures the rules and practices affecting the accessibility, coverage, scope and quality of credit information available through information sharing (Quality information sharing). Augmenting the base regression (1) with this variable renders:

$$
N_{i j c t}=\alpha_{c}+\alpha_{t}+\beta_{1} T_{c t}+\beta_{2} * \text { Quality }_{c t}+\varepsilon_{i j c t}
$$

Note that by construction Quality ct $_{\text {is }}$ only available for countries and years in which banks exchange borrower information $\left(T_{c t}=1\right)$. Based on our model we expect $\beta_{1}\left(\beta_{2}\right)$ to be positive (negative). Very effective information sharing ensures that all banks have access to the same comprehensive and high-quality information about loan applicants. This increases the inter-bank correlation in loan-rejection decisions and dampens the market-size effect of clustering. After all, it becomes less attractive for potential borrowers to travel to (distant) localities with many branches (as the probability that a loan application gets rejected at each of these branches becomes very similar). In the extreme case, in which all branches share all information and process these data in the same way, there would be no difference between having just one branch or having many branches in a locality. The increased effectiveness of information sharing will therefore at some point dampen clustering (all other factors kept constant).

\subsection{Empirical Results}

\subsubsection{Baseline Results}

Table 3.2 presents our baseline results. For each dependent variable - No. branches all banks, Branch same bank, No. branches same bank, and HHI - we show three specifications. In the first two we match newly-opened branches with all surrounding pre-existing branches within a $2-\mathrm{km}$ or a $5-\mathrm{km}$ radius. In the third specification, we match new branches with all existing branches in the same locality. All regressions include country and year fixed effects.

In line with our first hypothesis, columns 1-3 show that once a country introduces mandatory information sharing, banks start to open new branches in localities with more pre-existing branches compared to countries where information sharing has not (yet) been introduced. Our results are qualitatively similar when matching new branches with existing branches in a 2 (5) km radius (columns 1 and 2) or within the same locality (column 3). The impact of a credit-registry introduction is economically significant: column 3 indicates that with information sharing banks choose to locate new branches in towns and cities that have 57 more pre-existing bank branches. This is a large effect given that the average locality in our dataset contains 129 branches. 


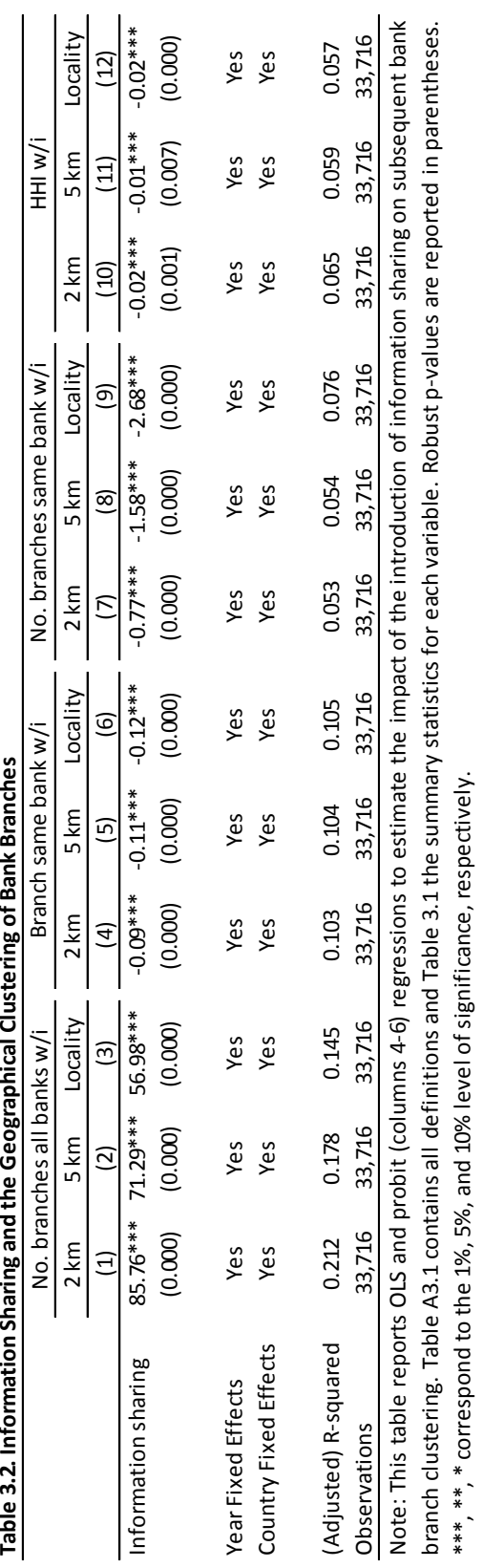


In sharp contrast, and in line with hypothesis 2, columns 4 to 9 show that information sharing induces banks to open new branches in localities where they have fewer existing branches of their own. This effect is again sizable: after the establishment of information sharing, banks are 12 percentage points less likely to locate a new branch in cities where they already own one or more branches of their own (column 6). The number of pre-existing own branches is reduced by almost 3 (the average is 4).

Lastly, columns 10 to 12 reveal that after the introduction of information sharing banks start to open new branches in less concentrated markets - as indicated by a lower HHI index. This aligns with our first result.

\subsubsection{Heterogeneous Impacts by Bank Type}

Not all banks may be equally affected by the introduction of information sharing. To analyze such heterogeneity, we interact in Table 3.3 the information sharing variable with dummies that identify foreign-owned banks. In line with Hypothesis 3, we expect that information sharing has stronger impacts on domestic banks as their lending relationships may be relatively vulnerable to the increased competition due to the information sharing.

The first three columns of Table 3.3 confirm show that while information sharing affects the clustering of all banks, the impact is indeed significantly stronger for domestic banks. Domestic banks in particular start to open new branches in localities with more pre-existing branches. For instance, after the establishment of information sharing, domestic banks tend to open new branches in localities with 76 more existing branches (compared with the situation before information sharing). This number is only 36 for foreign banks.

The results in the first three columns also show that before the introduction of information sharing, foreign banks opened branches in localities with more pre-existing branches. That is, compared to domestic banks, foreign banks typically added branches to well-established local banking markets rather than venturing into new territory. A possible explanation is that compared to domestic banks, foreign banks have built up less information about domestic clients and therefore mimic the locational choices of other banks to avoid excessive risk-taking. This effect is economically significant: foreign banks used to locate new branches in cities with 84 more pre-existing branches. The introduction of information sharing therefore partially levels the playing field between foreign and domestic banks: it allows foreign banks to open branches in underserved markets that they would previously have avoided.

In Appendix Table A3.5 we take this analysis one step further by distinguishing between greenfield and take-over foreign banks. This shows that, as expected, the introduction of information sharing is especially beneficial to greenfield foreign banks: these relatively young and inexperienced banks cluster less after the introduction of information sharing and can spread out their branch networks more widely. 


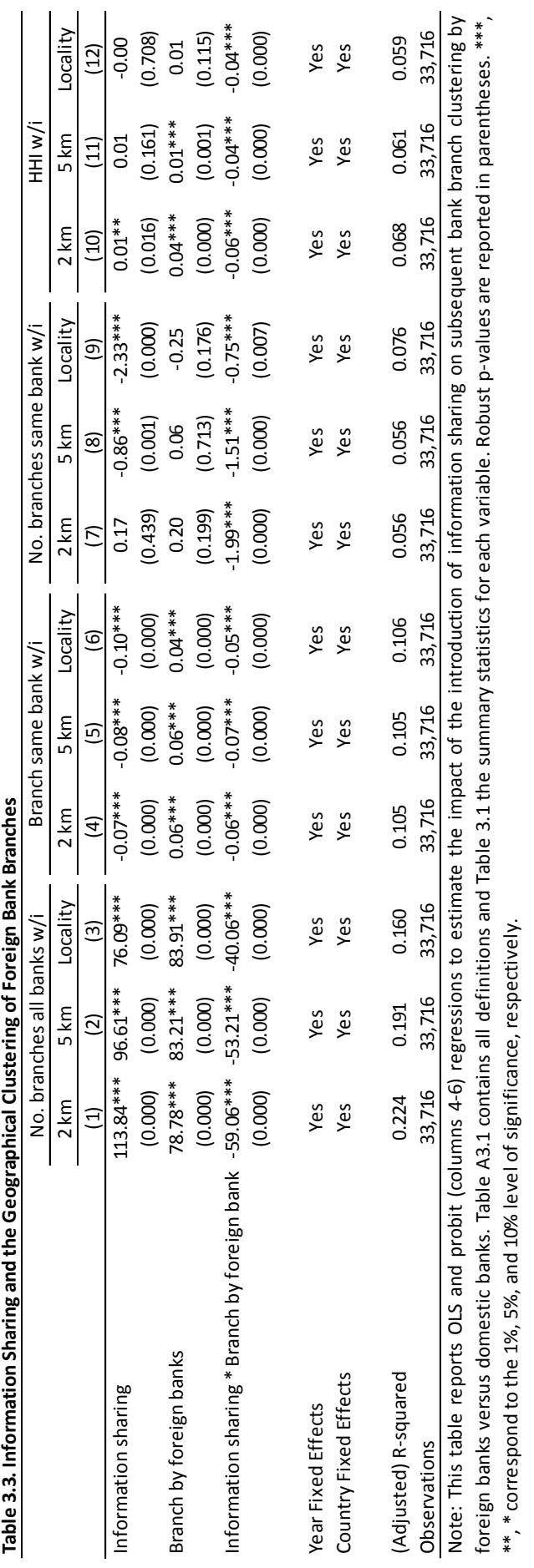




\subsubsection{Robustness and Placebo Tests}

We subject our results to various robustness and placebo tests. First, one may worry that the introduction of information sharing in a country is endogenous as it may reflect unobservable local circumstances that also bear directly on branch clustering. We wipe out time-invariant unobservable variation through country fixed effects and region-wide, timevarying variation through year fixed effects. However, we cannot control for unobservable country-specific and time-varying variables. We therefore instrument the introduction of information sharing in a country and year with the percentage of all neighboring countries that introduced information sharing in the past five years (Martinez Peria \& Singh, 2014). This instrument builds on the notion that financial reforms tend to converge regionally (Abiad \& Mody, 2005). The exclusion restriction is that the introduction of information sharing in nearby countries only has an impact on domestic bank clustering via an increase in the probability that information sharing is introduced domestically as well.

Table 3.5 reports our IV outcomes. The first stage shows a strong and positive correlation between the introduction of information sharing in neighboring countries in the recent past and the introduction of a credit registry or bureau in the country of observation. Both the Cragg-Donald Wald F-statistic and the Kleibergen-Paap F-statistic suggest that our instrument is strong. Moreover, the second stage estimates are qualitatively very similar to our OLS baseline results, suggesting that endogeneity in the introduction of information sharing is not driving our results.

Table 3.6 reports a battery of robustness tests related to the clustering of our standard errors. Our baseline approach, used throughout the paper, is to report robust standard errors. Table 3.6 shows that our results are robust to clustering errors at the bank level, country level and year level as well as at the level of bank*locality (each bank can have several observations in the same locality as it may open different branches in that locality at different points in time), country and year, or bank and year.

Finally, Table 3.7 shows the results of a placebo test where we replace for each country the actual year of introduction of the information sharing with a random (false) introduction year (from our sample period). As expected, the results disappear in this placebo test, suggesting that it is unlikely that our results are driven by unobservable characteristics or linear trends. 


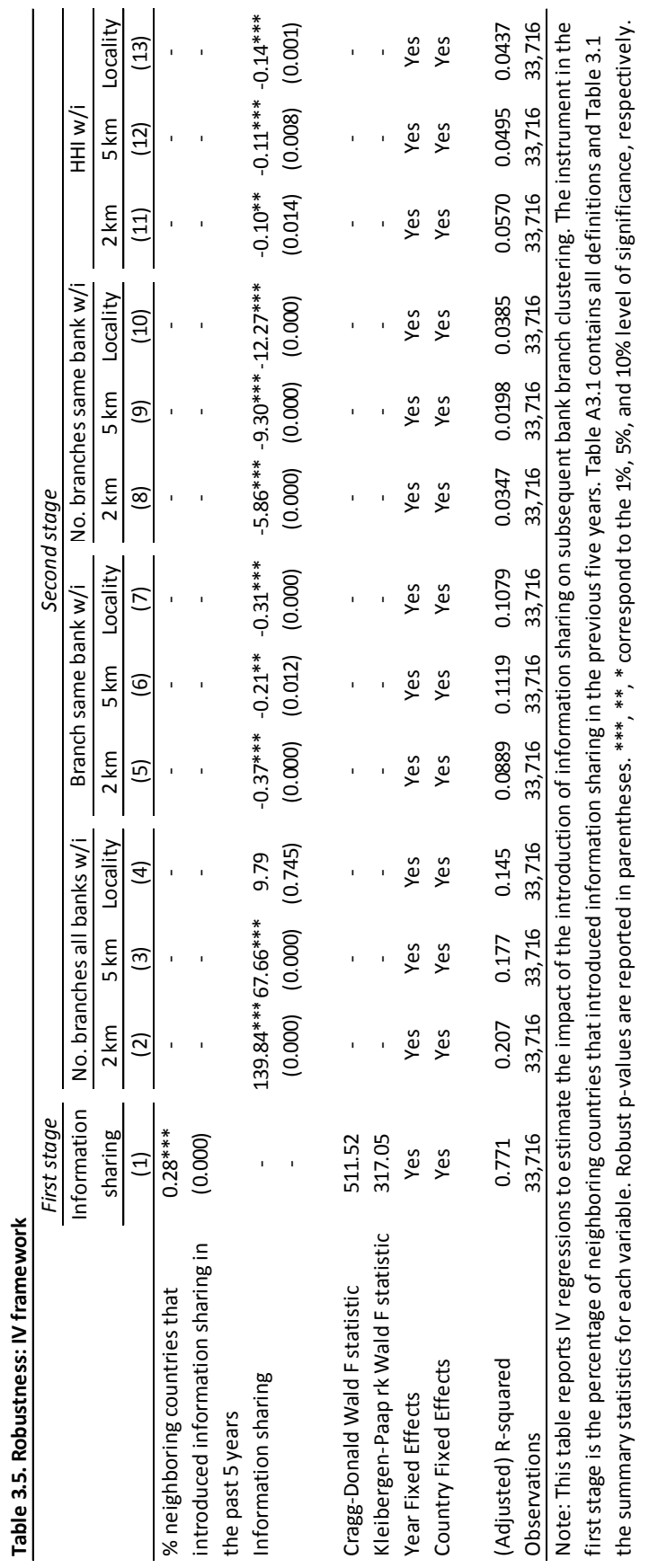




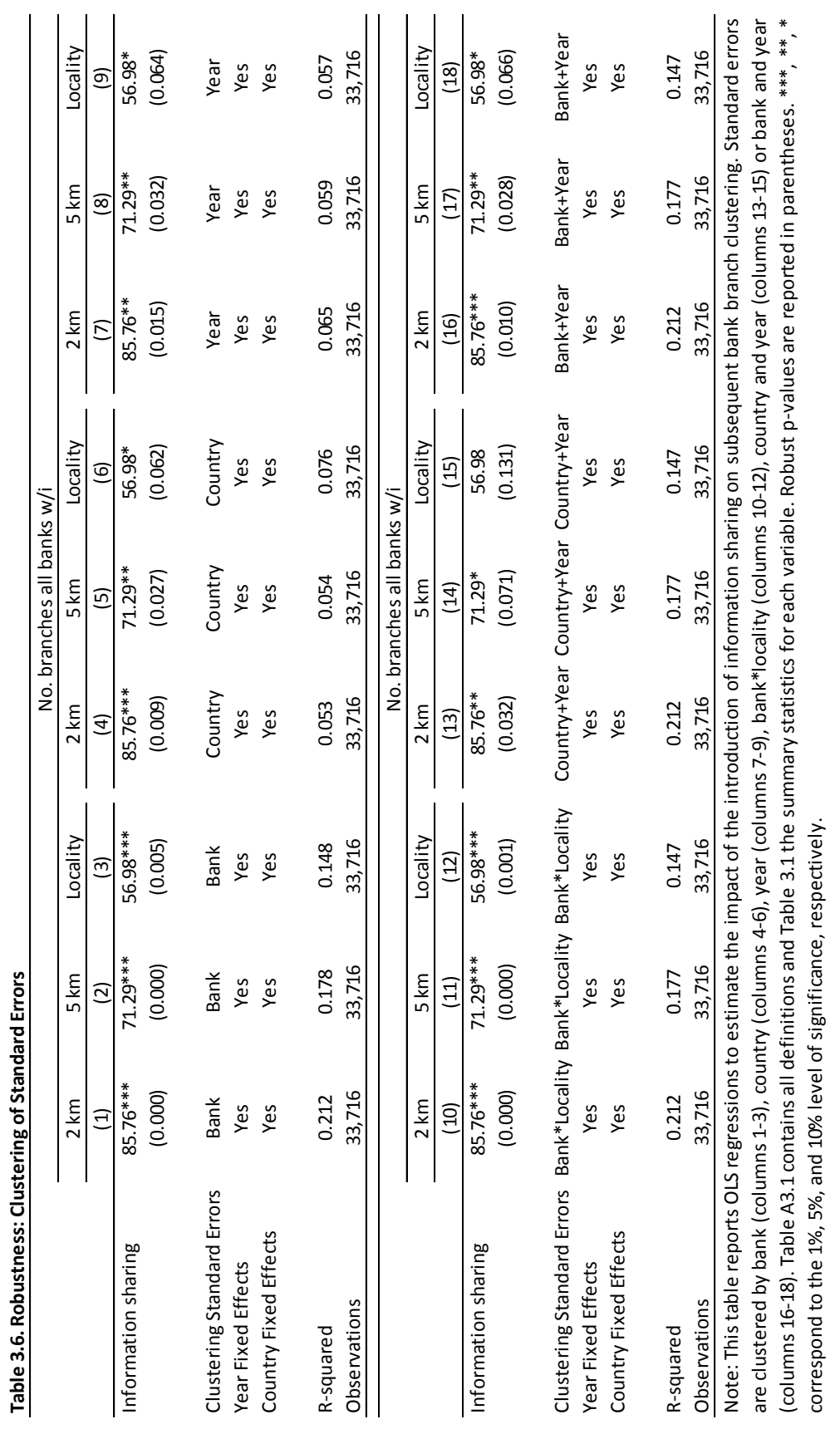


Table 3.7. Placebo Test: Random Introduction Dates of Information Sharing

\begin{tabular}{lccc}
\hline & \multicolumn{3}{c}{ No. branches all banks w/i } \\
\cline { 2 - 4 } & $2 \mathrm{~km}$ & $5 \mathrm{~km}$ & Locality \\
\cline { 2 - 4 } & $(1)$ & $(2)$ & $(3)$ \\
\hline Information sharing & 3.97 & 0.32 & -1.16 \\
& $(0.163)$ & $(0.929)$ & $(0.813)$ \\
Year Fixed Effects & & & \\
Country Fixed Effects & Yes & Yes & Yes \\
& Yes & Yes & Yes \\
Adjusted R-squared & & & \\
Observations & 0.202 & 0.171 & 0.144 \\
\hline
\end{tabular}

Note: This table reports placebo OLS regressions to estimate the impact of the introduction of information sharing on subsequent bank branch clustering. For each country the actual year of introduction of information sharing has been replaced by a random (false introduction) year. Table A3.1 contains all definitions and Table 3.1 the summary statistics for each variable. Robust $\mathrm{p}$-values are reported in parentheses. $* * *, * *, *$ correspond to the $1 \%, 5 \%$, and $10 \%$ level of significance, respectively.

\subsection{Conclusions}

It is well known that branches of different banks tend to cluster spatially. Yet, to date there exists surprisingly little theoretical and empirical research on the drivers of this phenomenon. Our contribution is to use the introduction of information sharing regimes as plausibly exogenous shocks that shift the relative advantages and disadvantages of branch clustering. We then observe how these shocks play out at a very disaggregated level namely that of individual villages, towns and cities - across various countries.

We start by building a simple spatial oligopoly model of bank clustering. The model focuses on the trade-off between the market-size effect and the price-cutting effect of branch clustering. It predicts that the establishment of information sharing will stimulate clustering due to an increase in competition from far-away bank branches. The model also predicts that after the introduction of information sharing, banks will be less likely to open additional branches in locations where they already have a presence. Finally, our model indicates that more effective information sharing systems gradually dampen bank branch clustering.

In the empirical part of the paper, we then test these theoretical predictions by exploiting dynamic information on the geographical locations of bank branches. We find that the establishment of information sharing has a significantly positive impact on bank clustering and that this impact is larger for domestic banks. We also show that after the establishment of information sharing banks are more likely to locate new branches in "virgin" localities (that is, where they do not have a branch presence yet). Finally, we establish that countries with more efficient credit information sharing systems exhibit less pronounced bank clustering.

Taken together, our results show that branch clustering is a function of the public availability of trustworthy borrower information. When such information is more broadly available, it allows banks - especially new players such as foreign-owned banks - to expand their branch network to new geographical localities that they would previously have avoided. At the same time, it becomes more important for banks to cluster together as a 
higher local variety of banks makes it easier to attract distant customers. Together these effects mean that banking markets become more homogenous in terms of composition - as they are served by the same banks that now operate across the country - but less homogenous in terms of size. While the public availability of information sharing leads to further clustering of banks in well-served locations, other (smaller) locations may lose out as access to credit deteriorates further. Assessing the real-economics impacts of such spatial variation in access to credit due to information sharing is a promising avenue for further research. 
Appendix

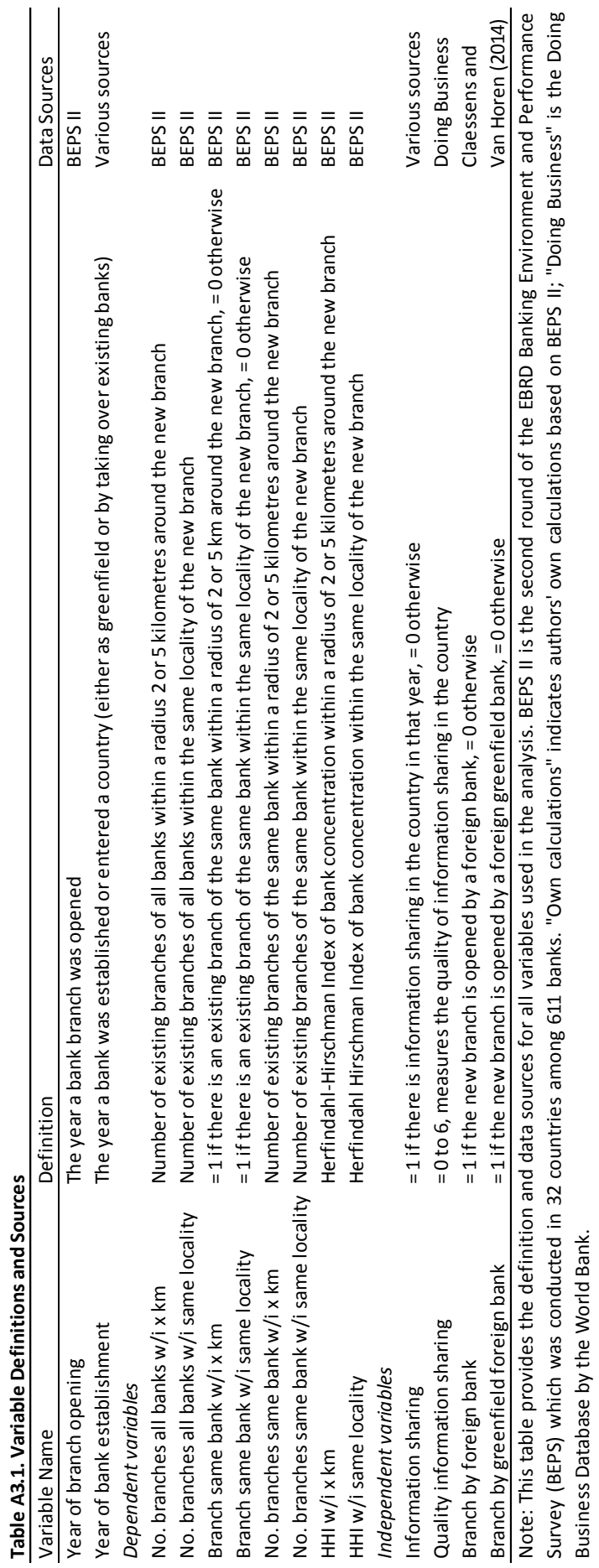




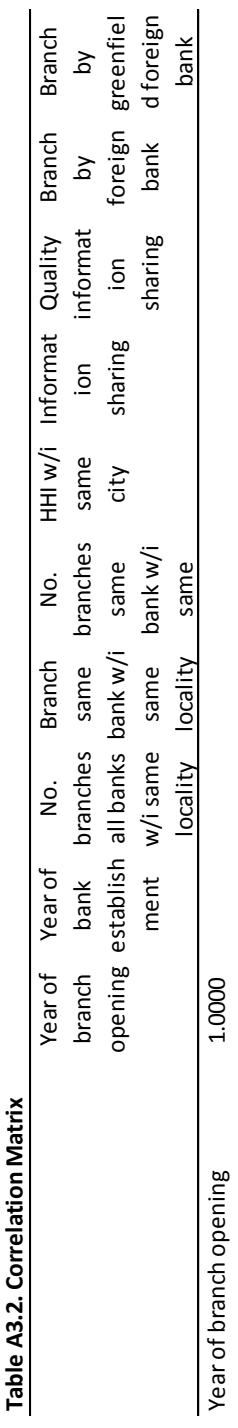

童

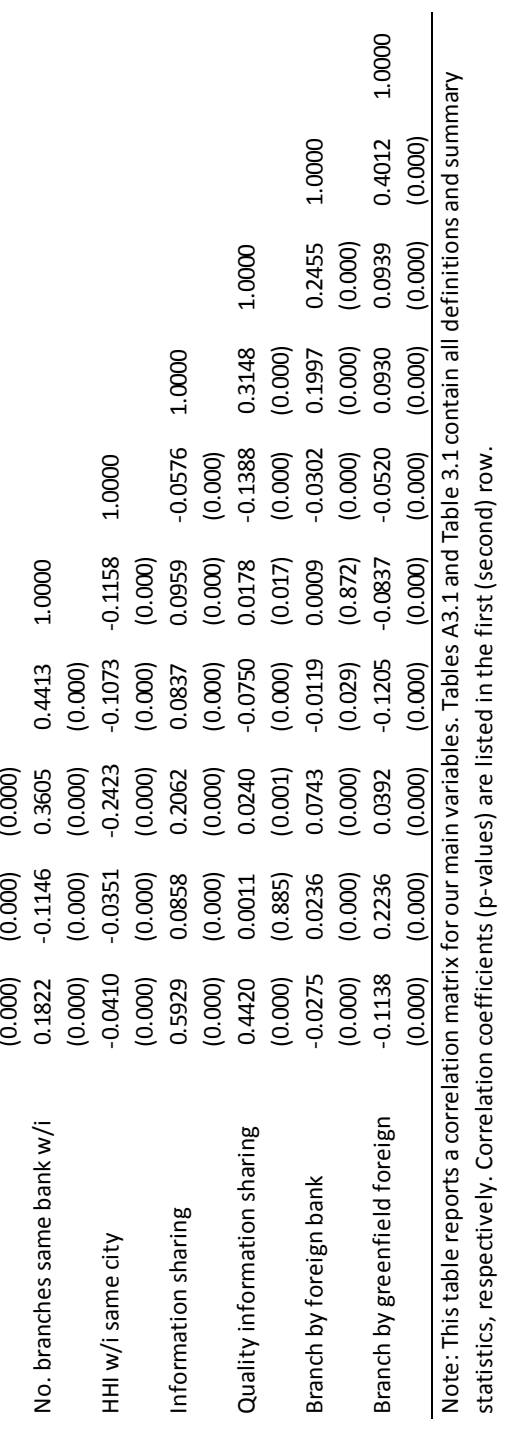


Chapter 3. Information Sharing and Bank Branching

Table A3.3. Overview of Branch Openings and Closures

\begin{tabular}{ccccccc}
\hline Year & $\begin{array}{c}\text { Opened } \\
\text { branches }\end{array}$ & $\begin{array}{c}\text { Closed } \\
\text { branches }\end{array}$ & & Country & $\begin{array}{c}\text { Opened } \\
\text { branches }\end{array}$ & $\begin{array}{c}\text { Closed } \\
\text { branches }\end{array}$ \\
\cline { 1 - 3 } \cline { 5 - 6 } 1995 & 2,391 & 0 & & Albania & 443 & 11 \\
1996 & 490 & 0 & & Armenia & 448 & 19 \\
1997 & 603 & 0 & & Azerbaijan & 335 & 13 \\
1998 & 552 & 0 & & Belarus & 2,481 & 9 \\
1999 & 555 & 0 & & Bosnia & 617 & 10 \\
2000 & 987 & 6 & & Bulgaria & 1,405 & 100 \\
2001 & 1,440 & 3 & & Croatia & 608 & 48 \\
2002 & 1,440 & 11 & & Czech Rep. & 382 & 19 \\
2003 & 2,735 & 10 & & Estonia & 60 & 56 \\
2004 & 4,675 & 36 & & Georgia & 703 & 108 \\
2005 & 2,391 & 24 & & Hungary & 1,538 & 287 \\
2006 & 2,700 & 25 & & Latvia & 195 & 9 \\
2007 & 7,999 & 66 & & Lithuania & 94 & 0 \\
2008 & 1,928 & 111 & & Macedonic & 189 & 16 \\
2009 & 665 & 269 & & Moldova & 1,300 & 180 \\
2010 & 789 & 272 & & Monteneg & 206 & 12 \\
2011 & 1,095 & 287 & & Poland & 3,192 & 51 \\
2012 & 281 & 248 & & Romania & 2,053 & 177 \\
& & & Serbia & 1,080 & 227 \\
& & & Slovakia & 153 & 0 \\
& & & Slovenia & 157 & 16 \\
& & & & Ukraine & 16,077 & 0 \\
\cline { 5 - 6 } Total & 33,716 & 1,368 & & Total & 33,716 & 1,368 \\
\hline
\end{tabular}

Note: This table provides an overview of the opening and closure of branches in our dataset by year (left) and by country (right). 
Chapter 3. Information Sharing and Bank Branching

Table A3.4. Introduction of Information Sharing

\begin{tabular}{|c|c|c|}
\hline Country & Public Credit Registry & Private Credit Bureau \\
\hline Albania & 2008 & 2009 \\
\hline Armenia & 2003 & 2004 \\
\hline Azerbaijan & 2005 & n.a. \\
\hline Belarus & 2007 & n.a. \\
\hline Bosnia & 2006 & 2001 \\
\hline Bulgaria & 1999 & 2005 \\
\hline Croatia & n.a. & 2007 \\
\hline Czech Republic & 2002 & 2002 \\
\hline Estonia & n.a. & 2001 \\
\hline Georgia & n.a. & 2005 \\
\hline Hungary & n.a. & 1995 \\
\hline Latvia & 2003 & n.a. \\
\hline Lithuania & 1995 & 2003 \\
\hline Macedonia & 1998 & 2010 \\
\hline Moldova & n.a. & 2011 \\
\hline Montenegro & 2008 & n.a. \\
\hline Poland & n.a. & 2001 \\
\hline Romania & 2000 & 2004 \\
\hline Serbia & 2002 & 2004 \\
\hline Slovak Republic & 1997 & 2004 \\
\hline Slovenia & 1994 & 2008 \\
\hline Ukraine & n.a. & 2007 \\
\hline \multicolumn{3}{|c|}{$\begin{array}{l}\text { Note: This table provides an overview of the introduction } \\
\text { years of public credit registries and private credit bureaus in } \\
\text { our } 22 \text { sample countries. n.a.: No credit bureau or registry has } \\
\text { as yet been introduced in this country. Source: World Bank } \\
\text { Doing Business Database, EBRD and various publications and } \\
\text { websites. }\end{array}$} \\
\hline
\end{tabular}




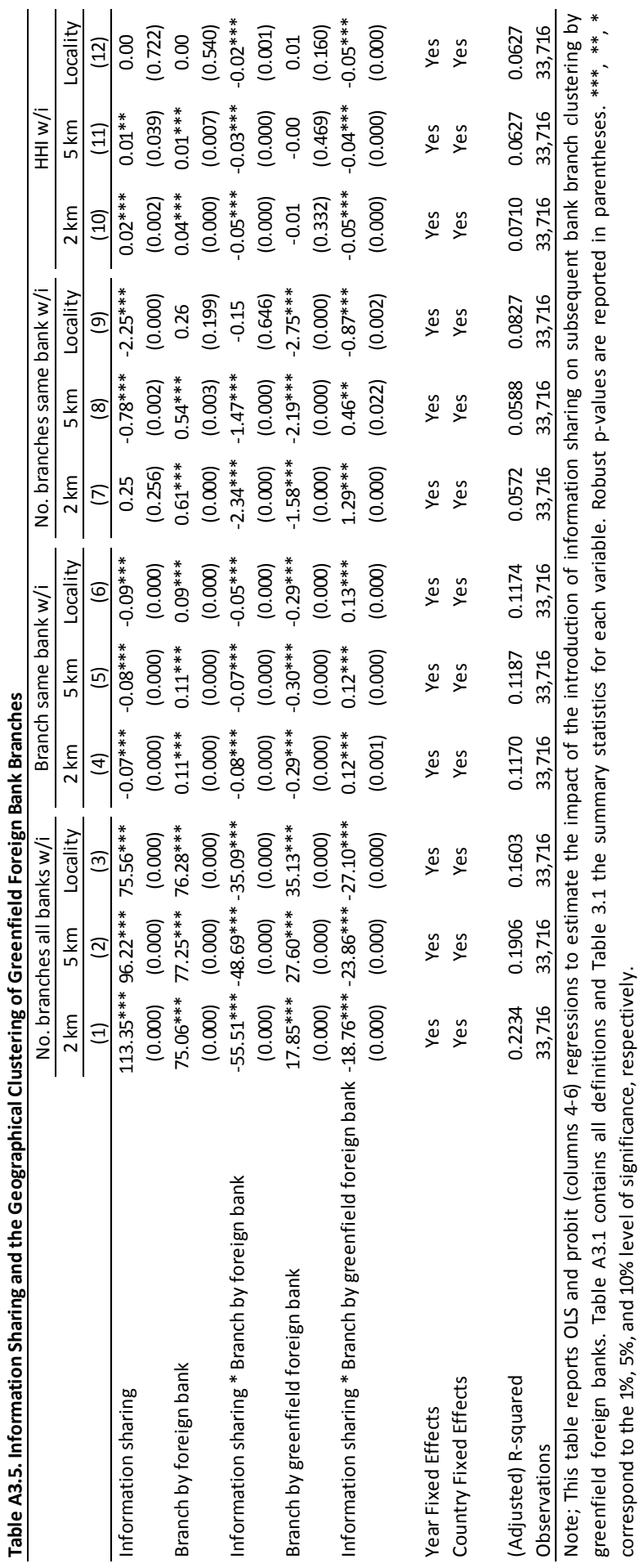


Table A3.6. Branch Clustering after the Establishment of Information Sharing: No Overlap Among Bank Localities

\begin{tabular}{|c|c|c|c|c|c|c|c|c|c|c|c|}
\hline \multirow[b]{2}{*}{$\begin{array}{l}\text { No. of } \\
\text { branches }\end{array}$} & \multicolumn{5}{|c|}{ Before the establishment of information sharing } & \multicolumn{6}{|c|}{ After the establishment of information sharing } \\
\hline & Radius & $\begin{array}{l}\text { Market } \\
\text { size }\end{array}$ & $\begin{array}{c}\text { Loan rate } \\
\text { in locality } \\
d \\
\end{array}$ & $\begin{array}{l}\text { Prob. no } \\
\text { loan in } \\
\text { locality } d\end{array}$ & Profit & Radius & $\begin{array}{l}\text { Market } \\
\text { size }\end{array}$ & $\begin{array}{c}\text { Loan rate } \\
\text { in locality } \\
d\end{array}$ & $\begin{array}{l}\text { Prob. no } \\
\text { loan in } \\
\text { locality } d\end{array}$ & $\begin{array}{c}\text { Prob. no } \\
\text { loan in } \\
\text { locality } w\end{array}$ & Profit \\
\hline 1 & 1.80 & 10.17 & 4.00 & 0.70 & 40.69 & 0.59 & 1.09 & 2.50 & 0.70 & 0.39 & 2.73 \\
\hline 2 & 3.28 & 16.85 & 3.00 & 0.53 & 50.55 & 1.48 & 3.43 & 2.25 & 0.60 & 0.39 & 7.72 \\
\hline 3 & 4.27 & 19.06 & 2.67 & 0.42 & 50.82 & 2.03 & 4.31 & 2.17 & 0.53 & 0.39 & 9.34 \\
\hline 4 & 4.97 & 19.36 & 2.50 & 0.34 & 48.39 & 2.40 & 4.51 & 2.13 & 0.48 & 0.39 & 9.59 \\
\hline 5 & 5.47 & 18.81 & 2.40 & 0.28 & 45.14 & 2.65 & 4.43 & 2.10 & 0.45 & 0.39 & 9.30 \\
\hline 6 & 5.85 & 17.90 & 2.33 & 0.24 & 41.78 & 2.84 & 4.22 & 2.08 & 0.43 & 0.39 & 8.78 \\
\hline 7 & 6.13 & 16.87 & 2.29 & 0.20 & 38.57 & 2.97 & 3.96 & 2.07 & 0.42 & 0.39 & 8.21 \\
\hline 8 & 6.35 & 15.83 & 2.25 & 0.18 & 35.63 & 3.07 & 3.70 & 2.06 & 0.40 & 0.39 & 7.64 \\
\hline 9 & 6.52 & 14.84 & 2.22 & 0.16 & 32.97 & 3.14 & 3.45 & 2.06 & 0.40 & 0.39 & 7.09 \\
\hline 10 & 6.65 & 13.91 & 2.20 & 0.15 & 30.59 & 3.20 & 3.22 & 2.05 & 0.39 & 0.39 & 6.59 \\
\hline 11 & 6.76 & 13.05 & 2.18 & 0.14 & 28.47 & 3.24 & 3.00 & 2.05 & 0.38 & 0.39 & 6.14 \\
\hline 12 & 6.85 & 12.27 & 2.17 & 0.13 & 26.57 & 3.27 & 2.80 & 2.04 & 0.38 & 0.39 & 5.72 \\
\hline 13 & 6.92 & 11.55 & 2.15 & 0.12 & 24.88 & 3.30 & 2.63 & 2.04 & 0.38 & 0.39 & 5.35 \\
\hline 14 & 6.97 & 10.90 & 2.14 & 0.11 & 23.36 & 3.32 & 2.47 & 2.04 & 0.38 & 0.39 & 5.02 \\
\hline 15 & 7.02 & 10.31 & 2.13 & 0.11 & 22.00 & 3.33 & 2.32 & 2.03 & 0.37 & 0.39 & 4.72 \\
\hline 16 & 7.06 & 9.77 & 2.13 & 0.10 & 20.77 & 3.34 & 2.19 & 2.03 & 0.37 & 0.39 & 4.45 \\
\hline 17 & 7.09 & 9.28 & 2.12 & 0.10 & 19.65 & 3.35 & 2.07 & 2.03 & 0.37 & 0.39 & 4.21 \\
\hline 18 & 7.12 & 8.83 & 2.11 & 0.10 & 18.64 & 3.36 & 1.97 & 2.03 & 0.37 & 0.39 & 3.99 \\
\hline 19 & 7.14 & 8.42 & 2.11 & 0.10 & 17.72 & 3.36 & 1.87 & 2.03 & 0.37 & 0.39 & 3.78 \\
\hline 20 & 7.16 & 8.04 & 2.10 & 0.09 & 16.89 & 3.37 & 1.78 & 2.03 & 0.37 & 0.39 & 3.60 \\
\hline 21 & 7.17 & 7.69 & 2.10 & 0.09 & 16.12 & 3.37 & 1.70 & 2.02 & 0.37 & 0.39 & 3.44 \\
\hline 22 & 7.19 & 7.37 & 2.09 & 0.09 & 15.41 & 3.37 & 1.62 & 2.02 & 0.37 & 0.39 & 3.28 \\
\hline 23 & 7.20 & 7.07 & 2.09 & 0.09 & 14.76 & 3.37 & 1.55 & 2.02 & 0.37 & 0.39 & 3.14 \\
\hline 24 & 7.21 & 6.80 & 2.08 & 0.09 & 14.16 & 3.38 & 1.49 & 2.02 & 0.37 & 0.39 & 3.01 \\
\hline 25 & 7.22 & 6.54 & 2.08 & 0.09 & 13.60 & 3.38 & 1.43 & 2.02 & 0.37 & 0.39 & 2.89 \\
\hline 26 & 7.22 & 6.30 & 2.08 & 0.09 & 13.09 & 3.38 & 1.38 & 2.02 & 0.37 & 0.39 & 2.78 \\
\hline 27 & 7.23 & 6.08 & 2.07 & 0.09 & 12.61 & 3.38 & 1.33 & 2.02 & 0.37 & 0.39 & 2.68 \\
\hline 28 & 7.24 & 5.87 & 2.07 & 0.09 & 12.16 & 3.38 & 1.28 & 2.02 & 0.37 & 0.39 & 2.58 \\
\hline 29 & 7.24 & 5.68 & 2.07 & 0.09 & 11.74 & 3.38 & 1.24 & 2.02 & 0.37 & 0.39 & 2.50 \\
\hline 30 & 7.24 & 5.49 & 2.07 & 0.09 & 11.35 & 3.38 & 1.20 & 2.02 & 0.37 & 0.39 & 2.41 \\
\hline
\end{tabular}

Note: This table presents comparative statics based on a calibration of our theoretical model that assumes no overlap among nearby bank localities. We assume that the probability of loan rejection is 70 per cent; the minimal loan rate is 2 percent; the oligopoly rent is 2 percent without information sharing and 0.5 percent with information sharing; the project return is 10 per cent; the commuting cost coefficient is 1 per cent; and the commuting cost of applying for a loan in a distant locality is 3.2. There are 10 bank branches in the distant locality $w$. After the establishment of a credit registry, the correlation among bank branches of the loan-rejection probability increases from 0.2 to 0.5 . 


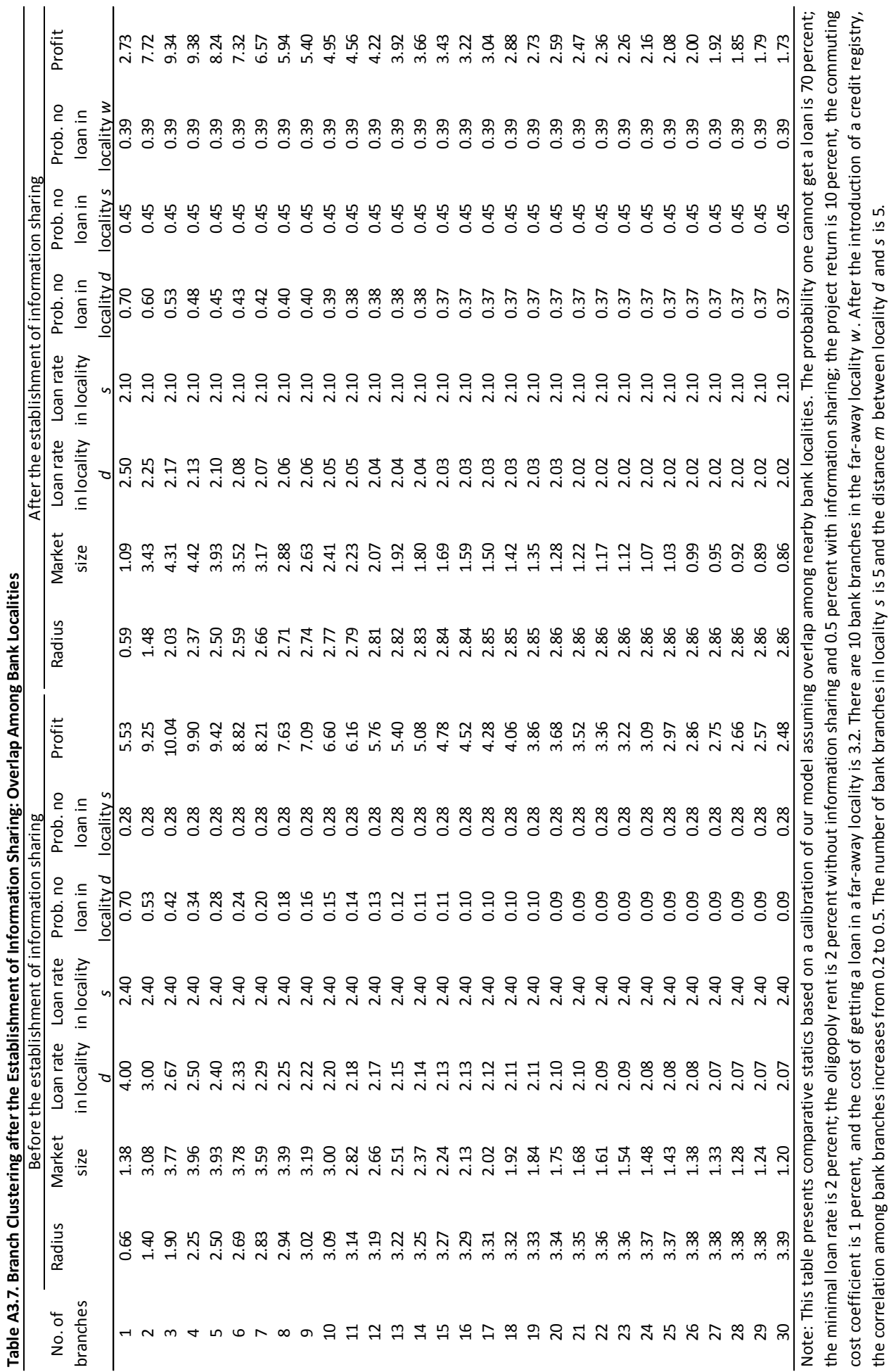


Table A3.8. The Role of Bank Competition

\begin{tabular}{lcc}
\hline \multirow{2}{*}{ Bank Type } & \multicolumn{2}{c}{ Equilibrium Number of Branches } \\
\cline { 2 - 3 } & $\begin{array}{c}\text { No Overlap among } \\
\text { Nearby Localities }\end{array}$ & $\begin{array}{c}\text { Overlap among } \\
\text { Nearby Localities }\end{array}$ \\
\hline More competitive banks & 20 & 13 \\
Less competitive banks & 26 & 19 \\
\hline Note: This table analyzes the difference between the impact of \\
information sharing on less and more competitive banks. When \\
information sharing is introduced, less competitive banks face more \\
severe competition from distant branches as there will now be \\
lower costs of applying for a loan in these distant locations (3.2 \\
compared to 3.3).
\end{tabular}

Table A3.9. Quality of Information Sharing

\begin{tabular}{ccc}
\hline \multirow{3}{*}{ Correlation } & \multicolumn{2}{c}{ Equilibrium Number of Branches } \\
\cline { 2 - 3 } & $\begin{array}{c}\text { No Overlap among } \\
\text { Nearby Localities }\end{array}$ & $\begin{array}{c}\text { Overlap among } \\
\text { Nearby Localities }\end{array}$ \\
\hline 0.50 & 26 & 19 \\
0.51 & 21 & 15 \\
0.52 & 17 & 12 \\
0.53 & 14 & 10 \\
0.54 & 12 & 8 \\
0.55 & 10 & 7 \\
0.56 & 8 & 5 \\
0.57 & 7 & 4 \\
0.58 & 6 & 4 \\
0.59 & 5 & 3 \\
0.60 & 4 & 3 \\
\hline
\end{tabular}

Note: This table shows the equilibrium level of branch clustering when the inter-branch correlation of loanrejection rates increases as information sharing systems become more effective. 


\section{Chapter 4}

\section{Firm Bribery and Credit Access}

\subsection{Introduction}

Corruption is found to significantly impede economic growth (Mauro, 1995) and investment (Rajan \& Zingales, 1998; Wei, 2000) on the macro level, while also decrease firms' growth opportunity (Fisman \& Svensson, 2007) and competitiveness (Gaviria, 2002) on the micro level, through various channels including investment, trading, political stability and human capital (Pellegrini \& Gerlagh, 2004; Mo, 2010). This paper presents a bank lending channel for corruption to affect firm growth by tightening firms' access to bank credit. This channel is important because bank credit is a major source of external finance and a driving force for economic growth (Levine et al., 2000), and a well-functioning banking system can enhance the performance and productivity of the whole economy (Levine \& Zervos, 1998; Beck \& Levine, 2004).

Yet, despite its importance, only a few studies have investigated the impact of corruption on credit access and the results are still mixed and not definite yet. In this paper, we investigate firm-level impact of bribery on credit access in a cross-country setting, with both firm-level measures of bribery and access to credit. All in all, the sample covers 12,006 firms across 22 transition countries from Europe, the Baltic States and the Caucasus from 2007 to $2014 .^{32}$

We focus on the transition countries as they are excellent settings for our study. First, most of these countries are greatly affected by corruption and are moving aggressively to address this issue by introducing stricter regulations or anti-corruption laws (Fungáčová et al., 2015). Second, given the fact that company law and creditor rights protections are relatively weak in these countries, how to deal with bribery is expected to be more important for the banks operating there (Brown et al. , 2009). Lastly, these transition countries present considerable within variation for both the credit market and the corruption practices during this period, which is essential for our identification.

The estimates demonstrate that access to bank credit is tighter for the firms that are more frequently involved in bribery practices, which itself is driven and, therefore, instrumented by the bribery behaviour of other firms in the same (or adjacent) locality and sector, or the local commitment of government and citizens to fight corruption. These findings are robust

\footnotetext{
${ }^{32}$ The 22 countries include: Albania, Armenia, Azerbaijan, Belarus, Bosnia and Herzegovina, Bulgaria, Croatia, Czech Republic, Estonia, Georgia, Hungary, Latvia, Lithuania, FYR Macedonia, Moldova, Montenegro, Poland, Romania, Serbia, Slovak Republic, Slovenia and Ukraine. Specifically, the data includes 153 firms in 2007, 4,613 firms in 2008, 757 firms in 2009, 398 firms in 2012, 5,919 firms in 2013, and 166 firms in 2014.
} 
in various alternative empirical settings and are also economically relevant. For example, a one-point (about a one standard deviation) increase in bribery tightens firms' credit access by 7.8 per cent. These findings support the law and finance theory pioneered by La Porta et al. (1997) that bureaucratic corruption induces greater uncertainty on the banks' claims and enforcement actions, therefore discouraging the banks from lending to these bribing firms. Furthermore, this detrimental impact is mainly driven by the supply-side rather than the demand-side factors. More specifically, this impact is less pronounced in localities where there are more foreign banks as they lack knowledge to distinguish the corrupt from uncorrupt firms and are less aware of the corruption risks in the local markets; or if the competition among banks is either very low or very high, which might affect banks' risktaking behaviours. Finally, bribery is also found to impede firm growth, partially through the tightening of firms' credit access.

This paper contributes to the current literature in four dimensions. First, it utilises firm-level measures of both bribery and credit access, which allows me to identify the microeconomic impact of bribery on firms' credit access. Therefore, this paper overcomes the limitations of aggregate data at the country level, which ignores compositional changes within a country. ${ }^{33}$ Second, this paper tries to address the endogeneity issue and define a causal relationship between firm bribery and credit access by utilizing both an instrumental variable approach and comprehensive robustness checks. Next, we further disentangle the supply-side and the demand-side driving factors of the detrimental impact of bribery on credit access. Moreover, by matching each firm with bank branches based on their geographical locations, this paper is also able to identify and estimate the supply-side impact of bribery on firms' credit access across different local banking structures. Lastly, this paper adds to the current literature by presenting a bank lending channel for corruption to obstacle economic growth and fostering the understanding of the mechanisms between corruption and growth.

This research is also fairly relevant from a policy perspective, as corruption has been a major challenge in transition countries and lots of countries are taking intensive efforts to combat this issue. The findings of this paper indicate that banks generally punish the bribing firms by tightening their access to credit. Hence, this punishment acts as a self-correcting mechanism that a sound banking system can be deterrence for corruption. These findings thus highlight the importance of cooperation among regulatory authorities to combat corruption. Banking market regulations, for example, on foreign bank entry, or on inter-bank competition, might exert a significant impact when fighting corruption and suggest that a broader framework should be incorporated in corruption regulations.

\footnotetext{
${ }^{33}$ To the best of my knowledge, Fungáčová et al. (2015) is the only other cross-country paper that studies the impact of bribery on bank credit at the firm-level. They combine information on bribery from the Business Environment and Enterprise Performance Survery (BEEPS II, III, and IV) with firm-level accounting data on bank debt ratios from Amadeus.
} 
The paper proceeds as follows. Section 2 reviews the theoretical evidence on the impact of bribery. Section 3 discusses the utilised data and summary statistics, Section 4 describes the methodology and section 5 demonstrates the empirical findings. Section 6 concludes.

\subsection{The Impact of Bribery}

Bribery can take place in a wide range of business settings, from dealing with taxes, courts, customs, licenses, permits, regulations, and services to applying for bank credit. This section reviews the theoretical linkage between bribery and firms' credit access both under the bureaucratic framework and during the lending process, both with contradictory views.

If bribery is viewed broadly under the bureaucratic framework, it is expected to reduce bank credit based on the law and finance theory pioneered by La Porta et al. (1997). They report that better creditor protections are associated with larger and broader credit markets. Later, Levine (1998, 1999), Djankov et al. (2007), Bae \& Goyal (2009) and Weill (2011) confirm that stronger creditor protection can lead to more bank credit while poor law enforcement hampers bank lending. The intuition is that in case of a loan default, the bank may wish to force repayment, grab collateral or even take control of the borrower firm. Consequently, creditor protections that empower banks to take such actions exert a positive influence on banks' lending behaviour. However, bureaucratic corruption can induce greater uncertainty on banks' claims and their enforcement actions against corrupt firms in case of a loan default. Therefore, this decreased enforcement power against these defaulting borrowers diminishes banks' willingness to lend to the bribing firms.

However, as first explained by Leff (1964) and Leys (1965), corruption may also "grease the wheels". Specifically, in a second-best world where institutions are all ill-functioning, bribery may be beneficial in the sense that bribery helps firms to circumvent inefficient institutions, thereby increasing efficiency and growth. For example, corruption can reduce effective tax rates to the extent that bribery is used to reduce tax liabilities, if the marginal bribe rate is below the official marginal tax rate (Olken \& Pande, 2012). Empirically, Chen et al. (2013) find that bribery largely determines the extent to which private firms access to bank credit in China. This is because China's financial sector is beset by corruption. Payments for loan approvals, massive theft by insiders, misuse of funds and large-scale fraud are routine in the Chinese banks. Therefore, compared to the non-bribing firms, the bribing firms might be more efficient and thus have better growth opportunities. Banks would be better-off if they lend to these bribing firms.

Bribery may also take place during the lending process through bribing bank officials (Beck et al., 2006). On the one hand, the bank officials might ask for a bribe to grant a loan. In this case, bribery would act as a tax on borrowers through an increasing cost of the loan, which decreases loan demand and reduces bank credit in general (Weill, 2011; Jõeveer, 2013). On the other hand, borrowers might initiate to offer a bribe to bank officials in order to get a loan. Bank officials might bias their behaviour towards their personal benefit and therefore, corruption may increase bank credit as well (Fungáčová et al., 2015). 


\subsection{Data and Variables}

In order to empirically investigate the impact of bribery on credit access on the firm-level in a cross-country setting, We utilise firm-level information on bribery and access to credit from the fourth and fifth waves of the Business Environment and Enterprise Performance Survey (BEEPS IV/V), which is conducted jointly by the European Bank for Reconstruction and Development (EBRD) and the World Bank. This survey consists of a representative sample of firms from transition countries in Europe, the Baltic States and the Caucasus. BEEPS IV is conducted in 2008-09, and BEEPS V in 2012-14. These two waves of the survey provide the most detailed information on firm bribery and their credit access, with a high degree of consistency in their survey designs. BEEPS survey consists of a representative sample of firms from transition countries in Europe, the Baltic States and the Caucasus, and covers a broad range of business environment aspects as far as credit access and bribery practices are concerned. The final sample covers 12,006 firms in total, including 5,523 firms from BEEPS IV and 6,483 firms from BEEPS V, across 22 transition countries. Table 4.1 reports detailed variable definitions and data sources.

To measure firms' bribery behaviour (Firm Bribery), we follow Fungáčová et al. (2015) to utilise BEEPS question Q39:

"Thinking about officials, would you say the following statement is always, usually, frequently, sometimes, seldom or never true: 'It is common for firms in my line of business to have to pay some irregular "additional payments/ gifts" to get things done with regard to customs, taxes, licenses, regulations, services, and etc.'”

Firms' responses are captured in a categorical variable ranging from 1 to 6 , where higher values correspond to more frequent involvement in bribery. In most settings, there is relatively little stigma associated with paying bribes, and so in many cases bribery can be precisely measured using surveys of bribe-payers (Olken \& Pande, 2012). Furthermore, as this type of survey-based measure of bribery is the most easily replicable one, consistent measurement and comparison can be easily carried out across countries and over time. Finally, this question measures bribery in a very broad sense, including the bribery practices during the lending process. As a result, banks are, to some extent, able to directly observe the bribery intention of each firm and then act accordingly. What's more, being involved in the local networks of business and government, and the experience in the domestic markets further grant banks the ability to detect the bribery behaviour of a firm, even when a firm does not directly pay a bribe to the bank. To empirically test this, we refer to Appendix A4.1 where we link firms' bribery practices with the level of corrupted local government officials 


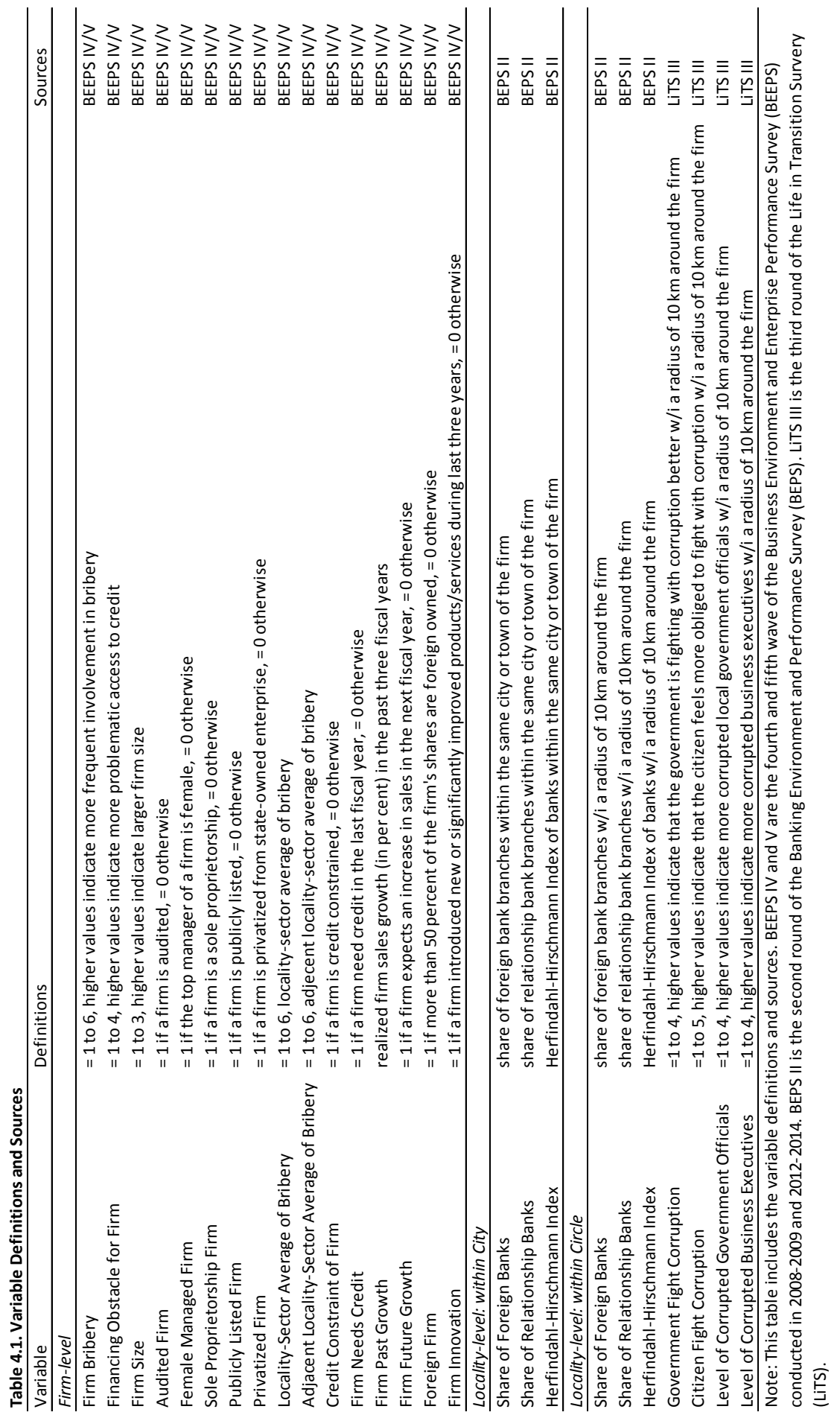


where we link firms' bribery practices with the level of corrupted local government officials or business executives reported by the citizens in the firms' locality of operation. ${ }^{34}$ The level of corrupted local government officials or business executives are classified in three groups with higher values indicate more corrupted officials or executives as reported by the citizens. The average Firm Bribery within each group are then compared under a two-sample t-test with unequal variances. We find that in localities where the citizens report more corrupted government officials or business executives, firms are also more likely to bribe. Thus these findings, at least partially, indicate that the bribery practices of firms are able to be detected by the citizens in that locality, so can the banks. ${ }^{35}$

To measure firms' credit access (Financing Obstacle for Firm), I first follow Brown et al. (2009) to utilize BEEPS question K30:

"Is access to finance, which includes availability and cost, interest rates, fees and collateral requirements, No Obstacle, a Minor Obstacle, a Moderate Obstacle, or a Major Obstacle to the current operations of this establishment?"

Firms' responses are coded on a scale from 1 to 4, where higher values correspond to more financing obstacles. This measure captures firms' perception about their own credit access and could disentangle the confounding effect of credit demand and credit access, which is a common problem in using firms' bank debt ratio as the dependent variable. It represents a full sample of firms and can distinguish between firms that do not need credit and those that are actually discouraged from applying credit. Furthermore, as empirically established by Hainz \& Nabokin (2013), this perception based measure of credit access is "surprisingly precise".

We also construct a set of commonly used firm-level control variables by BEEPS. Specifically, we first include Firm Size, where firms are classified into small (0-19), median (20-99) and large $(100+)$ firms based on the number of permanent full-time employees. Based on whether firms' annual financial statements are checked and certified by an external auditor,

\footnotetext{
${ }^{34}$ We apply the third round of Life in Transition Survey (LiTS) conducted by European Bank for Reconstruction and Development to measure the level of corrupted government officials or business executives reported by local citizens. Specifically, we utilise LiTS question q814d that ask how many local government representatives are corrupt. Answers are classified from 1 to 4 (None, some, most, all of them) where higher values indicate more corrupted government officials (Level of Corrupted Government Officials). We also apply question q814h that asks how many business executives are corrupt. The answer ranges between 1 and 4 with higher values indicate more corrupted business executives (Level of Corrupted Business Executives).

${ }^{35}$ This finding is in line with Olken (2009) who examines the accuracy of corruption perceptions by comparing Indonesian villagers' reported perceptions about corruption in a road-building project in their village with a more objective measure of 'missing expenditures' in the project. He finds that that villagers are sophisticated enough to distinguish between corruption in a particular road project and general corruption in the village. Charron (2016) uses a survey data based on 85,000 European respondents in 24 countries to show that the consistency between actual reported corruption, as well as the citizen and expert perceptions of corruption, is remarkably high and such perceptions are swayed little by 'outside noise'.
} 
a firm is classified into audited and unaudited firms (Audited Firm). Female Managed Firm measures whether the top manager of a firm is female. Firm ownerships are also included, including whether a firm is a Sole Proprietorship Firm; is a Publicly Listed Firm; and is a Privatized Firm from a former state-owned enterprise.

Table 4.2 shows the summary statistics for the full sample, as well as for BEEPS IV and BEEPS $V$ separately. Starting with the Financing Obstacle for Firm, it shows that on average, access to finance is a minor or moderate obstacle to firms and this obstacle is most severe during the financial crisis. These numbers also point to a substantial tightening of bank credit during the global financial crisis that peaks in 2008-09 at 2.46. Secondly, firms are less frequently involved in bribery over time, indicating the better control of corruption in these transition countries. Specifically, Firm Bribery drops from 2.03 in 2008-09 to 1.88 in 2012-14. Overall, it is not that common for firms to pay bribes.

Behind these averages lies substantial variation across firms within each country (see Figure 4.1 and Figure 4.2). Each dot represents an individual firm in the sample. Darker red indicates more tightened access to credit and more frequent involvement in bribery. For that reason, these transition countries serve as the great setting for my analysis that both corruption and credit access demonstrate substantial variations on the firm level, which is essential for the identification. This is in accordance with the literature that has shown substantial variation in corruption both cross countries (Djankov et al., 2002) and within countries in this region (Clarke \& Xu, 2004; Beck et al., 2017).

For locality-level control variables, that is, the local banking structures, we turn to the second round of the Banking Environment and Performance Survey (BEPS II), jointly undertaken by the EBRD and Tilburg University. We obtain bank information on both their ownerships (foreign versus domestic) and lending techniques (relationship versus transaction lending). As part of BEPS II, a specialized team of consultants further collected the geographical coordinates and the establishment dates of all bank branches across the sample countries. The survey collected both contemporaneous and historical information on branch locations, which allows me to paint a gradually changing picture of the branching landscape.

Following Beck et al. (2017), we connect the firm and branch data in two ways. First, we match firms and bank branches by locality (city or town). The underlying assumption is that a firm has access to all bank branches in the locality where it operates. Second, we draw a circle with a radius that equals $10 \mathrm{~km}$ around the geo-coordinates of each firm and link the firm to only those bank branches inside that circle. ${ }^{36}$ After matching (identifying the bank branches that surround each firm), we construct variables at the locality (or circle) level that measure the key characteristics of these banks, namely Share of Foreign Banks, Share of

\footnotetext{
${ }^{36}$ We also draw a circle with a radius of $5 \mathrm{~km}$ and the results are very similar.
} 


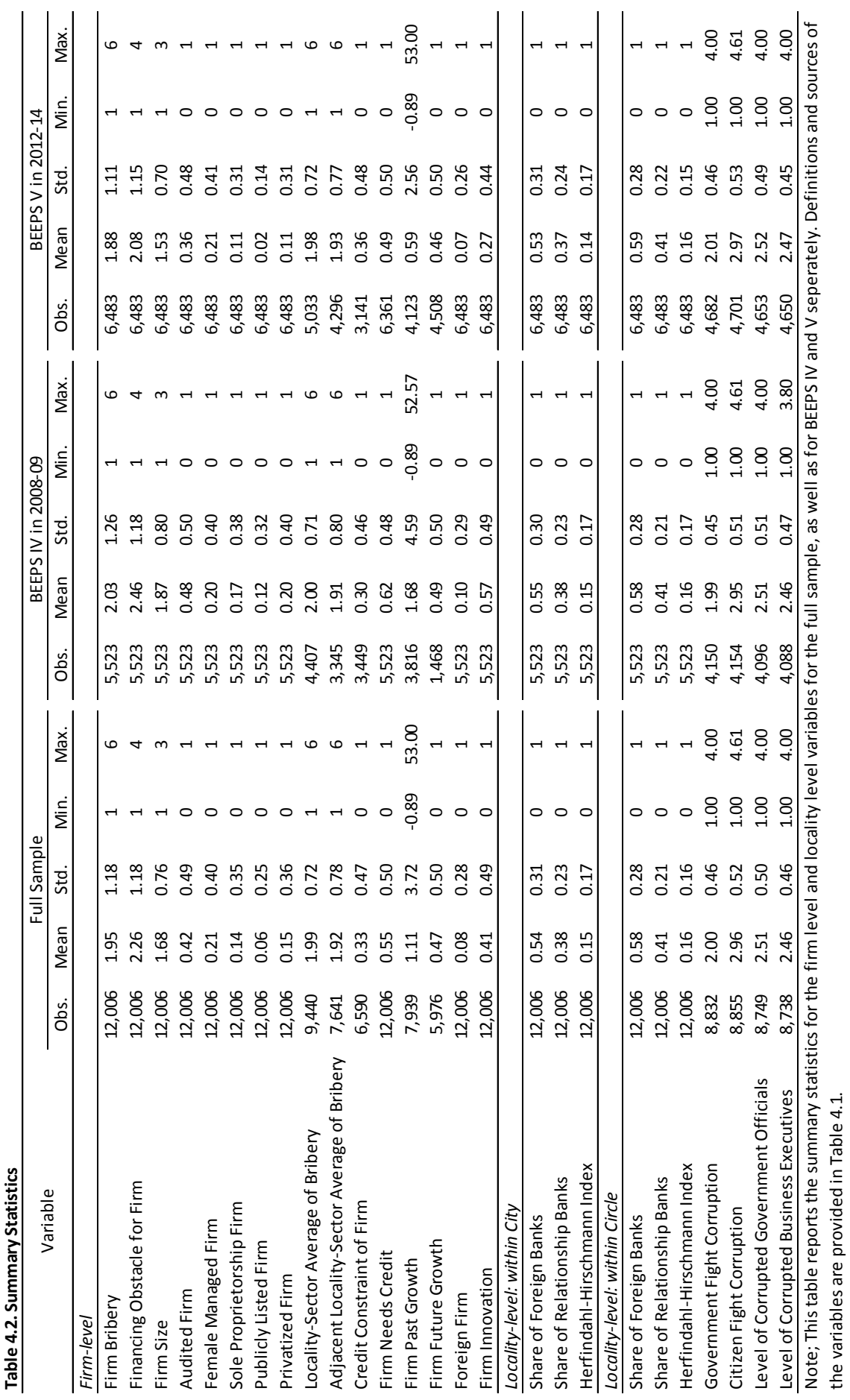


Figure 4.1. Heatmap of Financing Obstacle for Firm

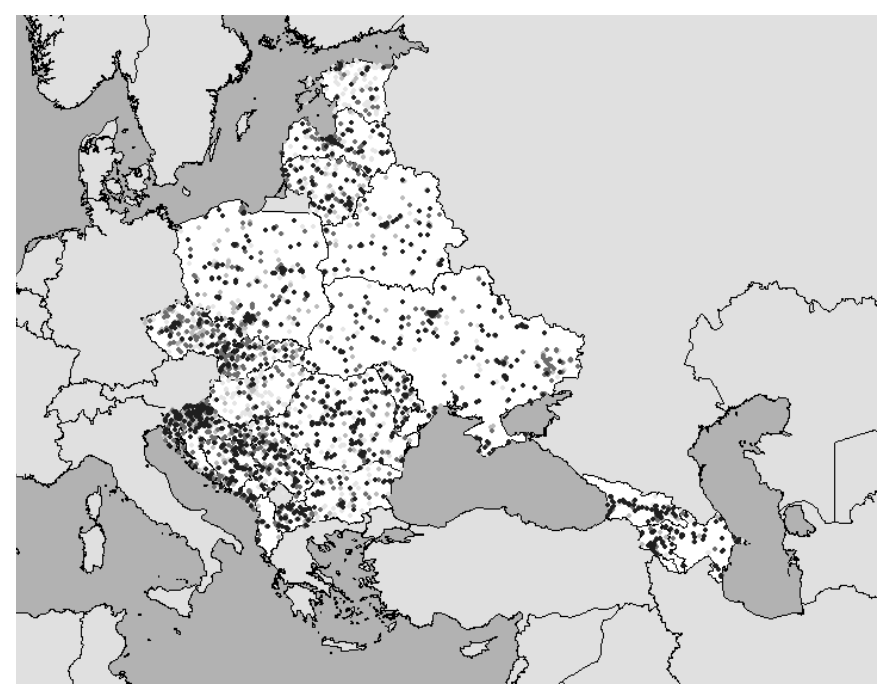

note: This heatmap reports the financing obstacle for all firms in the sample. Darker red indicates more severe financing obstacle for a firm and vice versa.

Figure 4.2. Heatmap of Firm Bribery

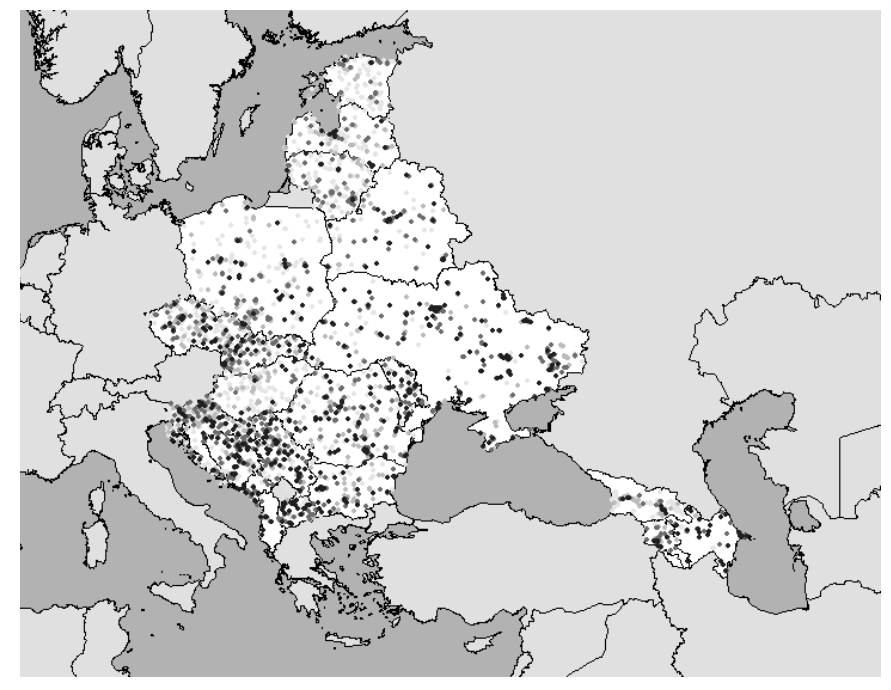

Note: This heatmap reports the bribery of all firms in the sample. Darker red indicates a firm bribing more frequent and vice versa. 
Relationship Banks, ${ }^{37}$ and Herfindahl-Hirschmann Index. All of these locality level variables are averages that are weighted by the number of branches a bank operates within a locality or circle. This enables us to distinguish between firms that are surrounded by foreign versus domestic banks or relationship versus transaction banks, and firms in a banking market where competition is either very low or very high.

As shown in Table 2.2, foreign ownership of banks is a key characteristic of the banking sector in the transition countries. Following the privatization policies, the market share of foreign banks is rather high in these transition countries. At the locality level or $10 \mathrm{~km}$ circle level, more than 50 per cent of all the bank branches are foreign-owned. The share of relationship banks is 38 per cent in general and stays quite stable over time at the locality level, which indicates that both relationship lending and transaction lending are important lending techniques that are used by banks in these countries. The Herfindahl-Hirschman Index stays around 0.15 , indicating that the banking markets are moderately concentrated in these countries. The statistics and patterns remain similar and consistent no matter how the firms are matched with the bank branches. Therefore, from what the data can tell, no systemic change occurs in the banking structures during and after the crisis.

\subsection{Methodology}

In order to estimate and identify the causal impact of bribery on firms' access to credit, I start with regressing Financing Obstacle for Firm on Firm Bribery while accounting for the country, sector and wave fixed effects, as well as other related firm-level and locality-level controls. Specifically, I estimate by OLS regressions of the form: ${ }^{38}$

Financing Obstacle for Firm Fi

$$
\alpha_{c}+\alpha_{s}+\alpha_{w}+\beta \text { Firm Bribery } \text { Bir }_{i}+\gamma X_{i}+\delta Y_{l}+\varepsilon_{i}
$$

where $i$ indexes firms, $c$ indexes countries, $s$ indexes industry sectors, I indexes localities and $w$ indexes BEEPS waves. Financing Obstacle for Firm measures the extent to which access to credit is an obstacle for the operation of the firm. Firm Bribery measures how frequent firms are involved in the bribery practices. $\alpha_{c}, \alpha_{s}$ and $\alpha_{w}$ are the country, sector and wave fixed effects, to control for all the time-invariant country, sector and wave characteristics. ${ }^{39}$ These

\footnotetext{
${ }^{37}$ To distinguish between relationship banks and transaction banks, we utilise the Banking Environment and Performance Survey (BEPS) question where CEOs were asked to rate on a five-point scale the importance of the following techniques when dealing with SMEs or large enterprises: relationship lending; fundamental and cash-flow analysis; business collateral; and personal collateral. We categorise banks that find relationship lending "very important" for both SMEs and large enterprises as relationship banks and banks that considers it only "important" or "neither important nor unimportant" as transactional banks.

${ }^{38}$ We also do the ordinal regression instead of OLS, but the results are similar, so for simplicity, we only report OLS results in the paper.

${ }^{39}$ Country-sector, country-wave and sector-wave interacted fixed effects are included in the last specification to more strictly control for the unobserved features at country-sector, country-wave and sector-wave levels.
} 
fixed-effects also control for country-specific, sector-specific and year-specific credit shocks, which may otherwise bias the estimates. $X$ represents firm-level control variables including Firm Size, Audited Firm, Female Managed Firm, Sole Proprietorship Firm, Publicly Listed Firm and Privatized Firm. $Y$ includes locality-level controls as Share of Foreign Banks, Share of Relationship Banks and Herfindahl-Hirschmann Index. $\varepsilon$ is the error term. Robust standard errors are clustered at the country-sector level. The main coefficient of interest is $\beta$, which identifies the impact of bribery on firms' credit access.

Significant coefficient estimates in Equation (1) can be explained either by firms being more likely to bribe as they need more credit or by banks being less willing to lend to bribing firms. Therefore, in order to disentangle between the supply and demand effects, and to address the reverse causality issue, we investigate if the impact of bribery on firms' credit access varies between firms with or without demand for credit in the last fiscal year, namely Firm Need Credit. The variable equals to 0 if a firm answers "Do not need a loan" to the BEEPS question K17: "What was the main reason the establishment did not apply for any line of credit or loan in the last fiscal year?". Intuitively, if a firm needs a loan in the last fiscal year, this firm is more likely to bribe, and at the same time, is also more likely to encounter tighter credit access. This methodology has been used by Beck and Brown (2015) in order to disentangle the supply and demand effects for household credit. The following equation is estimated:

Financing Obstacle for Firm fir $_{i}=\alpha_{c}+\alpha_{s}+\alpha_{w}+\beta_{1}$ Firm Bribery $_{i}+$

$$
\beta_{2} \text { Firm Bribery }_{i} * \text { Firm Need Credit }{ }_{i}+\beta_{3} \text { Firm Need Credit }_{i}+\gamma X_{i}+\delta Y_{l}+\varepsilon_{i}
$$

where Firm Need Credit specifies whether a firm needs any credit in the last fiscal year. $\beta_{1}$ estimates the baseline impact of bribery on firms' credit access. If the estimates in Equation (1) are not predominantly driven by demand-side factors, then an insignificant estimate of $\beta_{2}$ is expected, which also indicates that the reverse causality is less of a concern. Country, sector and wave fixed effects, as well as the same set of control variables are included, and robust standard errors are clustered at the country-sector level.

Then we focus on the supply-side of credit, namely, does the impact of bribery on firms' credit access vary across different local banking structures in the vicinity of the firm, and if yes, which effects are more pronounced? The intuition is that different types of banks may differ in their credit supply and cherry-pick their preferred clients. For example, Popov \& Udell (2012) present that banking market conditions could exert a strong impact on firms' credit access. Beck \& Brown (2015) document that, for instance, foreign banks would cherry-pick financially more transparent clients in the retail credit market. Thus, various local banking structures might differentiate credit supply to the bribing firms, and shape the relationship between bribery and credit access differently.

Specifically, we focus on three aspects of the local banking markets, including Share of Foreign Banks, Share of Relationship Banks and Herfindahl-Hirschmann Index. Foreign banks have been shown to exert significant impacts on credit supply and demand. For example, at 
the bank level, De Haas \& Van Lelyveld (2006) show that during a crisis, domestic banks contract their credit base while foreign banks do not, while on the firm-level, Brown et al. (2011) find that foreign bank presence discourages firms from applying for a loan but does not lead to stricter loan approval decisions. Furthermore, foreign banks are more likely to cherry-pick transparent firms, which may in turn lead to lower average lending rates (Degryse et al., 2012). Finally, foreign banks are important for credit access. Clarke et al., (2006) find a positive link between access to credit and foreign bank presence. However, Beck \& Peria (2010) indicate that foreign bank participation only benefits rich and urban areas. Regarding corruption, the stronger control of employees inside foreign banks and the presence of foreign managers result in less involvement in the domestic networks. For that reason, foreign banks possess less information to detect corrupt firms in the first place, compared to domestic banks. At the same time, foreign banks may also be less aware of the risks associated with corruption in the domestic market.

The lending techniques of the banks also affect firms' credit access, as has been shown both theoretically (Berger \& Udell, 2002) and empirically (Cole, 1998; Elsas and Krahnen, 1998). For example, relationship banks are found to be able to expand credit supply, especially during a financial crisis (Bolton et al., 2016; Beck et al., 2017). Transaction banks rely more on collateral and hard information, while relationship banks do the opposite, repeatedly interacting with customers in order to obtain the proprietary customer-specific information, which requires softer information and more subtle judgments (Boot, 2000). When it comes to corruption, relationship lenders might be better at differentiating between corrupt and uncorrupt firms. However, on the other hand, relationship banks themselves may be also more prone to corruption and leave more room for bribery.

Competition in the banking market is essential for economic growth (Cetorelli and Gambera, 2001), efficiency (Bertrand et al., 2007), as well as stability (Beck et al., 2013; Bekaert et al., 2013). More closely, Dick \& Lehnert (2010) document that increased competition among banks expands credit supply based on the experience of the relaxation of entry restrictions in the US. Likewise, in states with higher interstate branch openness, firms are more likely to borrow at lower rates (Rice \& Strahan, 2010). Beck et al. (2004) show empirical evidence that firms in concentrated bank markets have less access to credit while Guzman (2000) provides the theoretical mechanisms. The market competition also induces banks to flight to captivity (Dell'Ariccia \& Marquez, 2004). Importantly, Martinez-Miera \& Repullo (2010) theoretically show a U-shaped relationship between competition and the risk of bank failure, that is, the risk of bank failure is higher when competition is either very low or very high. As a result, to avoid excessive risk-taking and maintain solvent, banks might be more conservative and less willing to lend to the risky bribing firms.

To explicitly examine the impact from the supply-side, bribery is interacted seperately with one of the three measures of the local banking structures around the vicinity of the firm and the following regression is estimated: 
Financing Obstacle for Firm $i=\alpha_{c}+\alpha_{s}+\alpha_{w}+$

$\beta_{1}$ Firm Bribery $_{i}+\beta_{2}$ Firm Bribery $_{i} *$ Local Banking Structure $_{l}+$

$$
\beta_{3} \text { Local Banking Structure } e_{l}+\gamma X_{i}+\delta Y_{l}+\varepsilon_{i}
$$

where Local Banking Structure represents the various aspects of the local banking structures, including Share of Foreign Banks, Share of Relationship Banks and Herfindahl-Hirschmann Index. $\beta_{1}$ estimates the baseline impact of bribery on credit access and $\beta_{2}$ gives the estimates of additional supply-side impact across different local banking structures. Again, country, sector and wave fixed effects, as well as the same set of firm and locality controls, are included and robust standard errors are clustered at the country-sector level.

Finally, as shown by literature, corruption significantly obstructs economic growth on both the macro and micro level. Based on the experience of Asian crisis, Rajan \& Zingales (1998) indicate that relationship-based economic system, which includes corruption behaviours, can hold back investment and economic growth. More recently, Fisman \& Svensson (2007) find firm-level evidence that corruption results in lower firm growth. Therefore, it is vital to investigate the economic outcomes of bribery-that is, firm growth. Furthermore, as shown by Pellegrini \& Gerlagh (2004) and Mo (2010), corruption affects growth through various channels including investment, trading, political stability and human capital. This paper adds to the literature by providing a microeconomic channel through bank lending for corruption to affect growth. Therefore, this paper tests if the credit constraints impede firm growth, by utilising both the realised and the projected values of Financing Obstacle for Firm based on Firm Bribery. The following equation is utilised:

Firm Growth $_{i}=\alpha_{c}+\alpha_{s}+\alpha_{w}+$

$$
\beta_{1} \text { Firm Bribery }_{i}+\beta_{2} \text { Financing Obstacle for Firm }_{i}+\gamma X_{i}+\delta Y_{l}+\varepsilon_{i}
$$

The expected future growth of a firm is measured by the BEEPS question S.1a: "In the next fiscal year, do you expect this establishment's annual sales to increase, stay the same or decrease?" Firm Future Growth is equal to 1 if a firm answers "Increase" and 0 otherwise. Model (4) is first estimated on the realised values of Financing Obstacle for Firm and then on the projected values based on the variation of Firm Bribery. The same set of country, sector and wave fixed effects, control variables and clustering strategy are utilised.

\subsection{Results}

In accordance with the empirical settings in Section 4, we start with the baseline estimates in Equation (1), which is followed by various empirical settings to pin down the causal impact of bribery on firms' credit access. Afterwards, we disentangle the supply and demand effects by estimating Equation (2). Furthermore, the supply-side impact of local banking structures in the vicinity of the firm is estimated by Equation (3). Finally, real economic outcomes of bribery are analysed in Equation (4). 


\subsubsection{Baseline Estimates}

This section shows the baseline estimates of equation (1) regarding the impact of bribery on firms' credit access. Before presenting these estimates, we point to Table 4.3, which provides a vivid illustration that link firms' access to credit with their bribery practices. The firms are classified into six groups according to their bribery behaviours: firms that never (6,014 firms), seldom (2,511 firms), sometimes (2,213 firms), frequently (795 firms), usually (316 firms), and always (157 firms) bribe. The average Financing Obstacle for Firm among these groups of firms are compared under a two-sample t-test with unequal variances. The firms that pay more bribes are facing more limited access to credit. The only exception occurs between firms that usually and always bribe. Therefore, at a first sight, bribery firms are more limited in their access to credit and the relationship is linear.

Table 4.3. Bribery and Access to Credit: Univariate Results

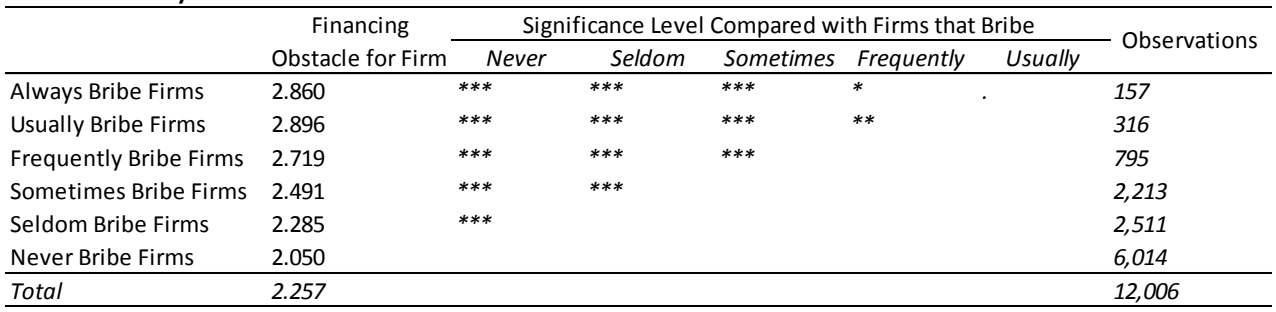

Note: This table reports univariate results on the relationship between bribery and access to credit. $*, * *, * * *$ indicate significance at the $10 \%, 5 \%$ and $1 \%$ level, respectively, for a two-sample t-test of a difference in means with unequal variances. Table 4.1 contains all definitions and Table 4.2 the summary statistics for each included variable.

The matching estimates are further utilised to match out the observed firm characteristics, as well as all the other omitted characteristics at the country, locality, sector and wave level (loannidou \& Ongena, 2010). Specifically, we apply the exact matching to match each bribing firm with all the same non-bribing firms based on various sets of variables, and the average treatment effect for the treated (bribing firms) is reported. A bribing firm is defined if Firm Bribery ranges between 3 and 6 (firms that sometimes, frequently, usually or always bribe). The results are reported in Table 4.4. Bribing firms are matched with all the same non-bribing firms based on country, sector and wave in model (1). Model (2) further includes a same set of firm-level characteristics as in Equation (1). Models (3) and (4) undertake the matching on the locality level. Across all the specifications, the bribing firms are found to be more credit constrained. Economically, based on the result in model (2), bribing firms are 41.4 per cent more constrained in their access to credit. 
Table 4.4. Bribery and Access to Credit: Matching Results

\begin{tabular}{|c|c|c|c|c|}
\hline & (1) & (2) & (3) & (4) \\
\hline Difference in Financing Obstacle for Firm & $\begin{array}{c}0.422 * * * \\
{[0.025]}\end{array}$ & $\begin{array}{c}0.414^{* * *} \\
{[0.032]}\end{array}$ & $\begin{array}{c}0.373 * * * \\
{[0.036]}\end{array}$ & $\begin{array}{c}0.306^{* * *} \\
{[0.058]}\end{array}$ \\
\hline \multicolumn{5}{|l|}{ Matching Variables } \\
\hline Country & Yes & Yes & No & No \\
\hline Locality & No & No & Yes & Yes \\
\hline Sector & Yes & Yes & Yes & Yes \\
\hline Wave & Yes & Yes & Yes & Yes \\
\hline Firm Size & No & Yes & No & Yes \\
\hline Audited Firm & No & Yes & No & Yes \\
\hline Female Managed Firm & No & Yes & No & Yes \\
\hline Sole Proprietorship Firm & No & Yes & No & Yes \\
\hline Publicly Listed Firm & No & Yes & No & Yes \\
\hline Privatized Firm & No & Yes & No & Yes \\
\hline Observations & 12,006 & 11,142 & 10,577 & 9,355 \\
\hline \multicolumn{5}{|c|}{$\begin{array}{l}\text { Note: This table reports the difference in financing obstacle between firms that } \\
\text { bribe and matched non-bribing firms. Bribing firms are those that Firm Bribery } \\
\text { ranges from } 3 \text { to } 6 \text { (sometimes, frequently, usually and always) and non-bribing } \\
\text { firms are those that Firm Bribery ranges from } 1 \text { to } 2 \text { (never and seldom). Exact } \\
\text { matching is applied and average treatment effects for bribing firms (ATET) are } \\
\text { reported. Table } 4.1 \text { contains all definitions and Table } 4.2 \text { the summary statistics for } \\
\text { each included variable. Differences are listed in the first row, standard errors are } \\
\text { reported below in the brackets, and the corresponding significance levels are placed } \\
\text { adjacently. }{ }^{* * *} \text { Significant at } 1 \%,{ }^{* *} \text { significant at } 5 \%, * \text { significant at } 10 \% \text {. }\end{array}$} \\
\hline
\end{tabular}

We report the baseline regressions in Table 4.5. Financing Obstacle for Firm is the dependent variable, and the robust standard errors are clustered at the country-sector level. Model (1) starts with the simplest specification that only includes Firm Bribery as the sole explanatory variable. In models (2) and (3), a set of firm-level and locality-level control variables is added respectively. Country, sector, and wave fixed effects are further included in model (4) while country-sector, country-wave, and sector-wave fixed effects are defined in model (5). Across all the specifications, the estimates endorse that bribery significantly tightens firms' access to credit, where the impact is also economically relevant. For example, in column (4), which is in accordance with Equation (1), a one-point (or approximately a one standard deviation) increase in bribery tightens firms' credit access by 7.8 per cent compared with its mean. 
Table 4.5. Bribery and Access to Credit: Baseline Regression Results

\begin{tabular}{|c|c|c|c|c|c|}
\hline & \multicolumn{5}{|c|}{ Financing Obstacle for Firm } \\
\hline & (1) & $(2)$ & (3) & (4) & (5) \\
\hline \multirow[t]{2}{*}{ Firm Bribery } & $0.208 * * *$ & $0.206^{* * *}$ & $0.207^{* * *}$ & $0.176 * * *$ & $0.179 * * *$ \\
\hline & {$[0.013]$} & {$[0.012]$} & {$[0.012]$} & [0.012] & [0.012] \\
\hline \multirow[t]{2}{*}{ Firm Size } & & 0.019 & 0.019 & $-0.049 * * *$ & $-0.046^{* *}$ \\
\hline & & {$[0.020]$} & [0.020] & [0.018] & [0.019] \\
\hline \multirow[t]{2}{*}{ Audited Firm } & & -0.048 & -0.046 & -0.018 & 0.001 \\
\hline & & [0.029] & [0.029] & [0.028] & [0.029] \\
\hline \multirow[t]{2}{*}{ Female Managed Firm } & & -0.037 & -0.039 & -0.013 & -0.010 \\
\hline & & {$[0.030]$} & [0.030] & [0.026] & {$[0.026]$} \\
\hline \multirow[t]{2}{*}{ Sole Proprietorship Firm } & & $0.121 * * *$ & $0.118^{* * *}$ & 0.035 & 0.042 \\
\hline & & [0.039] & [0.039] & {$[0.034]$} & [0.034] \\
\hline \multirow[t]{2}{*}{ Publicly Listed Firm } & & $0.197^{* * *}$ & $0.199 * * *$ & $0.105^{* *}$ & 0.062 \\
\hline & & {$[0.060]$} & {$[0.060]$} & {$[0.050]$} & {$[0.051]$} \\
\hline \multirow[t]{2}{*}{ Privatized Firm } & & $0.078^{*}$ & $0.072^{*}$ & 0.015 & 0.015 \\
\hline & & {$[0.041]$} & [0.041] & {$[0.035]$} & [0.034] \\
\hline \multirow[t]{2}{*}{ Share of Foreign Banks } & & & 0.006 & -0.064 & -0.072 \\
\hline & & & [0.065] & [0.072] & {$[0.074]$} \\
\hline \multirow[t]{2}{*}{ Share of Relationship Banks } & & & -0.129 & -0.002 & 0.029 \\
\hline & & & [0.079] & [0.097] & {$[0.100]$} \\
\hline \multirow[t]{2}{*}{ Herfindahl-Hirschmann Index } & & & 0.075 & $0.103^{*}$ & 0.092 \\
\hline & & & [0.069] & [0.062] & {$[0.063]$} \\
\hline Country Fixed Effects & No & No & No & Yes & No \\
\hline Sector Fixed Effects & No & No & No & Yes & No \\
\hline Wave Fixed Effects & No & No & No & Yes & No \\
\hline Country*Sector Fixed Effects & No & No & No & No & Yes \\
\hline Country*Wave Fixed Effects & No & No & No & No & Yes \\
\hline Sector*Wave Fixed Effects & No & No & No & No & Yes \\
\hline R-squared & 0.043 & 0.047 & 0.048 & 0.102 & 0.128 \\
\hline Observations & 12,006 & 12,006 & 12,006 & 12,006 & 12,006 \\
\hline \multicolumn{6}{|c|}{$\begin{array}{l}\text { Note; This table reports the baseline regression results. Table } 4.1 \text { contains all } \\
\text { definitions and Table } 4.2 \text { the summary statistics for each included variable. }\end{array}$} \\
\hline \multirow{2}{*}{\multicolumn{6}{|c|}{$\begin{array}{l}\text { Coefficients are listed in the first row, robust country*sector clustered standard } \\
\text { errors are reported below in the brackets, and the corresponding significance }\end{array}$}} \\
\hline levels are placed adjacently. * & * Significar & & & & gnificar \\
\hline
\end{tabular}

This impact is not driven by a specific country or sector, as shown in Figure 4.3. The height of bars represents the magnitude of the coefficient of Firm Bribery. Those coefficients that are significantly different from zero at the 10 per cent level have darker shades. A significantly positive relationship between Firm Bribery and Financing Obstacle for Firm is found for most of the countries and for all the industrial sectors. More importantly, Figure 4.3 also visualises the regression estimates for different types of firms. We first distinguish between foreign and domestic firms. Intuitively, when businesses launch establishments abroad and become multinational, they are distinguished from the already established enterprises in that host country-that is, domestic firms. Foreign firms bring proprietary technology that is used in their home countries (Grilli, 1989). Similarly, foreign firms may also come along with culture from their home country and, in this case, bribery behaviour. Therefore, the bribery behaviour of foreign firms is less likely to be affected by host country conditions, which makes it more exogenous. We define a firm as a Foreign Firm if more than 
50 per cent of the firms' shares are foreign-owned. Figure 4.3 shows that bribery tightens firms' credit access, for both foreign and domestic firms. Second, we address a possible concern that comes with firm expansion. The findings of the baseline estimates may be explained by the fact that on the one hand an expanding firm is more likely to encounter obstacles in the credit access, while on the other hand this firm is also more likely to bribe in order to obtain the required licenses or permits. Therefore, firm expansion might simultaneously drive Financing Obstacle for Firm and Firm Bribery. In order to tease this out, we utilise Firm Innovation that is equal to 1 if the firm has introduced new or significantly improved products or services during the last three years, to distinguish between the expanding and non-expanding firms. We find that the detrimental impact of bribery on firms' credit access comes out significantly for both the expanding and non-expanding firms. In addition, the results rule out another alternative explanation, that is, the detrimental impact is mainly driven by the poor performing firms. Intuitively, these poor performing firms may blame their failure on other parties, including the corruption of other firms and the discrimination of banks.

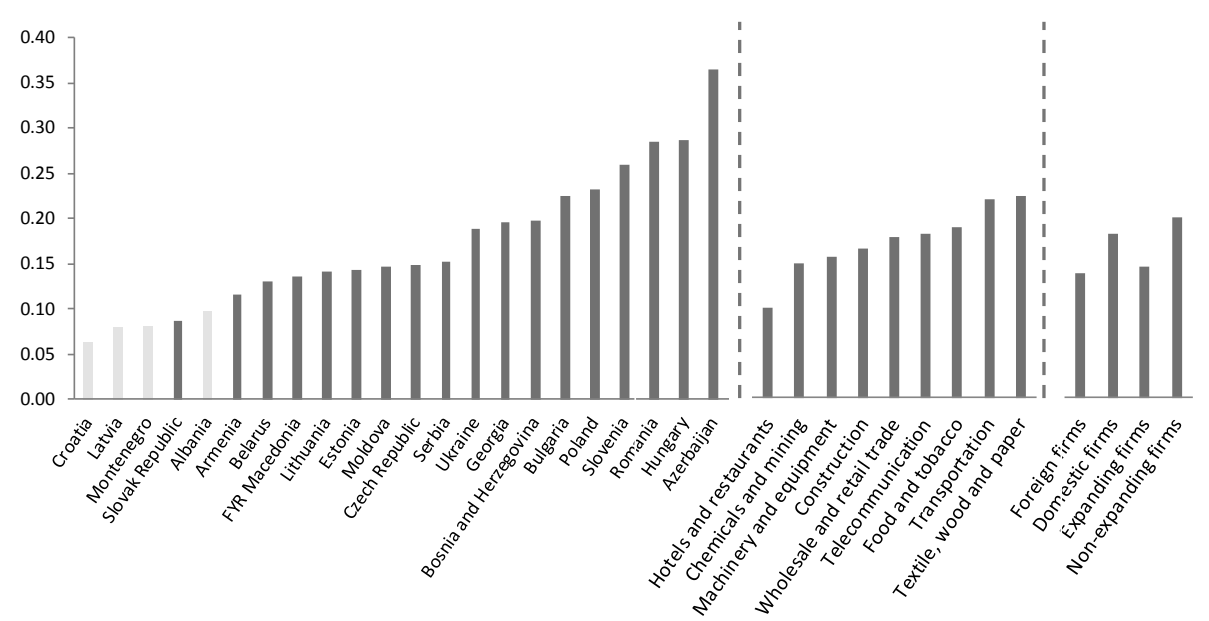

Note: This figure contains information on the relationship between bribery and access to credit across countries, sectors and different types of firms in the sample. In the figure, the height of the bars shows the magnitude of the coefficient of Firm Bribery when regressing Financing Obstacle for Firm on Firm Bribery under baseline regression for each country, sector or year separately. The bars are sorted from low to high and the country, sector and firm types labels are mentioned on the $\mathrm{X}$-axis. The coefficients that are significantly different from zero at the 10 percent level have a darker shade.

\subsubsection{Instrumental Variable Estimates}

In order to tackle the potential endogeneity issue, we first follow Fisman \& Svensson (2007) to instrument Firm Bribery by the Locality-Sector Average of Bribery. For each individual firm, Firm Bribery is averaged across all the other firms within the same locality and sector, but 
excludes the firm itself. ${ }^{40}$ Locality-Sector Average of Bribery is very likely to be determined by the underlying technologies of the sector and the rent-extraction inclinations or talents of the bureaucrats, which is exogenous to the firm. For instance, such sector specific factors include the extent to which the sector is import or export reliance, and the dependence of public goods and services. Similarly, the rent extraction through bribery might differ across localities simply because some bureaucrats are more effective or eager at extracting bribes than others. Bribery practices also tend to be more common in markets with ill-functioning institutions. So instrumenting Firm Bribery by Locality-Sector Average of Bribery can get rid of the omitted drivers that are correlated with bribery at the firm, but not the locality-sector, level. Results are reported by models (1) to (4) in Table 6. The first-stage estimates confirm that Firm Bribery is significantly positively correlated with Locality-Sector Average of Bribery. Intuitively, a firm that is operating in a corrupted sector or is based in a corrupted locality is also more likely to bribe. The weak instrument statistics are both above the critical values and thus rejects the null hypothesis that the instrument is weak. The second-stage results confirm the baseline estimates in Table 5 that bribery significantly limits firms' credit access, with increased economic magnitudes. For example, a one-point (or around a one standard deviation) increase in bribery significantly constrains firms' access to credit by 16.1 per cent in model (1).

The Locality-Sector Average of Bribery might not be valid if the corruption level at a certain locality in a certain industrial sector is correlated with lower access to credit. To address this issue, we utilise the Adjacent Locality-Sector Average of Bribery instead. In detail, we match each firm with all the other firms that operate in the same sector and locate at the adjacent areas. We draw two circles, one with a radius that equals $5 \mathrm{~km}$ and the other with a radius of $15 \mathrm{~km}$, around the geo-coordinates of each firm and then link the firm to only those firms between those two circles. Thus instrumenting Firm Bribery by the Adjacent Locality-Sector Average of Bribery can also get rid of the omitted drivers that are correlated with bribery at the locality-sector level. Results are shown in models (5) to (8) of Table 6. We find that a firm is more likely to bribe if the other firms within the same sector in the nearby areas are more corrupted. The second-stage results confirm similar findings that bribery limits firms' access to credit.

Still, concerns might arise if all the firms' bribery behaviours reflect something in common that is correlated with the general level of access to credit. So instead of instrumenting the bribery behaviour of a firm by other firms' bribery practices, we instrument Firm Bribery by the households' attitudes toward corruption in the same locality. To measure households' opinion about corruption, we seek to the third round of the Life in Transition Survey (LiTS) conducted by the European Bank for Reconstruction and Development. Specifically, we use LiTS question q817b that ask to what extent does a household agree that "If I would witness an act of corruption, I would feel personally obliged to report". Answers are classified from

\footnotetext{
${ }^{40}$ For locality-sectors with only one single firm, this firm is dropped from the instrumental regression, as it is meaningless to instrument a firm by itself. Specifically, 2,556 out of 12,006 firms are single in a locality sector, which are dropped out of sample. On average, there are 26 other firms within each locality sector.
} 


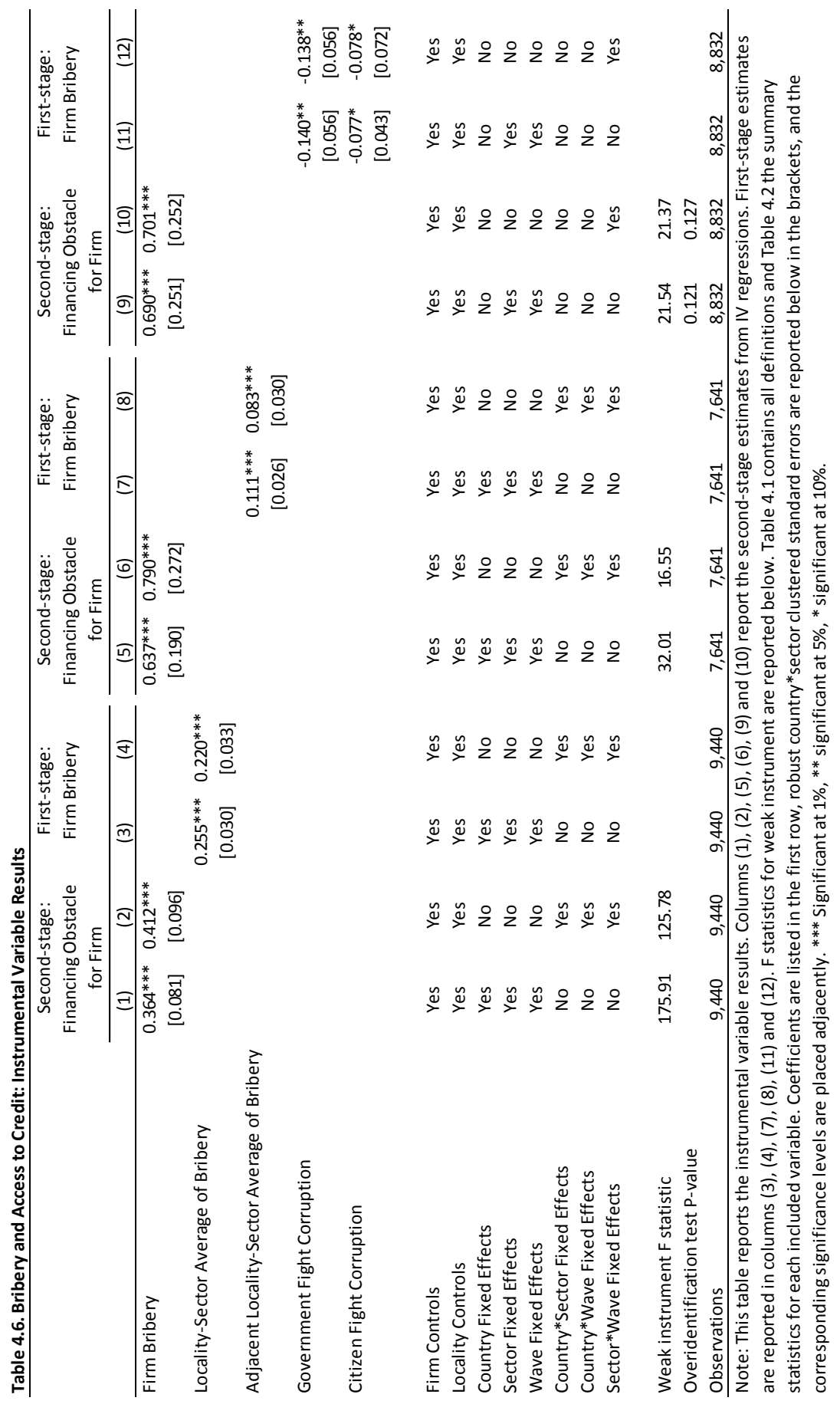


1 to 5 where higher values indicate stronger agreement with this statement (Citizen Fight Corruption). We also apply another question q818 that asks how well the government is fighting corruption. The answer ranges between 1 and 4 with higher values indicate that the government is doing a better job in fighting corruption (Government Fight Corruption). The extent to which the citizens and the government are fighting with corruption would directly be related with the bribery behaviours of firms in that locality, but is very unlikely to affect the credit decision of banks for a certain firm. To match each firm with nearby households, we draw a circle with a radius that equals $10 \mathrm{~km}$ around the geo-coordinates of each firm and then link the firm to only those households inside that circle. As these measures capture how people and the government are fighting corruption in general, so there is only limited within-country variation and we do not control for the country fixed effects. Models (9) to (12) in Table 6 show the results. The first-stage results indicate that in localities where the citizens and the government are fighting corruption very well, the firms are less frequently involved with bribery. The statistics for the weak instrument and over-identification indicate that the instruments are both strong and valid. The second-stage regressions present similar results, which confirm a significantly detrimental impact of bribery on firms' credit access.

\subsubsection{Robustness Checks}

Besides the instrumental variable approach, we also try to directly control for all the locality and sector level drivers in Appendix A4.2. Specifically, in models (1) and (2), instead of country fixed effects, locality fixed effects are utilised, which can control for the factors that vary within a country but are locality specific. In models (3) and (4), we further include the locality-sector interacted fixed effects to control for all the locality-sector specific omitted variables. These findings confirm that the detrimental impact of bribery on credit access is not totally driven by locality and sector level drivers. Similarly, some unobserved firm level characteristics may still induce endogeneity concerns of the estimates. In order to tackle this issue, we repeat the baseline analysis using a panel generated from the two waves of BEEPS. Of the total 5,523 firms covered by the BEEPS IV, 1,264 firms are also surveyed in BEEPS V, which enables me to construct a panel with 1,264 firms across 22 transition countries over BEEPS IV and V. Among all these firms, 373 firms increase their bribery level and 397 firms bribe less frequently. The results are reported in Appendix A4.3. Models (1) and (2) utilise the same specifications as in models (4) and (5) in Table 4.5. The firm fixed effects are included in models (3) and (4) to control for all omitted firm-level time-invariant unobservables. The significantly positive coefficients estimates confirm that bribery tightens firms' credit access, which is not driven by firm specific omitted variables.

We also utilise a more practical-based measure of firms' credit access, Credit Constraint of Firm, as indicated by Popov \& Udell (2012) and Beck et al. (2017) as a robustness check. ${ }^{41}$

\footnotetext{
${ }^{41}$ This paper uses Financing Obstacle for Firm, rather than Credit Constraint of Firm, as the primary measure for firms' credit access for two main reasons. First, selection bias might exist in Credit Constraint of Firm, in the sense that it is only observable if the firm needs credit in the last fiscal year. But the perception based measure, Financing Obstacle for Firm, can reveal the credit access situation for a full sample of firms, including firms that do not need a loan in the last fiscal year. Intuitively, assume if a firm gets a loan just before the last fiscal year,
} 
Specifically, we employ BEEPS question K16: "Did the establishment apply for any loans or lines of credit in the last fiscal year?" For firms that answer "No", we move to question K17, which asks: "What was the main reason the establishment did not apply for any line of credit or loan in the last fiscal year?" For firms that answer "Yes", the question K18a subsequently asks: "In the last fiscal year, did this establishment apply for any new loans or new credit lines that were rejected?" We classify firms that answer both "Yes" to K16 and "No" to K18a as credit unconstrained, and firms are constrained if they either answer "Yes" to K18a or answer "Interest rates are not favorable"; "Collateral requirements are too high"; "Size of loan and maturity are insufficient"; or "Did not think it would be approved" to question K17. This strategy allows us to directly measure firms' credit access in practice and also differentiate between firms that do not apply for any loan because they do not need one and those that do not apply because they are discouraged. The results are presented in Appendix A4.4 where are replicate the same analysis as shown in Table 4.5 but apply the Credit Constraint of Firm as the dependent variable. The same significantly positive coefficients are found which further confirms the validity of the baseline results using Financing Obstacle for Firm as the dependent variable.

However, bribing firms could differ from non-bribing firms in ways that would explain our results absent any taste-based discrimination. For example, if firms' bribery practices would capture some firm-level omitted risks or performance indicators, these bribing firms might have more limited access to credit. The firm-level control variables and fixed effects we have included in our tests so far only imperfectly control for firm growth or risk. To investigate this point more formally, we now analyse the difference in firm growth across firm bribery. In Table 4.7, we repeat our main tests in Table 4.5 where the independent variable is realized firm sales growth in the past 3 fiscal years (Firm Past Growth). The results suggest that conditioning on firm and locality level observables and on country, industry and wave fixed effects, there are no significant differences between bribing and non-bribing firms in terms of sales growth. These results suggest that there is no evidence that firms' bribery practices capture some firm-level omitted risks or performance dimensions.

but with a lot of difficulties, then this firm may not need a loan in the last year and cannot be captured by Credit Constraint of Firm. However, this firm is seemingly to have a very tight access to credit in reality, which can be measured by Financing Obstacle for Firm. Second, Financing Obstacle for Firm provides more variation than Credit Constraint of Firm in measuring the degree of firms' credit access. For example, assume there are two firms, A and B, and both firms apply for two loans. For firm A, one application is approved and the other is rejected, while both applications are rejected for firm B. In the context of Credit Constraint of Firm, both firm $A$ and firm $B$ are classified as credit constrained and are treated as the same. However, in reality, firm B is more credit constrained than firm A. This difference can be revealed by Financing Obstacle for Firm that, for example, firm A self-selects into "a Minor Obstacle" and firm B enters "a Major Obstacle". 
Table 4.7. Bribery and Access to Credit: Past Growth

\begin{tabular}{lccccc}
\hline & \multicolumn{5}{c}{ Firm Past Growth } \\
\cline { 2 - 6 } & $(1)$ & $(2)$ & $(3)$ & $(4)$ & $(5)$ \\
\hline Firm Bribery & 0.023 & 0.026 & 0.030 & -0.017 & -0.030 \\
& {$[0.042]$} & {$[0.043]$} & {$[0.043]$} & {$[0.042]$} & {$[0.042]$} \\
Firm Controls & No & Yes & Yes & Yes & Yes \\
Locality Controls & No & No & Yes & Yes & Yes \\
Country Fixed Effects & No & No & No & Yes & No \\
Sector Fixed Effects & No & No & No & Yes & No \\
Wave Fixed Effects & No & No & No & Yes & No \\
Country*Sector Fixed Effects & No & No & No & No & Yes \\
Country*Wave Fixed Effects & No & No & No & No & Yes \\
Sector*Wave Fixed Effects & No & No & No & No & Yes \\
& & & & & \\
R-squared & 0.000 & 0.002 & 0.003 & 0.033 & 0.040 \\
Observations & 7,939 & 7,939 & 7,939 & 7,939 & 7,939 \\
\hline
\end{tabular}

Note: This table reports the relationship between bribery and the past growth rate in the last three years. Table 4.1 contains all definitions and Table 4.2 the summary statistics for each included variable. Coefficients are listed in the first row, robust country*sector clustered standard errors are reported below in the brackets, and the corresponding significance levels are placed adjacently. ${ }^{* * *}$ Significant at $1 \%$, ** significant at $5 \%$, * significant at $10 \%$.

Finally, another concern is whether Firm Bribery captures the bribery behaviour of the firm itself or it also includes information about other firms in the same locality and sector. If the answer is yes, then would this change our main findings? We now address the issue formally by assuming a locality-sector with $n$ firms. If the Firm Bribery measure captures a weighted average of bribery of the firm itself (with a weight equals to $\alpha$ ) and all the other firms (with a weight equals to $1-\alpha$ ) in the same locality and sector, then we have the following formula:

$$
\text { Firm Bribery } y_{i}=\alpha * \text { Firm Bribery }{ }_{i}^{*}+(1-\alpha) * \sum_{1}^{n-1} \text { Firm Bribery } \text { Bir }^{*} /(n-1)
$$

Then we calculate the true bribery behaviour of each firm based on Equation (5) within each group of firms in the same locality and sector. Figure 4.4 reports the coefficient estimates of the true value of Firm Bribery* under the baseline regression for $\alpha$ ranging from $5 \%$ to $95 \%$. The height of bars represents the magnitude of the coefficient and the coefficients that are significantly different from zero at the 10 per cent level have darker shades. Even though the magnitudes vary a lot with a $\alpha$ from $5 \%$ to $95 \%$, the results are all significantly positive at the 1 per cent level. ${ }^{42}$ Therefore, the findings confirm that even if Firm Bribery also captures information about other firms in the same locality and sector than the firm itself, we can still find that bribery tightens firms' access to credit. Having said that, it is very likely that a firm mainly focuses, or putting more weight on its own bribery practices when responding to the question. Therefore, Firm Bribery is very likely to be an indicator of a firm's own bribery level (Joulfaian, 2009).

\footnotetext{
${ }^{42}$ After the calculation, the bribery level of each firm is no longer ranging between 1 and 6 , but with a larger interval, especially when $\alpha$ is relatively small. So the coefficient estimates are relatively small in those cases.
} 


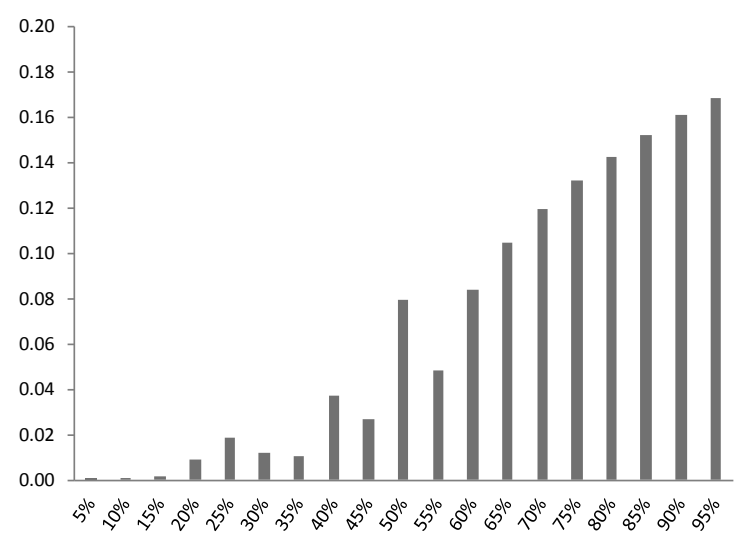

\begin{abstract}
Note: This figure contains information on the relationship between bribery and access to credit across different weight on the firm's own information. In the figure, the height of the bars shows the magnitude of the coefficient of Firm Bribery with different weights on own information when regressing Financing Obstacle for Firm on Firm Bribery under the baseline regression. The bars are sorted from low to high and the wights on own informatoin are mentioned on the $\mathrm{X}$-axis. The coefficients that are significantly different from zero at the 10 percent level have a darker shade.
\end{abstract}

Therefore, our baseline findings support the law and finance theory pioneered by La Porta et al. (1997) that corruption induces greater uncertainty on banks' claims and enforcement actions against corrupt firms in case of default. As a result, this decreased enforcement power against the defaulting borrowers diminishes banks' willingness to lend to the bribing firms.

\title{
4.5.4 Demand versus Supply
}

The detrimental effects of bribery on credit access can be driven by either demand-side or supply-side factors. From the demand-side, firms that need credit in the last fiscal year may be those that are more incentivized to bribe and, at the same time, may be also more likely to encounter obstacles to obtaining credit. From the supply-side, banks may also tailor their lending strategies so they do not lend to the bribing firms. Therefore, in order to disentangle the demand-side impact from supply-side impact and to address the reverse causality issue, we implement the methodology in Beck \& Brown (2015) to test whether the detrimental effects of bribery on firms' access to credit differentiates between firms with or without demand for credit in the last fiscal year, which is indicated by Firm Need Credit.

Estimates are shown in Table 4.8. Firm Need Credit is included in models (1) and (2) and the estimates indicate that conditional on all the other factors, firms that need a loan in the last fiscal year are also more likely to be constrained in their credit access. Furthermore, models (3) and (4) also include the interaction term between Firm Bribery and Firm Need Credit. The 
insignificant coefficients of the interaction term show that the detrimental impact of bribery on credit access is not predominantly driven by demand-side factors and reverse causality is less of a concern in this research. Therefore, the results confirm that the detrimental impact of bribery on firms' credit access is mainly driven by banks not willing to lend to the bribing firms.

Table 4.8. Bribery and Access to Credit: Demand versus Supply

\begin{tabular}{|c|c|c|c|c|}
\hline & \multicolumn{4}{|c|}{ Financing Obstacle for Firm } \\
\hline & $(1)$ & $(2)$ & (3) & (4) \\
\hline \multirow[t]{2}{*}{ Firm Bribery } & $0.147^{* * *}$ & $0.150 * * *$ & $0.144^{* * *}$ & $0.148^{* * *}$ \\
\hline & [0.011] & [0.012] & {$[0.016]$} & [0.016] \\
\hline \multirow[t]{2}{*}{ Firm Needs Credit } & $0.690 * * *$ & $0.684^{* * *}$ & $0.680^{* * *}$ & $0.678^{* * *}$ \\
\hline & [0.023] & [0.024] & {$[0.040]$} & {$[0.040]$} \\
\hline \multirow[t]{2}{*}{ Firm Bribery*Firm Needs Credit } & & & 0.005 & 0.003 \\
\hline & & & [0.017] & [0.017] \\
\hline Firm Controls & Yes & Yes & Yes & Yes \\
\hline Locality Controls & Yes & Yes & Yes & Yes \\
\hline Country Fixed Effects & Yes & No & Yes & No \\
\hline Sector Fixed Effects & Yes & No & Yes & No \\
\hline Wave Fixed Effects & Yes & No & Yes & No \\
\hline Country*Sector Fixed Effects & No & Yes & No & Yes \\
\hline Country*Wave Fixed Effects & No & Yes & No & Yes \\
\hline Sector*Wave Fixed Effects & No & Yes & No & Yes \\
\hline R-squared & 0.180 & 0.203 & 0.180 & 0.203 \\
\hline Observations & 12,006 & 12,006 & 12,006 & 12,006 \\
\hline \multicolumn{5}{|c|}{$\begin{array}{l}\text { Note: This table disentangles demand-side from supply-side drivers of the } \\
\text { results. Table } 4.1 \text { contains all definitions and Table } 4.2 \text { the summary statistics } \\
\text { for each included variable. Coefficients are listed in the first row, robust } \\
\text { country*sector clustered standard errors are reported below in the brackets, } \\
\text { and the corresponding significance levels are placed adjacently. }{ }^{* * *}\end{array}$} \\
\hline \multicolumn{5}{|c|}{ Significant at $1 \%, * *$ significant at $5 \%, *$ significant at $10 \%$} \\
\hline
\end{tabular}

As the supply-side factors are found to be the main drivers behind bribery affecting credit access, we turn to the supply-side impact by interacting with various types of local banking structures. Specifically, we examine if and how different types of banks may distinguish and treat bribery differently, by testing the impact of bribery on access to credit across different local banking structures.

Regression results are reported in Table 4.9. Panel A presents the results when Firm Bribery is interacted with continuous measures of local banking structures in the vicinity of the firm. These specifications test if the local banking structures exert a linear heterogeneous effect. Specifically, Firm Bribery is interacted with the Share of Foreign Banks, Share of Relationship Banks and Herfindahl-Hirschmann Index separately. These local banking structure measures are also included in the regressions, but are not reported. Country, sector, and wave fixed effects (or country-sector, country-wave and sector-wave fixed effects) are utilised with the same set of control variables. Estimates of which firms are matched with the bank branches either within the locality or within the $10 \mathrm{~km}$ circle are reported in models (1-6) and models (7-12) respectively. Results indicate that the impact of bribery on firms' credit access is less pronounced in those localities with a higher share of foreign banks, which is valid regardless 
of whether firms and bank branches are matched by locality or by a circle. In contrast, no linear effects are found regarding the share of relationship banks and the level of banking market competition. The results are also economically significant. For example, as indicated in model (1), in Slupsk of Poland where the share of foreign banks is 45 per cent, a one-point increase in bribery would decrease firms' credit access by 8.2 per cent. However, in Warsaw where 70 per cent of the bank branches are foreign-owned, the impact of bribery on credit access is 6.9 per cent.

Then we examine the non-linear effects of the local banking structures on the relationship between bribery and credit access. ${ }^{43}$ The intuition is that the local banking structures may only make a difference in extreme cases, where the market is dominated by a certain type of banks. In these cases, firms in the local markets have no choices other than being served by this particular type of banks. In contrast, in local markets where there are considerable mixes of different types of banks, firms still get a choice. Specifically, Foreign Bank Market is defined if Share of Foreign Banks is greater than or equal 80 per cent, while Domestic Bank Market is defined if it is no more than 20 per cent. Similarly, the Relationship Bank Market is defined if Share of Relationship Banks is greater than or equal 80 per cent, while Transaction Bank Market is defined when it is no more than 20 per cent. Based on the US Department of Justice, a market with Herfindahl-Hirschmann Index of less than 0.1 is considered to be "well diversified"; a result between 0.1 and 0.18 "moderately concentrated"; and a result of 0.18 or greater "highly concentrated". Therefore, we define the Low Competition Bank Market if Herfindahl-Hirschmann Index is no less than 0.18, and the High Competition Bank Market if it is smaller than 0.1 .

Results are shown in Panel B of Table 4.9. Firms in the foreign bank market are less affected by bribery while in domestic bank market the impact is more pronounced. This may due to the fact that compared to domestic banks, foreign banks are less involved in the domestic networks and thus have less necessary knowledge or information to detect corrupt firms. At the same time, foreign banks may be also less aware of the risks associated with corrupt firms in the domestic market. There are no significant differences between relationship and transaction lenders in general. Importantly, the detrimental impact of bribery on access to credit is stronger when local banking competition is either very low or very high. A possible explanation lies in a U-shaped relationship between competition and the risk of bank failure (Martinez-Miera and Repullo, 2010), where the risk of bank failure is higher if competition is either very low or very high. Therefore, to avoid excessive risk-taking and maintain solvent, banks would be less willing to lend to the bribing firms in both cases because of the higher uncertainty in case of loan default. Economically, within the locality, bribing firms located in the foreign bank market and in the domestic bank market are 3.5 per cent better off and 3.0 per cent worse off respectively in terms of credit access. Firms in high and low competition

\footnotetext{
${ }^{43}$ Hermes and Lensink (2001) present a non-linear relationship between foreign bank entry and domestic bank performance, indicating that the impact only take place after foreign bank penetration reach a certain level. Similary results are found for the impact of foreign bank presence on investment (Lensink and Murinde, 2006). Martinez-Miera and Repullo (2010) show the theoretic existence of a non-linear relationship between bank competition and risk-taking behaviours.
} 
bank markets are 2.8 per cent and 3.5 per cent worse off respectively than firms in a market where competition is moderate.

\begin{tabular}{|c|c|c|c|c|c|c|c|c|c|c|c|c|}
\hline \multirow[b]{3}{*}{ Panel A: Linear Effects } & \multicolumn{12}{|c|}{ Financing Obstacle for Firm } \\
\hline & \multicolumn{6}{|c|}{ Within City } & \multicolumn{6}{|c|}{ Within Circle } \\
\hline & & & & & & & & & & & & \\
\hline Model & $(1)$ & $(2)$ & (3) & (4) & $(5)$ & (6) & (7) & $(8)$ & (9) & $(10)$ & $(11)$ & $(12)$ \\
\hline Firm Bribery & $\begin{array}{c}0.238^{* * *} \\
{[0.022]}\end{array}$ & $\begin{array}{c}0.241 * * * \\
{[0.024]}\end{array}$ & $\begin{array}{c}0.205^{* * *} \\
{[0.019]}\end{array}$ & $\begin{array}{c}0.204^{* * *} \\
{[0.019]}\end{array}$ & $\begin{array}{c}0.175^{* * *} \\
{[0.015]}\end{array}$ & $\begin{array}{c}0.177^{* * *} \\
{[0.016]}\end{array}$ & $\begin{array}{c}0.248 * * * \\
{[0.026]}\end{array}$ & $\begin{array}{c}0.253^{* * *} \\
{[0.029]}\end{array}$ & $\begin{array}{c}0.198 * * * \\
{[0.022]}\end{array}$ & $\begin{array}{c}0.196^{* * *} \\
{[0.023]}\end{array}$ & $\begin{array}{c}0.183^{* * *} \\
{[0.015]}\end{array}$ & $\begin{array}{c}0.184 * * * \\
{[0.016]}\end{array}$ \\
\hline \multicolumn{13}{|l|}{ Firm Bribery* } \\
\hline Share of Foreign Banks & $\begin{array}{c}-0.116 * * * \\
{[0.036]}\end{array}$ & $\begin{array}{c}-0.115^{* * *} \\
{[0.038]}\end{array}$ & & & & & $\begin{array}{c}-0.127 * * * \\
{[0.039]}\end{array}$ & $\begin{array}{c}-0.129^{* * *} \\
{[0.042]}\end{array}$ & & & & \\
\hline Share of Relationship Banks & & & $\begin{array}{c}-0.077^{*} \\
{[0.039]}\end{array}$ & $\begin{array}{l}-0.065 \\
{[0.040]}\end{array}$ & & & & & $\begin{array}{l}-0.054 \\
{[0.043]}\end{array}$ & $\begin{array}{c}-0.042 \\
{[0.045]}\end{array}$ & & \\
\hline Herfindahl-Hirschmann Index & & & & & $\begin{array}{c}0.007 \\
{[0.063]}\end{array}$ & $\begin{array}{c}0.014 \\
{[0.064]}\end{array}$ & & & & & $\begin{array}{l}-0.047 \\
{[0.057]}\end{array}$ & $\begin{array}{l}-0.039 \\
{[0.057]}\end{array}$ \\
\hline R-squared & 0.100 & 0.112 & 0.099 & 0.111 & 0.099 & 0.111 & 0.100 & 0.112 & 0.099 & 0.111 & 0.099 & 0.111 \\
\hline Observations & 12,006 & 12,006 & 12,006 & 12,006 & 12,006 & 12,006 & 12,006 & 12,006 & 12,006 & 12,006 & 12,006 & 12,006 \\
\hline \multicolumn{13}{|l|}{ Panel B: Non-linear Effects } \\
\hline Model & (1) & (2) & (3) & (4) & (5) & (6) & (7) & (8) & (9) & (10) & (11) & (12) \\
\hline Firm Bribery & $\begin{array}{c}0.182^{* * *} \\
{[0.014]}\end{array}$ & $\begin{array}{c}0.182 * * * \\
{[0.015]}\end{array}$ & $\begin{array}{c}0.168^{* * *} \\
{[0.014]}\end{array}$ & $\begin{array}{c}0.173^{* * *} \\
{[0.014]}\end{array}$ & $\begin{array}{c}0.125^{* * *} \\
{[0.017]}\end{array}$ & $\begin{array}{c}0.131^{* * *} \\
{[0.017]}\end{array}$ & $\begin{array}{c}0.186^{* * *} \\
{[0.013]}\end{array}$ & $\begin{array}{c}0.186 * * * \\
{[0.014]}\end{array}$ & $\begin{array}{c}0.173 * * * \\
{[0.013]}\end{array}$ & $\begin{array}{c}0.177^{* * *} \\
{[0.014]}\end{array}$ & $\begin{array}{c}0.132 * * * \\
{[0.017]}\end{array}$ & $\begin{array}{c}0.138^{* * *} \\
{[0.017]}\end{array}$ \\
\hline \multicolumn{13}{|l|}{ Firm Bribery* } \\
\hline Foreign Bank Market & $\begin{array}{c}-0.078^{* * *} \\
{[0.022]}\end{array}$ & $\begin{array}{c}-0.070^{* * * *} \\
{[0.023]}\end{array}$ & & & & & $\begin{array}{c}-0.074 * * * \\
{[0.022]}\end{array}$ & $\begin{array}{c}-0.068^{* * *} \\
{[0.022]}\end{array}$ & & & & \\
\hline Domestic Bank Market & $\begin{array}{c}0.067^{* *} \\
{[0.028]}\end{array}$ & $\begin{array}{c}0.077^{* *} \\
{[0.030]}\end{array}$ & & & & & $\begin{array}{c}0.070^{* *} \\
{[0.029]}\end{array}$ & $\begin{array}{c}0.085 * * * \\
{[0.032]}\end{array}$ & & & & \\
\hline Relationship Bank Market & & & $\begin{array}{c}-0.046 \\
{[0.053]}\end{array}$ & $\begin{array}{l}-0.050 \\
{[0.055]}\end{array}$ & & & & & $\begin{array}{l}-0.020 \\
{[0.067]}\end{array}$ & $\begin{array}{l}-0.018 \\
{[0.070]}\end{array}$ & & \\
\hline Transaction Bank Market & & & $\begin{array}{c}0.044^{*} \\
{[0.025]}\end{array}$ & $\begin{array}{c}0.034 \\
{[0.026]}\end{array}$ & & & & & $\begin{array}{c}0.026 \\
{[0.025]}\end{array}$ & $\begin{array}{c}0.013 \\
{[0.028]}\end{array}$ & & \\
\hline Low Competition Bank Market & & & & & $\begin{array}{c}0.064^{* *} \\
{[0.025]}\end{array}$ & $\begin{array}{c}0.062^{* *} \\
{[0.026]}\end{array}$ & & & & & $\begin{array}{l}0.050^{* *} \\
{[0.024]}\end{array}$ & $\begin{array}{c}0.049^{* *} \\
{[0.024]}\end{array}$ \\
\hline High Competition Bank Market & & & & & $\begin{array}{c}0.078^{* * *} \\
{[0.025]}\end{array}$ & $\begin{array}{c}0.073^{* * *} \\
{[0.025]}\end{array}$ & & & & & $\begin{array}{c}0.073 * * * \\
{[0.025]}\end{array}$ & $\begin{array}{c}0.068^{* * *} \\
{[0.025]}\end{array}$ \\
\hline R-squared & 0.101 & 0.112 & 0.099 & 0.111 & 0.100 & 0.112 & 0.100 & 0.112 & 0.099 & 0.111 & 0.100 & 0.111 \\
\hline Observations & 12,006 & 12,006 & 12,006 & 12,006 & 12,006 & 12,006 & 12,006 & 12,006 & 12,006 & 12,006 & 12,006 & 12,006 \\
\hline Firm Controls & Yes & Yes & Yes & Yes & Yes & Yes & Yes & Yes & Yes & Yes & Yes & Yes \\
\hline Locality Controls & Yes & Yes & Yes & Yes & Yes & Yes & Yes & Yes & Yes & Yes & Yes & Yes \\
\hline Interaction Controls & Yes & Yes & Yes & Yes & Yes & Yes & Yes & Yes & Yes & Yes & Yes & Yes \\
\hline Country Fixed Effects & Yes & No & Yes & No & Yes & No & Yes & No & Yes & No & Yes & No \\
\hline Sector Fixed Effects & Yes & No & Yes & No & Yes & No & Yes & No & Yes & No & Yes & No \\
\hline Wave Fixed Effects & Yes & No & Yes & No & Yes & No & Yes & No & Yes & No & Yes & No \\
\hline Country Fixed Effects & No & Yes & No & Yes & No & Yes & No & Yes & No & Yes & No & Yes \\
\hline Sector Fixed Effects & No & Yes & No & Yes & No & Yes & No & Yes & No & Yes & No & Yes \\
\hline Wave Fixed Effects & No & Yes & No & Yes & No & Yes & No & Yes & No & Yes & No & Yes \\
\hline $\begin{array}{l}\text { Note: This table reports the supp } \\
\text { applied in Panel A and Panel B ut } \\
\text { while Domestic Bank Market is } \\
\text { than or equal to } 80 \text { percent, whil } \\
\text { Herfindahl-hirschmann Index is } \\
\text { definitions and Table } 4.2 \text { the sum } \\
\text { are matched with bank branches }\end{array}$ & $\begin{array}{l}\text { ly side imp } \\
\text { ilises discre } \\
\text { lefined whe } \\
\text { e Transactio } \\
\text { arger than o } \\
\text { mary statis } \\
\text { on the local }\end{array}$ & $\begin{array}{l}\text { act across c } \\
\text { ete measur } \\
\text { en it is no } \mathrm{m} \\
\text { on Bank Mc } \\
\text { or equal to } \\
\text { stics for eac } \\
\text { lity or circl }\end{array}$ & $\begin{array}{l}\text { different loc } \\
\text { res. Foreign } \\
\text { nore than } 20 \\
\text { arket is def } \\
0.18 \text {, while } \\
\text { ch included } \\
\text { le level. Coe }\end{array}$ & $\begin{array}{l}\text { Cal bankin } \\
20 \text { percent. } \\
\text { fined when } \\
\text { High Com } \\
\text { variable. } \\
\text { efficients }\end{array}$ & $\begin{array}{l}\text { Relationshi } \\
\mathrm{n} \text { it is no mo } \\
\text { All the othe }\end{array}$ & $\begin{array}{l}\text { S around th } \\
\text { ned when } S \\
\text { ip Bank Ma } \\
\text { ore than } 20 \\
\text { ink Market } \\
\text { er interactio }\end{array}$ & percent. Lo & $\begin{array}{l}\text { eign Banks } \\
\text { ned when } \\
\text { when it is sr } \\
\text { are include } \\
\text { ountry*sec }\end{array}$ & $\begin{array}{l}\text { is greater of } t \\
\text { Share of Re } \\
\text { ition Bank } \\
\text { maller than } \\
\text { d seperate } \\
\text { ctor cluster }\end{array}$ & $\begin{array}{l}\text { he local ba } \\
\text { than or equ } \\
\text { Mationship } \\
\text { Market is d } \\
0.1 \text {. Table } \\
\text { ly but are } n\end{array}$ & $\begin{array}{l}\text { ual to } 80 \text { pe } \\
\text { Banks is gr } \\
\text { defined wh } \\
4.1 \text { contair } \\
\text { not reporte }\end{array}$ & $\begin{array}{l}\text { ctures are } \\
\text { ercent, } \\
\text { eater } \\
\text { en } \\
\text { ns all } \\
\text { d. Firms }\end{array}$ \\
\hline
\end{tabular}

\subsubsection{Economic Impact}

Finally, we investigate the economic outcome of bribery on expected firm growth in the next fiscal year to provide a microeconomic channel through bank lending. Specifically, this paper tests if credit constraints impede Firm Future Growth, by utilising both the realised and the projected values of Financing Obstacle for Firm based on Firm Bribery.

Results are shown in Table 4.10. The impact of realised access to credit on firm future growth is presented in models (1) and (2). The significantly negative coefficient estimates 
confirm the findings of previous literature that credit constraints limit firms' growth opportunities. Then models (3) and (4) apply the projected values of Financing Obstacle for Firm based on Firm Bribery as the independent variable. Together, these results imply the existence of the bank lending channel for corruption to obstacle growth opportunity of a firm. Economically, a one-point increase in Financing Obstacle for Firm that is driven by increased Firm Bribery decreases future firm growth by 6 or 6.5 per cent, which is very sizeable. Hence, Financing Obstacle for Firm impedes Firm Future Growth, partially through an increase in Firm Bribery.

Table 4.10. Bribery and Access to Credit: Future Growth

\begin{tabular}{|c|c|c|c|c|}
\hline & \multicolumn{4}{|c|}{ Firm Future Growth } \\
\hline & \multicolumn{2}{|c|}{ True Values } & \multicolumn{2}{|c|}{ Projected Values } \\
\hline & (1) & $(2)$ & (3) & (4) \\
\hline \multirow[t]{2}{*}{ Financing Obstacle for Firm } & $-0.013 * *$ & $-0.012 *$ & $-0.060 * *$ & $-0.065^{* *}$ \\
\hline & {$[0.006]$} & {$[0.006]$} & {$[0.030]$} & {$[0.031]$} \\
\hline Firm Controls & Yes & Yes & Yes & Yes \\
\hline Locality Controls & Yes & Yes & Yes & Yes \\
\hline Country Fixed Effects & Yes & No & Yes & No \\
\hline Sector Fixed Effects & Yes & No & Yes & No \\
\hline Wave Fixed Effects & Yes & No & Yes & No \\
\hline Country*Sector Fixed Effects & No & Yes & No & Yes \\
\hline Country*Wave Fixed Effects & No & Yes & No & Yes \\
\hline Sector*Wave Fixed Effects & No & Yes & No & Yes \\
\hline R-squared & 0.072 & 0.110 & 0.072 & 0.110 \\
\hline Observations & 5,976 & 5,976 & 5,976 & 5,976 \\
\hline
\end{tabular}

Note: This table reports the impact of credit access on firm growth in the next year. The true values of Financing Obstacle for Firm are utilised in model (1) and (2), whle model (3) and (4) utilise the projected value of Financing Obstacle for Firm on Firm Bribery. Table 4.1 contains all definitions and Table 4.2 the summary statistics for each included variable. Coefficients are listed in the first row, robust country*sector clustered standard errors are reported below in the brackets, and the corresponding significance levels are placed adjacently. ${ }^{* * *}$ Significant at $1 \%$,

** significant at $5 \%$, significant at $10 \%$.

\subsection{Conclusions}

This paper provides firm-level evidence on the impact of bribery on firms' access to credit. The baseline estimates indicate that access to credit is more limited for firms that are more frequently involved in bribery, which is also the case in an instrumental variable approach. The findings of this paper can be explained under the law and finance theory pioneered by La Porta et al., (1997) that bureaucratic corruption induces greater uncertainty on the banks' claims and enforcement actions, which diminishes banks' willingness to lend to bribing firms. Hence, credit rationing occurs, where banks do not want to take excessive risks by lending to these bribing firms.

This paper further indicates that the detrimental effect of bribery on credit access is mainly driven by supply-side rather than demand-side factors. More explicitly from the supply-side, the impact is less pronounced if there are more foreign banks in the vicinity of the firm; or if 
competition in the local banking market is either very low or very high. Bribery is also found to significantly impede firm growth, which is partially through the tightening of firms' credit access. Economically, a one-point (or roughly a one standard deviation) increase in bribery tightens firms' credit access by 7.8 per cent.

This research is also important politically by giving the first insight into the microeconomic impact of bribery on firms' credit access, as well as on firm growth. What's more, this paper presents, from the supply-side, how the local banking structures may shape the relationship between bribery and credit access.

The findings of the paper highlight the importance of combatting corruption to restore the credit market and trigger economic growth, as well as the importance of cooperation among regulatory authorities when fighting corruption. The banks' punishment on the bribing firms serves as a self-correcting mechanism that a sound banking system could be deterrence for corruption. Banking regulations on market competition, or on foreign bank entry, may exert significant impacts on corruption, which suggests that a much broader framework should be incorporated in corruption regulations. 


\section{Appendix}

Table A4.1. Detecting Bribery: Univariate Results

\begin{tabular}{|c|c|c|c|c|}
\hline & \multirow{2}{*}{ Bribery } & \multicolumn{2}{|c|}{ Significance Level w.r.t. } & \multirow{2}{*}{ - Observations } \\
\hline & & {$[1,2]$} & $(2,3]$ & \\
\hline Level of Corrupted Government Officials & 1.967 & & & 8,749 \\
\hline$(3,4]$ & 2.434 & $* * *$ & $* * *$ & 1,594 \\
\hline$(2,3]$ & 1.873 & * & & 5,726 \\
\hline$[1,2]$ & 1.822 & & & 1,429 \\
\hline Level of Corrupted Business Executives & 1.968 & & & 8,738 \\
\hline$(3,4]$ & 2.220 & *** & $* * *$ & 609 \\
\hline$(2,3]$ & 1.981 & $* * *$ & & 6,791 \\
\hline$[1,2]$ & 1.784 & & & 1,338 \\
\hline
\end{tabular}

Note: This table reports univariate results on the relationship between firm bribery and the level of corrupted local government officials or business executives reported by the citizens. $*, * *, * * *$ indicate significance at the $10 \%, 5 \%$ and $1 \%$ level, respectively, for a two-sample ttest of a difference in means with unequal variances. Table 4.1 contains all definitions and Table 4.2 the summary statistics for each included variable.

Table A4.2. Bribery and Access to Credit: Fixed Effects Results

\begin{tabular}{lcccc}
\hline & \multicolumn{4}{c}{ Financing Obstacle for Firm } \\
\cline { 2 - 5 } & $0.162^{* * *}$ & $0.161^{* * *}$ & $0.167^{* * *}$ & $0.166^{* * *}$ \\
& {$[0.013]$} & {$[0.013]$} & {$[0.017]$} & {$[0.017]$} \\
Firm Bribery & & & & \\
Firm Controls & Yes & Yes & Yes & Yes \\
Locality Controls & Yes & Yes & Yes & Yes \\
Locality Fixed Effects & Yes & Yes & No & No \\
Sector Fixed Effects & Yes & No & No & No \\
Wave Fixed Effects & Yes & No & Yes & No \\
Locality*Sector Fixed Effects & No & No & Yes & Yes \\
Country*Wave Fixed Effects & No & No & No & Yes \\
Sector*Wave Fixed Effects & No & Yes & No & Yes \\
& & & & \\
R-squared & 0.314 & 0.315 & 0.490 & 0.501 \\
Observations & 12,006 & 12,006 & 12,006 & 12,006 \\
\hline
\end{tabular}

Note: This table reports the regression results with stricter fixed effects. Table 4.1 contains all definitions and Table 4.2 the summary statistics for each included variable. Coefficients are listed in the first row, robust clustered standard errors are reported below in the brackets, and the corresponding significance levels are placed adjacently. ${ }^{* * *}$ Significant at $1 \%,{ }^{* *}$ significant at $5 \%,{ }^{*}$ significant at $10 \%$. 
Table A4.3. Bribery and Access to Credit: Panel Data Results

\begin{tabular}{lcccc}
\hline & \multicolumn{4}{c}{ Financing Obstacle for Firm } \\
\cline { 2 - 5 } & (1) & (2) & (3) & (4) \\
\hline Firm Bribery & $0.175^{* * *}$ & $0.168^{* * *}$ & $0.201^{* * *}$ & $0.184^{* * *}$ \\
& {$[0.022]$} & {$[0.024]$} & {$[0.039]$} & {$[0.040]$} \\
Firm Controls & Yes & Yes & Yes & Yes \\
Locality Controls & Yes & Yes & Yes & Yes \\
Firm Fixed Effects & No & No & Yes & Yes \\
Country Fixed Effects & Yes & No & No & No \\
Sector Fixed Effects & Yes & No & No & No \\
Wave Fixed Effects & Yes & No & Yes & No \\
Country*Sector Fixed Effects & No & Yes & No & No \\
Country*Wave Fixed Effects & No & Yes & No & Yes \\
Sector*Wave Fixed Effects & No & Yes & No & Yes \\
& & & & \\
R-squared & 0.108 & 0.196 & 0.603 & 0.638 \\
Observations & 2,528 & 2,528 & 2,528 & 2,528 \\
\hline Note: This table reports the robustres
\end{tabular}

Note: This table reports the robustness check with panel data (only include firms that participate in both BEEPS IV and V). Table 4.1 contains all definitions and Table 4.2 the summary statistics for each included variable. Coefficients are listed in the first row, robust country*sector clustered standard errors are reported below in the brackets, and the corresponding significance levels are placed adjacently. ${ }^{* * *}$ Significant at $1 \%, * *$ significant at $5 \%,{ }^{*}$ significant at $10 \%$.

Table A4.4. Bribery and Access to Credit: Impact in Practice

\begin{tabular}{lccccc}
\hline & \multicolumn{5}{c}{ Credit Constraint of Firm } \\
\cline { 2 - 6 } & $(1)$ & $(2)$ & $(3)$ & $(4)$ & $(5)$ \\
\hline Firm Bribery & $0.030^{* * *}$ & $0.024^{* * *}$ & $0.022^{* * *}$ & $0.012^{* *}$ & $0.010^{*}$ \\
& {$[0.006]$} & {$[0.005]$} & {$[0.005]$} & {$[0.005]$} & {$[0.005]$} \\
Firm Controls & No & Yes & Yes & Yes & Yes \\
Locality Controls & No & No & Yes & Yes & Yes \\
Country Fixed Effects & No & No & No & Yes & No \\
Sector Fixed Effects & No & No & No & Yes & No \\
Wave Fixed Effects & No & No & No & Yes & No \\
Country*Sector Fixed Effects & No & No & No & No & Yes \\
Country*Wave Fixed Effects & No & No & No & No & Yes \\
Sector*Wave Fixed Effects & No & No & No & No & Yes \\
& & & & & \\
R-squared & 0.006 & 0.054 & 0.059 & 0.093 & 0.101 \\
Observations & 6,590 & 6,590 & 6,590 & 6,590 & 6,590 \\
\hline
\end{tabular}

Note: This table reports the impact of bribery on access to credit in practice. Table 4.1 contains all definitions and Table 4.2 the summary statistics for each included variable. Coefficients are listed in the first row, robust country*sector clustered standard errors are reported below in the brackets, and the corresponding significance levels are placed adjacently. ${ }^{* * *}$ Significant at $1 \%,{ }^{* *}$ significant at $5 \%$, * significant at $10 \%$. 


\section{Chapter 5}

\section{Concluding Remarks}

This dissertation examines the functioning of financial intermediaries from both macro and micro perspectives. The results have implications for the determinants of access to financial services. Chapter 2 and 3 are from a macro angle that focuses on cross-border banking and bank branching. Chapter 4 , in addition, examines the micro drivers of access to credit.

In Chapter2, we analyze the role of deposit insurance as a determinant for cross-border deposit allocation. Maybe somewhat surprisingly, the empirical literature as to date does not provide unambiguous evidence on the relevance of deposit insurance for cross-border depositing. By employing a unique data set of bilateral cross-border retail deposits, we show that not only the mere existence of deposit insurance but also the way deposit insurance schemes are designed matter for cross-border depositing. This is in line with the literature that indicate an effective deposit insurance system should consist of a credible guarantee, effective monitoring by supervisors, and an efficient resolution mechanism. What's more, in crises times depositors have more incentives to search for "Safe Haven" than to engage in "Regulatory Arbitrage". When it comes to a global financial crisis it is the emergency actions of the countries that matter and that can lead to substantial relocations of cross-border deposits. As such, these actions do not only rescue the banks and the domestic depositors of the countries taking these emergency actions. In addition, they also have measurable and sizeable effects on other countries in a globalized financial market. As such, this calls for coordination across national regulators taking possible spillovers into account.

Next, in Chapter 3, we provide a country level analysis on the contributing factors of bank branch clustering over time. It is well known that branches of different banks tend to cluster spatially. Yet, to date there exists surprisingly little theoretical and empirical research on the drivers of this phenomenon. The contribution of this chapter is to utilise the introduction of credit information sharing systems (e.g. public credit registry or private credit bureau) as exogenous shocks that change the balance between the relative advantages and disadvantages of branch clustering. We then observe how these shocks play out at a very disaggregated level - namely that of individual villages, towns and cities - across various countries.

We start by building a simple spatial oligopoly model of bank clustering. The model focuses on the trade-off between the market-size effect and the price-cutting effect of branch clustering. It predicts that the establishment of information sharing will stimulate clustering due to an increase in competition from far-away bank branches. The model also predicts that after the introduction of information sharing, banks will be less likely to open additional 
branches in locations where they already have a presence. Finally, the model indicates that more effective information sharing systems gradually dampen bank branch clustering. In the empirical part of the analysis, I then test these theoretical predictions by exploiting dynamic information on the geographical locations of bank branches. I find that the establishment of information sharing has a significantly positive impact on bank clustering and that this impact is larger for domestic banks. I also show that after the establishment of information sharing banks are more likely to locate new branches in places where they do not have a branch presence yet. Finally, I establish that countries with more efficient credit information sharing systems exhibit less pronounced bank clustering.

In Chapter 4 of this dissertation, we provide a firm level analysis on the impact of corruption (bribery) on firms' credit access. Corruption is found to be a major determinant and also impedes economic growth. Therefore, this chapter contributes to the current literature on the economic channels for corruption to obstruct productivity and efficiency, including investment, trading, political stability and human capital.

The estimates indicate that access to credit is more limited for firms that are more frequently involved in bribery practices. This remains the case when using an instrumental variable approach or an exact matching strategy. The findings of the paper can be explained under the law and finance theory that bureaucratic corruption induces greater uncertainty on banks' claims and enforcement actions, which diminishes banks' willingness to lend to bribing firms. The results can also be understood by means of the information asymmetry theory: due to adverse selection, corruption would only withdraw safe borrowers and the remaining borrowers are more likely to be a worse risk. Hence, credit rationing occurs, where banks do not want to take excessive risks by lending to these bribing firms. All in all, the estimates in this paper support the theoretical hypothesis that bribery limits firms' credit access. This paper also shows that the detrimental effect is mainly driven by supplyside rather than demand-side factors. More explicitly from the supply-side, the impact is less pronounced if there are more foreign banks in the vicinity of the firm; or if competition in the local banking market is either very low or very high. Bribery is also found to significantly impede firm growth, which is partially through the tightening of firms' credit access. 


\section{Chapter 6}

\section{Valorization}

This dissertation contributes to the understanding of the financial intermediaries from both the macro and micro perspectives, including the role of deposit insurance in providing "Safe Haven" or "Regulatory Arbitrage", the fundamental factors that drive the physical location of bank branches, as well as the banking lending channel for corruption to affect economic growth.

Chapter 2 contributes to the understanding of the role of deposit insurance schemes, as well as the determinants of cross-border banking. This study analyses retail deposits, which are actually covered by deposit insurance and enable us to identify the direct insurance effects. Furthermore, we investigate not only the attractiveness of the bank countries' deposit insurance, but also the differences of deposit insurance between the depositor country and the bank country. Lastly, we investigate not only the effect of explicit deposit insurance but also consider its specific features, as the effectiveness of deposit insurance depends crucially on its design and implementation.

The findings add therefore to the debate on the design of macro-prudential instruments in globalized financial markets. This discussion, currently focused on cross-border banking, questions their effectiveness when parties are able to circumvent these measures via regulatory arbitrage and calls for coordination among national regulators. As our analyses cover regulatory differences across countries we can provide in-depth insights into which features can induce regulatory arbitrage. Likewise, the findings, documenting a novel pattern of save haven and regulatory arbitrage driven behaviour by depositors, also stress the need for a coordinated regulatory strategy with respect to deposit insurance schemes. For example, the analysis shows the potentially changing importance of safe havens and regulatory arbitrage during stable versus crisis times, as well as the impact and efficiency of emergency actions taken by many countries in response to the severity of the 2008/09 financial crisis, which included explicit and often enhanced government guarantees over and above the regular deposit insurance coverage.

Chapter 3 fills the gap that theoretically explains and empirically identifies the fundamental factors that drive the physical location of bank branches. The contribution of the chapter is to develop a simple and intuitive framework in which banks rationally trade off the marketsize and price-cutting effects of geographical bank clustering. We then empirically test the model predictions in an international context, using the introduction of information sharing as country-level exogenous shocks that move banks towards a new clustering equilibrium. Second, this chapter uncovers an important mechanism on the economic impacts of 
information sharing: the central availability of borrower information leads to different equilibrium levels of branch clustering, which may be associated with a reduction in spatial credit rationing.

Taken together, the results show that branch clustering is a function of the public availability of trustworthy borrower information. When such information is more broadly available, it allows banks to expand their branch networks to new geographical localities that they would previously have avoided. At the same time, it becomes more important for banks to cluster together as a higher local variety of banks makes it easier to attract distant customers. Together these effects mean that banking markets become more homogenous in terms of composition - as they are served by the same banks that now operate across the country - but less homogenous in terms of size. While the public availability of information sharing leads to further clustering of banks in well-served locations, other (smaller) locations may lose out as access to credit deteriorates further. Assessing the real-economics impacts of such spatial variation in access to credit due to information sharing is a promising avenue for further research. Therefore, information sharing can not only directly improve access to credit by reducing information asymmetry, but also lead to denser bank branch networks and expand credit indirectly through increased competition.

Chapter 4 contributes to an important strand of determinants of access to credit in three dimensions. First, this research examines the impact of corruption on credit access at the firm level, where we try to address the endogeneity issue and define a causal relationship by utilizing both an instrumental variable approach and an exact matching strategy. Second, the results show that the detrimental impact of bribery on firms' credit access is mainly driven by supply-side rather than by demand-side factors. In other words, the impact is predominately driven by banks being less willing to lend to the bribing firms. Thus local banking structures are vital in shaping the impact of corruption. Lastly, this chapter, for the first time, presents a bank lending channel for corruption to impede economic growth, which is important to deepen our understanding of the relationship between corruption and economic growth.

This chapter is relevant from a policy perspective, as corruption has been a major challenge in transition countries and lots of countries are making intensive efforts to combat this issue. The findings indicate that banks generally punish bribing firms by tightening their credit access. This punishment could act as a self-correcting mechanism that a sound banking system can be deterrence for corruption. Therefore, this chapter highlights the importance of cooperation among regulatory authorities to combat corruption. The banking market regulations, for example, on foreign bank entry, or on inter-bank competition, might exert a significant impact on the effectiveness of corruption regulations. 


\section{References}

Abiad, A. \& A. Mody (2015). Financial reform: What shakes it? What shapes it? American Economic Review, 95(1), 66-88.

Agarwal, S., \& Hauswald, R. (2010). Distance and private information in lending. Review of Financial Studies, 23(7), 2757-88.

Allen, F., \& Santomero, A. M. (2001). What do financial intermediaries do?. Journal of Banking \& Finance, 25(2), 271-294.

Alworth, J. S., \& Andresen, S. (1992). The determinants of cross border non-bank deposits and the competitiveness of financial market centres. Money Affairs, 5(2), 105-33.

Anderson, J. E., \& Van Wincoop, E. (2003). Gravity with gravitas: A solution to the border puzzle. American Economic Review, 93(1), 170-192.

Aviat, A., \& Coeurdacier, N. (2007). The geography of trade in goods and asset holdings. Journal of International Economics, 71(1), 22-51.

Bae, K. H., \& Goyal, V. K. (2009). Creditor rights, enforcement, and bank loans. The Journal of Finance, 64(2), 823-860.

Baldwin, R., \& Taglioni, D. (2006). Gravity for dummies and dummies for gravity equations (No. w12516). National Bureau of Economic Research.

Baltagi, B. H., Egger, P., \& Pfaffermayr, M. (2003). A generalized design for bilateral trade flow models. Economics Letters, 80(3), 391-397.

Barros, P. P. (1999). Multimarket competition in banking, with an example from the Portuguese market. International Journal of Industrial Organization, 17(3), 335-352.

Barth, J. R., Caprio, G., \& Levine, R. (2001). The regulation and supervision of banks around the world: A new database (Vol. 2588). World Bank Publications.

Barth, J. R., Caprio, G., \& Levine, R. (2004). Bank regulation and supervision: What works best? Journal of Financial Intermediation, 13(2), 205-248.

Baxter, M., \& Kouparitsas, M. A. (2006). What determines bilateral trade flows? (No. w12188). National Bureau of Economic Research.

Beck, T., \& Brown, M. (2015). Foreign bank ownership and household credit. Journal of Financial Intermediation, 24(4), 466-486.

Beck, T., \& Levine, R. (2004). Stock markets, banks, and growth: Panel evidence. Journal of Banking and Finance, 28(3), 423-442.

Beck, T., \& Peria, M. S. M. (2010). Foreign bank participation and outreach: Evidence from Mexico. Journal of Financial intermediation, 19(1), 52-73.

Beck, T., De Jonghe, O., \& Schepens, G. (2013). Bank competition and stability: Crosscountry heterogeneity. Journal of Financial intermediation, 22(2), 218-244.

Beck, T., Degryse, H., De Haas, R. \& van Horen, N. (2017), When arms' length is too far: relationship banking over the business cycle, Journal of Financial Economics, forthcoming.

Beck, T., Demirgüç-Kunt, A., \& Levine, R. (2010). Financial institutions and markets across countries and over time: The updated financial development and structure database. The World Bank Economic Review, 24(1), 77-92.

Beck, T., Demirguc-Kunt, A., \& Maksimovic, V. (2004). Bank competition and access to finance: International evidence. Journal of Money, Credit, and Banking, 36(3), 627648.

Beck, T., Demirgüç-Kunt, A., \& Maksimovic, V. (2008). Financing patterns around the world: Are small firms different?. Journal of Financial Economics, 89(3), 467-487. 
Beck, T., Demirgüç-Kunt, A., Laeven, L., \& Maksimovic, V. (2006). The determinants of financing obstacles. Journal of International Money and Finance, 25(6), 932-952.

Beck, T., loannidou, V., \& Schäfer, L. (2017), Foreigners vs. natives: Bank lending technologies and loan pricing, Management Science, forthcoming.

Beck, T., Levine, R. \& Levkov, A. (2010). Big bad banks? The winners and losers from bank deregulation in the United States. Journal of Finance, 65(5), 1712-30.

Bekaert, G., Harvey, C. R., Lundblad, C. T., \& Siegel, S. (2013). The European union, the Euro, and equity market integration. Journal of Financial Economics, 109(3), 583-603.

Benfratello, L., Schiantarelli, F. \& Sembenelli, A. (2008), Banks and innovation: Microeconometric evidence on Italian firms, Journal of Financial Economics, 90(2), 197-217.

Berger, A. N. (1991). Market discipline in banking. In Federal Reserve Bank of Chicago Proceedings (No. 328).

Berger, A. N., \& Mester, L. J. (2003). Explaining the dramatic changes in performance of US banks: Technological change, deregulation, and dynamic changes in competition. Journal of Financial Intermediation, 12(1), 57-95.

Berger, A. N., \& Udell, G. F. (2002). Small business credit availability and relationship lending: The importance of bank organizational structure. Economic Journal, 112(477), 32-53.

Berkowitz, D., Hoekstra, M., \& Schoors, K. (2014), Bank privatization, finance, and growth, Journal of Development Economics, 114, 93-106.

Bernet, B., \& Walter, S. (2009). Design, structure and implementation of a modern deposit insurance scheme (Vol. 5). SUERF.

Bertrand, M., Schoar, A., \& Thesmar, D. (2007). Banking deregulation and industry structure: Evidence from the French banking reforms of 1985. The Journal of Finance, 62, 597628.

Bharath, S. T., Dahiya, S., Saunders, A., \& Srinivasan, A. (2007). So what do I get: A bank's view of lending relationships. Journal of Financial Economics, 85(2), 368-419.

Bolton, P., Freixas, X., Gambacorta, L., \& Mistrulli, P. E. (2016). Relationship and transaction lending in a crisis. Review of Financial Studies, hhw041.

Boot, A. W. A. (2000). Relationship banking: What do we know? Journal of Financial intermediation, 9(1), 3-25.

Brown, M., Jappelli, T., \& Pagano, M. (2009). Information sharing and credit: Firm-level evidence from transition countries. Journal of Financial intermediation, 18(2), 151172.

Brown, M., Ongena, S., Popov, A., \& Yeşin, P. (2011). Who needs credit and who gets credit in Eastern Europe? Economic Policy, 65, 93-130.

Buch, C. M. (2005). Distance and international banking. Review of International Economics, 13(4), 787-804.

Buch, C. M., \& Lipponer, A. (2007). FDI versus exports: Evidence from German banks. Journal of banking \& Finance, 31(3), 805-826.

Calomiris, C. W., \& Jaremski, M. (2016). Deposit insurance: Theories and facts. Annual Review of Financial Economics, 8, 97-120.

Campbel, T. S., \& Kracaw, W. A. (1980). Information production, market signalling, and the theory of financial intermediation. The Journal of Finance, 35(4), 863-882.

Cerasi, V., Chizzolini, B., \& Ivaldi, M. (2002). Branching and competition in the European banking industry. Applied Economics, 34(17), 2213-2225 
Cetorelli, N., \& Gambera, M. (2001). Banking market structure, financial dependence and growth: International evidence from industry data. The Journal of Finance, 56, 617648.

Chang, A., Chaudhuri, S., \& Jayaratne, J. (1997). Rational herding and the spatial clustering of bank branches: an empirical analysis.

Cihak, M., Demirgüç-Kunt, A., Martínez Pería, M. S., \& Mohseni-Cheraghlou, A. (2012). Bank regulation and supervision around the world: A crisis update (No. 6286). World Bank Policy Research Working Paper.

Claessens, S., \& Horen, N. (2014). Foreign banks: Trends and impact. Journal of Money, Credit and Banking, 46(s1), 295-326.

Clarke, G. R., \& Xu, L. C. (2004). Privatization, competition, and corruption: how characteristics of bribe takers and payers affect bribes to utilities. Journal of Public economics, 88(9), 2067-2097.

Clarke, G. R., Cull, R., \& Peria, M. S. M. (2006). Foreign bank participation and access to credit across firms in developing countries. Journal of Comparative Economics, 34(4), 774-795.

Coccorese, P. (2012). Banks as 'fat cats': Branching and price decisions in a two-stage model of competition. Journal of Economics and Business, 64(5), 338-363.

Coeurdacier, N., \& Martin, P. (2009). The geography of asset trade and the euro: Insiders and outsiders. Journal of the Japanese and International Economies, 23(2), 90-113.

Cohen, A., \& Mazzeo, M. J. (2010). Investment strategies and market structure: An empirical analysis of bank branching decisions. Journal of Financial Services Research, 38(1), 121.

Cole, R. A. (1998). The importance of relationships to the availability of credit. Journal of Banking and Finance, 22, 959-977.

Dale, R., Bruni, F., \& de Boissieu, C. (2000). Strengthening financial infrastructure: Deposit insurance and lending of last resort. SUERF-The European Money and Finance Forum.

De Haas, R., \& Van Lelyveld, I. (2006). Foreign banks and credit stability in Central and Eastern Europe. A panel data analysis. Journal of Banking and Finance, 30(7), 19271952.

Degryse, H., \& Ongena, S. (2005). Distance, lending relationships, and competition. The Journal of Finance, 60(1), 231-266.

Degryse, H., Havrylchyk, O., Jurzyk, E., \& Kozak, S. (2012). Foreign bank entry, credit allocation and lending rates in emerging markets: Empirical evidence from Poland. Journal of Banking and Finance, 36(11), 2949-2959.

Dell'Ariccia, G. (2001). Asymmetric information and the structure of the banking industry. European Economic Review, 45(10), 1957-1980.

Dell'Ariccia, G., \& Marquez, R. (2004). Information and bank credit allocation. Journal of Financial Economics, 72(1), 185-214.

Deller, S., \& Sundaram-Stukel, R. (2012). Spatial patterns in the location decisions of US credit unions. The Annals of Regional Science, 49(2), 417-445.

Demirgüç-Kunt, A., \& Detragiache, E. (1997). The determinants of banking crises-evidence from developing and developed countries (Vol. 106). World Bank Publications.

Demirgüç-Kunt, A., \& Detragiache, E. (2002). Does deposit insurance increase banking system stability? An empirical investigation. Journal of Monetary Economics, 49(7), 1373-1406. 
Demirgüç-Kunt, A., Kane, E. J., \& Laeven, L. (2014). Deposit insurance database (No. w20278). National Bureau of Economic Research.

Diamond, D. W. (1983). Bank runs, deposit insurance, and liquidity. Journal of Political Economy, 91(3), 401-419.

Diamond, D. W., \& Dybvig, P. H. (1983). Bank runs, deposit insurance, and liquidity. Journal of Political Economy, 91(3), 401-419.

Diamond, D. W., \& Dybvig, P. H. (1986). Banking theory, deposit insurance, and bank regulation. Journal of Business, 59(1), 55-68.

Dick, A. A., \& Lehnert, A. (2010). Personal bankruptcy and credit market competition. The Journal of Finance, 65(2), 655-686.

Ding, W., Domac, I., \& Ferri, G. (1998). Is there a credit crunch in East Asia? (No. 1959). World Bank Policy Research Working Paper.

Djankov, S., La Porta, R., Lopez-de-Silanes, F., \& Shleifer, A. (2002). The regulation of entry. The quarterly Journal of economics, 117(1), 1-37.

Djankov, S., McLiesh, C., \& Shleifer, A. (2007). Private credit in 129 countries. Journal of Financial Economics, 84(2), 299-329.

Eisenbeis, R. A., \& Kaufman, G. G. (2006). Cross-border banking: Challenges for deposit insurance and financial stability in the European Union (No. 2006-15a). Federal Reserve Bank of Atlanta.

Eisenbeis, R. A., \& Kaufman, G. G. (2008). Cross-border banking and financial stability in the EU. Journal of Financial Stability, 4(3), 168-204.

Eisenbeis, R. A., \& Kaufman, G. G. (2015). Deposit insurance issues in the post-2008 crisis world. In Berger, A.N., Molyneux P., \& Wilson, J.O.S. (Eds.), The Oxford handbook of banking (pp. 527-549). Oxford, England: Oxford University Press.

Elsas, R., \& Krahnen, J. P. (1998). Is relationship lending special? Evidence from credit-file data in Germany. Journal of Banking and Finance, 22, 1283-1316.

Favara, G. \& Imbs, J. (2015). Credit supply and the price of housing. American Economic Review, 105(3), 958-992.

Fisman, R., \& Svensson, J. (2007). Are corruption and taxation really harmful to growth? Firm level evidence. Journal of Development Economics, 83(1), 63-75.

Fungáčová, Z., Kochanova, A., \& Weill, L. (2015). Does money buy credit? Firm-Level evidence on bribery and bank debt. World Development, 68, 308-322.

Garcia, G. G. H. (1999). Deposit insurance: A survey of actual and best practices. New York, NY: International Monetary Fund.

Gaviria, A. (2002). Assessing the effects of corruption and crime on firm performance: evidence from Latin America. Emerging Markets Review, 3(3), 245-268.

Grilli, V. (1989). Europe 1992: Issues and prospects for the financial markets. Economic Policy, 4(9), 387-421.

Guiso, L., Sapienza, P. \& Zingales, L. (2004). Does local financial development matter?, Quarterly Journal of Economics, 119, 929-69.

Gupta, R. C., \& Tao, H. (2010). A generalized correlated binomial distribution with application in multiple testing problems. Metrika, 71(1), 59-77.

Guzman, M. G. (2000). Bank structure, capital accumulation and growth: a simple macroeconomic model. Economic Theory, 16(2), 421-455.

Hainz, C., \& Nabokin, T. (2013). Measurement and determinants of access to Loans (No. 4190). CESifo Group Munich. 
Hauswald, R., \& Marquez, R.. 2006. Competition and Strategic Information Acquisition in Credit Markets. Review of Financial Studies, 19, 967-1000.

Helpman, E., \& Krugman, P. R. (1985). Market structure and foreign trade: Increasing returns, imperfect competition, and the international economy. Cambridge, MA: MIT Press.

Hermes, C. L. M., and Lensink, B. W. (2001). The impact of foreign bank entry on domestic banking markets: A note. University of Groningen.

Herrera, A.M. \& Minetti, R. (2007), Informed finance and technological change: Evidence from credit relationships. Journal of Financial Economics, 83, 223-269.

Heuchemer, S., Kleimeier, S., \& Sander, H. (2009). The determinants of cross-border lending in the Euro zone. Comparative Economic Studies, 51(4), 467-499.

Ho, K., \& Ishii, J. (2011). Location and competition in retail banking. International Journal of Industrial Organization, 29(5), 537-546.

Hoelscher, D. S., Taylor, M., \& Klueh, U. H. (2006). The design and implementation of deposit insurance systems (No. 251). International Monetary Fund Publications.

Houston, J. F., Lin, C., \& Ma, Y. (2012). Regulatory arbitrage and international bank flows. The Journal of Finance, 67(5), 1845-1895.

Huizinga, H., \& Nicodème, G. (2004). Are international deposits tax-driven? Journal of Public Economics, 88(6), 1093-1118.

Huizinga, H., \& Nicodème, G. (2006). Deposit insurance and international bank liabilities. Journal of Banking \& Finance, 30(3), 965-987.

Ilzetzki, E., Reinhart, C., \& Rogoff, K. (2008). The country chronologies and background material to exchange rate arrangements in the 21st century: Which anchor will hold? mimeo, University of Maryland.

loannidou, V., \& Ongena, S. (2010). "Time for a change": loan conditions and bank behavior when firms switch banks. The Journal of Finance, 65(5), 1847-1877.

Jappelli, T., \& Pagano, M. (2002). Information sharing, lending and defaults: Cross-country evidence. Journal of Banking \& Finance, 26(10), 2017-2045.

Jayaratne, J. \& Strahan, P. E. (1996). The finance-growth nexus: Evidence from bank branch deregulation, Quarterly Journal of Economics, 111(3), 639-70.

Jiménez, G., Lopez, J. A., \& Saurina, J. (2013). How does competition affect bank risktaking?. Journal of Financial Stability, 9(2), 185-195.

Jõeveer, K. (2013). Firm, country and macroeconomic determinants of capital structure: Evidence from transition economies. Journal of comparative economics, 41(1), 294308.

Joulfaian, D. (2009). Bribes and business tax evasion. European Journal of Comparative Economics, 6(2), 227-244.

Kim, M., Lozano-Vivas, A., \& Morales, A. J. (2007). Multistrategic spatial competition in banking. International Journal of the Economics of Business, 14(3), 351-366

Kleimeier, S., Sander, H., \& Heuchemer, S. (2013). Financial crises and cross-border banking: New evidence. Journal of International Money and Finance, 32, 884-915.

Konishi, H. (2005). Concentration of competing retail stores. Journal of Urban Economics, $58(3), 488-512$.

Kroszner, R. S., \& Strahan, P. E. (2014). Regulation and deregulation of the US banking industry: causes, consequences, and implications for the future. In Economic Regulation and Its Reform: What Have We Learned? (pp. 485-543). University of Chicago Press. 
Krugman, P. (1980). Scale economies, product differentiation, and the pattern of trade. American Economic Review, 70(5), 950-959.

La Porta, R., Lopez-de-Silanes, F., Shleifer, A., \& Vishny, R. W. (1997). Legal determinants of external finance. The Journal of Finance, 22, 1131-1150.

Laeven, L., \& Beck, T. (2006). Resolution of failed banks by deposit insurers: Cross-country evidence (No. 3920). World Bank Policy Research Working Paper.

Laeven, L., \& Valencia, F. (2008). Systemic banking crises: A new database (No. 08/224). International Monetary Fund.

Laeven, L., \& Valencia, F. (2010). Resolution of banking crises: The good, the bad, and the ugly (No. 10/146). International Monetary Fund.

Laeven, L., \& Valencia, F. (2012). Systemic banking crises database: An update (No. 12/163). International Monetary Fund.

Lane, P. R., \& Milesi-Ferretti, G. M. (2008). International investment patterns. Review of Economics and Statistics, 90(3), 538-549.

Lane, P. R., \& Sarisoy, S. (2000). Does deposit insurance stimulate capital inflows? Economics Letters, 69(2), 193-200.

Leff, N. H. (1964). Economic development through bureaucratic corruption. American Behavioral Scientist, 8(3), 8-14.

Leland, H. E., \& Pyle, D. H. (1977). Informational asymmetries, financial structure, and financial intermediation. The Journal of Finance, 32(2), 371-387.

Lensink, R., \& Murinde, V. (2006). Does foreign bank entry really stimulate gross domestic investment?. Applied Financial Economics, 16(8), 569-582.

Levine, R. (1998). The legal environment, banks, and long-run economic growth. Journal of Money, Credit and Banking, 596-613.

Levine, R. (1999). Law, finance, and economic growth. Journal of Financial intermediation, 8(1), 8-35.

Levine, R., \& Zervos, S. (1998). Stock markets, banks and economic growth. American Economic Review, 88, 537-558.

Levine, R., Loayza, N., \& Beck, T. (2000). Financial intermediation and growth: Causality and causes. Journal of Monetary Economics, 46(1), 31-77.

Leys, C. (1965). What is the Problem about Corruption?. The Journal of Modern African Studies, 3(02), 215-230.

MacAskill, A. \& White, L. (2016, June 20), Britain's Poorer Communities, Hit Hardest by Bank Closures, May Face Shut Out, Reuters. Retrieved from http://www.reuters.com/article/us-britain-banks-branches-idUSKCNOZ60BX.

Martin, P., \& Rey, H. (2004). Financial super-markets: Size matters for asset trade. Journal of International Economics, 64(2), 335-361.

Martinez Peria, M., \& Schmukler, S. (2001). Do depositors punish banks for bad behavior? Market discipline, deposit insurance, and banking crisis. Journal of Finance, 56(3), 1029-1051.

Martinez-Miera, D., \& Repullo, R. (2010). Does competition reduce the risk of bank failure?. Review of Financial Studies, 23(10), 3638-3664.

Martinez-Peria, M. S., \& Singh, S. (2014). The impact of credit information sharing reforms on firm financing?. World Bank Policy Research Working Paper, (7013).

Mauro, P. (1995). Corruption and growth. Quarterly Journal of Economics, 110, 681-712. 
Merton, R. C., \& Thakor, R. T. (2015). Customers and investors: A framework for understanding financial institutions (No. w21258). National Bureau of Economic Research.

Mian, A.R. (2006), Distance constraints: The limits of foreign lending in poor economies, Journal of Finance 61, 1465-1505.

Mo, P. H. (2001). Corruption and economic growth. Journal of comparative economics, 29(1), 66-79.

Morgan, D., Pinkovsky, M. \& Yang, B. (2016, March 7), Banking deserts, branch closings, and soft information, Liberty Street Economics. Retrieved from http://libertystreeteconomics.newyorkfed.org/2016/03/banking-deserts-branchclosings-and-soft-information.html.

Nguyen, H. L. Q. (2015). Do bank branches still matter? The effect of closings on local economic outcomes. Working paper.

Okawa, Y., \& Van Wincoop, E. (2012). Gravity in international finance. Journal of International Economics, 87(2), 205-215.

Olken, B. A., \& Pande, R. (2012). Corruption in developing countries. Annu. Rev. Econ., 4(1), 479-509.

Ongena, S., Popov, A., \& Udell, G. F. (2013). "When the cat's away the mice will play": Does regulation at home affect bank risk-taking abroad?. Journal of Financial Economics, 108(3), 727-750.

Padilla, A. J., \& Pagano, M. (1997). Endogenous communication among lenders and entrepreneurial incentives. Review of Financial Studies, 10(1), 205-236.

Padilla, A. J., \& Pagano, M. (2000). Sharing default information as a borrower discipline device. European Economic Review, 44(10), 1951-1980.

Park, S., \& Peristiani, S. (1998). Market discipline by thrift depositors. Journal of Money, Credit and Banking, 30(3), 347-364.

Pellegrini, L., \& Gerlagh, R. (2004). Corruption's effect on growth and its transmission channels. Kyklos, 57(3), 429-456.

Petersen, M.A., \& Rajan, R.G. (2002). Does distance still matter? The information revolution in small business lending. Journal of Finance, 57, 2533-70.

Poghosyan, T., \& Poghosyan, A. (2010). Foreign bank entry, bank efficiency and market power in Central and Eastern European Countries. Economics of Transition, 18(3), 571-598.

Popov, A., \& Udell, G. F. (2012). Cross-border banking, credit access, and the financial crisis. Journal of International Economics, 87(1), 147-161.

Portes, R., \& Rey, H. (2005). The determinants of cross border equity flows. Journal of International Economics, 65(2), 269-296.

Pöyhönen, P. (1963). A tentative model for the volume of trade between countries. Weltwirtschaftliches Archiv, 90(1), 93-99.

Rajan, R. G., \& Zingales, L. (1998). Which capitalism? Lessons from the east Asian crisis. Journal of Applied Corporate Finance, 11(3), 40-48.

Reinhardt, D., \& Sowerbutts, R. (2015). Regulatory arbitrage in action: Evidence from banking flows and macroprudential policy (No. 546). Bank of England.

Reuters (2016), Britain's poorer communities, hit hardest by bank closures, may face shut out, available at http://uk.reuters.com/article/uk-britain-banks-branchesidUKKCNOZ60BP. 
Rice, T., \& Strahan, P. E. (2010). Does credit competition affect small-firm finance? The Journal of Finance, 65(3), 861-889.

Rochet, J.-C. (2004). Market discipline in banking: Where do we stand. In C Borio, WC Hunter, G Kaufman, K Tsatsaronis (Eds), Market discipline across countries and industries (pp. 55-68). Cambridge, MA: MIT Press.

Rose, A. K. (2005). Does the WTO make trade more stable? Open Economies Review, 16(1), 7-22.

Rossi, M. (1999). Financial fragility and economic performance in developing economies: do capital controls, prudential regulation and supervision matter? (No. 99/66). International Monetary Fund.

Rossi, M. (1999). Financial fragility and economic performance in developing economies: Do capital controls, prudential regulation and supervision matter? (No. 99/66). International Monetary Fund.

Salop, S. C. (1979). Monopolistic competition with outside goods. The Bell Journal of Economics, 141-156.

Sander, H., Kleimeier, S., \& Heuchemer, S. (2013). E(M)U effects in global cross-border banking. Economics Letters, 118(1), 91-93.

Sander, H., Kleimeier, S., \& Heuchemer, S. (2016). The Resurgence of cultural borders during the financial crisis: The changing geography of Eurozone cross-border depositing. Forthcoming in Journal of Financial Stability.

Stiglitz, J. E., \& Weiss, A. (1981). Credit rationing in markets with imperfect information. American Economic Review, 71, 393-410.

Temesvary, J. (2014). Dynamic branching and interest rate competition of commercial banks: Evidence from Hungary. Available at SSRN 2532662.

Tinbergen, J. (1962). Shaping the world economy; suggestions for an international economic policy. In Jan Tinbergen (Ed.), Books (Jan Tinbergen). New York, NY: Twentieth Century Fund.

Wei, S.-J. (2000). How taxing is corruption on international investors? Review of Economics and Statistics, 82(1), 1-11.

Weill, L. (2011). Does corruption hamper bank lending? Macro and micro evidence. Empirical Economics, 41(1), 25-4.

Wooldridge, J. (2007). What's new in econometrics? Lecture 10 difference-in-differences estimation. NBER Summer Institute. 


\section{Curriculum Vitae}

Shusen Qi was born in Yishui, China on $21^{\text {st }}$ August, 1989. He earned his BSc in Financial Mathematics from Shandong University in China. He then continued to pursue his Research Master in Finance in the same university. During this period, he went to Tilburg University in the Netherlands to obtain both an MSc in Finance with cum laude and a Research Master in Finance.

In 2014, Shusen Qi joined the Finance Department of Maastricht University as a PhD student. He taught courses in Banking and Ethics, Organizations and Society. In 2016, he visited the Office of the Chief Economist at the European Bank for Reconstruction and Development to co-author Chapter 4: Financial Inclusion in EBRD Transition Report 2016-17.

Shusen's research has been published in China \& World Economy. His research projects has been presented at the EEA/FMA/CICF Annual Meetings, IADI Biennial Research Conference, INFINITI Conference on International Finance, the Emerging Scholars in Banking and Finance Conference, Financial Intermediation in Emerging Markets Conference, BIS-CGFS Workshop on "Research on Global Financial Stability", EBC Network Workshop, Bank for International Settlement, Bank of England, European Bank for Reconstruction and Development, Magyar Nemzeti Bank, Narodowy Bank Polski, Tilburg University, KU Leuven, University of Antwerp, RWTH Aachen University, Sun Yat-Sen University, Maastricht University, Xiamen University and University of Groningen.

Shusen Qi is going to join Xiamen University in China as an Assistant Professor in Finance. 